\title{
The Pupae of the Mosquitoes of New Guinea
}

\author{
George Henry PenN ${ }^{1}$
}

\section{INTRODUCTION}

MANY FAUNISTIC PUBLICATIONS on mosquitoes dismiss the pupal stage with a general account of its external morphology and a few remarks to the effect that the pupa is of no practical significance in taxonomic work. This study of the pupae of New Guinea mosquitoes demonstrates, however, that pupal characters are relatively constant for any given species and that the examination of pupae is a valuable adjunct not only in the taxonomy of mosquitoes, but also in throwing light on some of the puzzles of species relationships and evolutionary trends within the family Culicidae.

Since the pupal stage is ordinarily of short duration it might be assumed that little change would occur in pupae in evolutionary processes, and such is probably the case. For example, the pupae of most species of the genera Aedes and Culex are more readily grouped into their respective subgenera than into their respective genera. On the other hand, specific differences seem to have been accentuated, and pupae of very closely related species, such as Uranotaenia nigerrima and $U$. papua, Aedes kochi and $A$. wallacei, are more easily separated than are the adults.

With the exception of a paper by Hill (1925) nothing of significance had been published prior to World War II concerning the pupae of New Guinea mosquitoes, and only a few papers which include pupae of the indigenous mosquito fauna have appeared since the war.

Of the 167 species which are autochthonous to the Australasian Region, the pupal stage of 27 has been fragmentarily described or figured

\footnotetext{
${ }^{1}$ Department of Zoology, The Tulane University of Louisiana, New Orleans. Approved for publication October 28, 1947.
}

in papers by Hill (1925: 62-77) and by Taylor (1929: 271-278). Other species found also in the Oriental Region and Wallacea, including Anopbeles barbirostris, An. karwari, An. subpictus, Megarbinus splendens, Harpagomyia genurostris, Mansonia africana, M. uniformis, Aedomyia catasticta, Aedes aurantius, and Culex sitiens, have been described, some of them rather completely, by such workers as Senevet (1931: 38; 1932: 209, 223), Crawford (1938: 39, 89), Baisas (1936a: 74; 1936b: 212; 1938: 181), Barraud (1931: 1131), De Meijere (1911: 164), Edwards (1941: 384, 417), and Edwards and Given (1928: 341). The species of cosmopolitan distribution, such as Aedes aegypti, $A$. vexans, and Culex fatigans, have received attention by several workers in different parts of the world.

Sixty-eight of the 196 species of mosquitoes recorded from New Guinea by Bick (manuscript) are now known in the pupal stage and are included in this paper. Thirty-six species are here fully described and illustrated for the first time. Thirty-two species have been variously described previously by others. I have redescribed and illustrated six of these; the descriptions of the remaining 26, 16 of which were only very poorly described and not available for examination, have been quoted without change from original sources.

An opportunity to collect material for this study was presented when Dr. George H. Bick and the writer were placed in charge of U. S. Naval Malaria Control Teams and assigned to duty in the southwest Pacific. Our combined collecting efforts, pooled after 15 months in New Guinea, amounted to 1,508 separate collections of larvae and pupae. Nine localities along the northern coast of New Guinea from 
Milne Bay on the east to Amsterdam Island on the west are represented in the collections. The localities are the villages of Gamadodo $\left(10^{\circ} 25^{\prime}\right.$ $\left.\mathrm{S}, 150^{\circ} 22^{\prime} \mathrm{E}\right)$, WagaWaga $\left(10^{\circ} 25^{\prime} \mathrm{S}, 150^{\circ}\right.$ $\left.25^{\prime} \mathrm{E}\right)$, Hilimoi $\left(10^{\circ} 25^{\prime} \mathrm{S}, 150^{\circ} 29^{\prime} \mathrm{E}\right)$, and KanaKope $\left(10^{\circ} 30^{\prime} \mathrm{S}, 150^{\circ} 40^{\prime} \mathrm{E}\right)$ on the south shore of Milne Bay in Papua; Morobe $\left(7^{\circ} 45^{\prime}\right.$ S, $\left.147^{\circ} 35^{\prime} \mathrm{E}\right)$, Draeger Harbor $\left(6^{\circ} 35^{\prime} \mathrm{S}, 147^{\circ}\right.$ $\left.50^{\prime} \mathrm{E}\right)$, and Saidor $\left(5^{\circ} 40^{\prime} \mathrm{S}, 146^{\circ} 30^{\prime} \mathrm{E}\right)$ in Northeast New Guinea; and Mios Woendi ( $1^{\circ}$ $\left.15^{\prime} \mathrm{S}, 136^{\circ} 20^{\prime} \mathrm{E}\right)$ and Amsterdam Island $\left(0^{\circ}\right.$ $20^{\prime} \mathrm{S}, 132^{\circ} 10^{\prime} \mathrm{E}$ ) in Netherlands New Guinea.

Representative samples of each of the collections were selected for rearing in isolated containers and the larval and pupal exuviae were thus associated with the adults.

The material has been divided among several institutions. The largest lot has been de- posited in the United States National Museum, and representative series of associated larvae, pupae, and adults have been placed in the collections of Cornell University at Ithaca, New York, and the University of Queensland, Brisbane, Australia.

Magnification of figures is indicated by the lines beside them which represent $0.5 \mathrm{~mm}$.

Acknowledgments: I am particularly indebted to Dr. George H. Bick of Tulane University, who collected and contributed much of the material used in this study. The men of our units, the 25th and 28th Naval Malaria Control Teams, were of invaluable assistance in carrying on the surveys of the several bases; for their initiative and interest in the work, I am grateful to Alfred C. Bodenman, William L. Schmid, Ralph E. Geiger, Jack P. Gallagher,

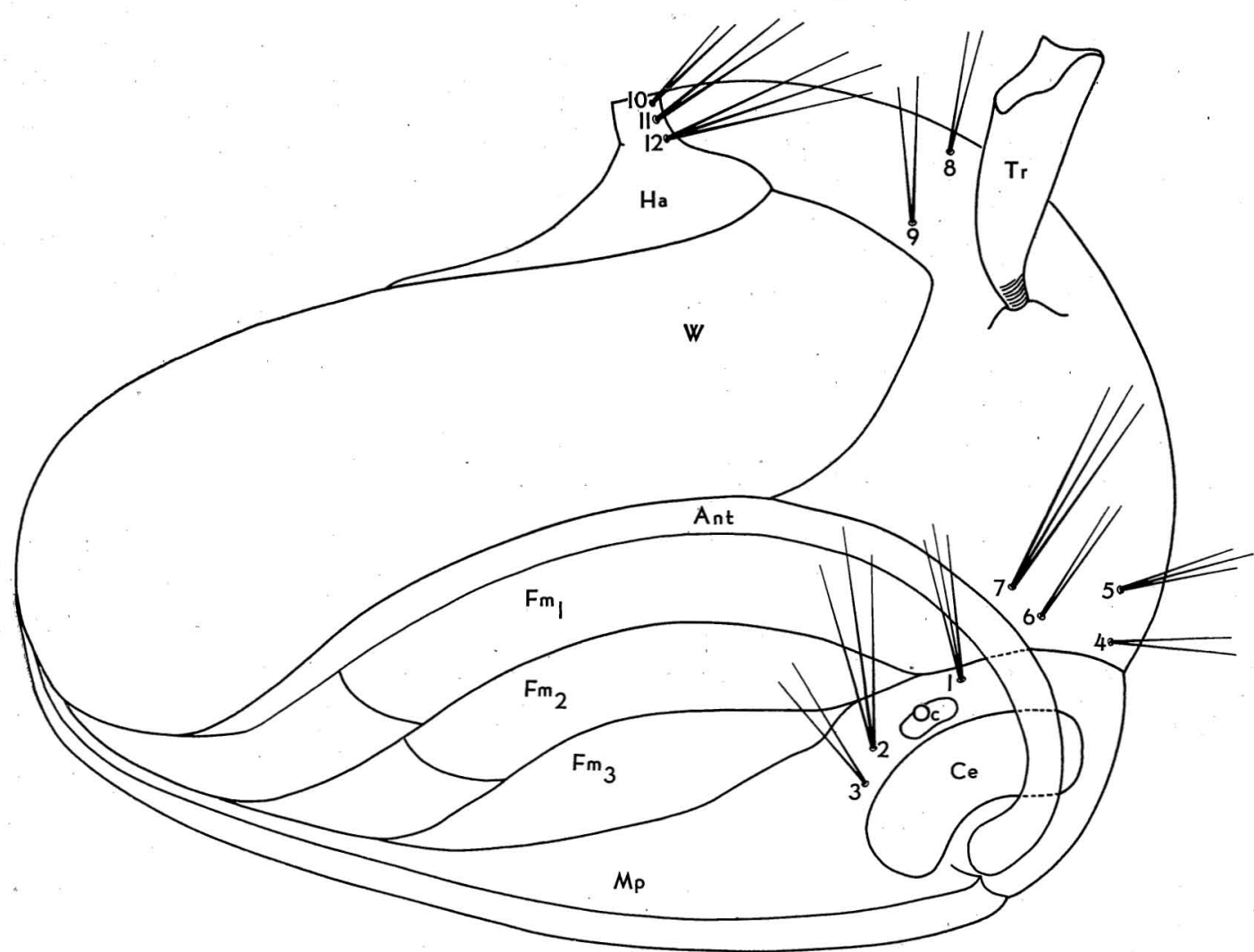

FIG. 1. Generalized cephalothorax of pupa in lateral view. Ant, antenna; Ce, compound eye; Fm 1, 2, 3, femora of pro-, meso-, and metathorax; Ha, haltere; $\mathrm{M}_{2}$, mouth parts; Oc, ocellus; $\mathrm{Tr}$, respiratory trumpet; W, wing pad. 
M. A. Greenblatt, William W. Bonds, Harold

W. Dorman, A. S. Griswold, James E. Surgenor, William T. Whitfield, Peter B. Tompkins, and Otis L. Andrews.

Dr. Alan Stone of the U. S. Bureau of Entomology and Plant Quarantine confirmed the determinations of most of the species; Professor F. A. Perkins and Miss Elizabeth N. Marks of the Entomological Laboratories of the University of Queensland generously assisted in the identification and storage of materials collected during the early months of our stay in New Guinea.

Finally, I am especially grateful to Dr. Robert Matheson of Cornell University, who directed and encouraged the study of this problem and whose friendly interest and counsel will long be remembered and appreciated.

\section{FEATURES OF TAXONOMIC IMPORTANCE}

Although the first attempted identification of mosquito pupae utilized the arrangement and branching of the abdominal setae (Mitchell, 1907: appendix) it was not until Macfie (1920: 161-169) published his account of the pupal chaetotaxy of Aedes aegypti that the value of setae in the classification of pupae was recognized.

Most of the early workers based their classifications on gross structures such as the shape and size of the respiratory trumpets and natatory paddles. Thus Banks (1908: 235-258), Wesche (1910: 7-50), Jacobson (1911: 158161), De Meijere (1911: 162-167), Howard, Dyar, and Knab (1912-1917), Ingram and Macfie (1917: 73-91; 1919: 59-69), Wigglesworth (1920: 59-68), and Hill (1925: 62-77) described or figured mosquito pupae from various parts of the world.

Modern taxonomy of mosquito pupae utilizes all of the morphological features and chaetotaxy which may be of use in determining each species. The following discussion and table will elucidate the characters and terminology used in the present paper.

\section{Morphology}

The general appearance of a mosquito pupa is like a comma with an exaggerated dot, the dot being the head and thorax fused into a cephalothorax, the tail of the comma being the abdomen. Generally the size of the pupa corresponds to the size of the imago.

CEPHALOTHORAX.-The head is marked by the appearance of the compound eyes of the adult near the anterior margin (Fig. 1, Ce) and the smaller pupal eyes just posterior to them (Fig. 1, Oc). The mouth parts (Fig. 1, Mp) can be seen closely compressed and developing in the central part of an ovoid shield which covers the front and sides of the cephalothorax. The antennae (Fig. 1, Ant) extend from the sides of the epicranial region and run outward to the sides of the cephalothorax, one beneath the anterior margin of each wing.

The mesothorax is marked by the respiratory trumpets (Fig. 1, Tr), which provide the only opening in the integument of the pupa. The spiracular opening is always at the base of the trumpet in the Culicinae, but may be either at the middle or nearer the apex in the Chaoborinae. Each trumpet (Fig. 2) is divided into a tubular portion, the meatus, and an open funnel-shaped portion, the pinna. The meatus is often plainly divisible into a proximal tracheoid portion provided with numerous concentric ridges, and a distal reticulate portion, the surface of which is covered by a fine network. The trumpets are composed of an inner and outer wall which are usually closely adherent, but in species of the genus Harpagomyia the walls are well separated. The opening of the

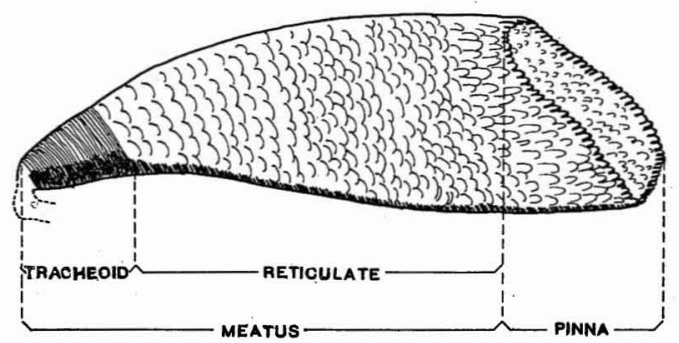

FIG. 2. Generalized trumpet of culicine pupa. 
pinna may be circular, oval, or quite irregular with a slit-like projection. The proportions of these parts and the shape of the opening are fairly constant and hence are useful in taxonomic work.

The wing-pads (Fig. 1, W) appear as flat oblong plates arising behind the bases of the trumpets and extending caudad and ventrad.

The metanotum is readily distinguished as a plate set off by sutures from the rest of the cephalothorax cephalad of the first abdominal tergite. The metanotum consists of a pair of triangular plates enclosing the halteres (Fig. 1, $\mathrm{Ha}$ ) and connected dorsally by a narrow bridge.

ABDOMEN.-The abdomen is dorso-ventrally compressed and exceedingly flexible in this direction. It is the only part of the pupa in which segmentation is readily recognizable. Each segment has a sclerotized tergum and sternum, and successive segments are joined shingle fashion by soft intersegmental membranes.

Nine segments are visible dorsally (Fig. 3). The first eight correspond in general, but segments I and VIII are usually smaller and modified for articulation with the metanotum and paddles respectively. Segment I further differs from the others in the sclerotization of its tergum, being conspicuously thicker along the cephalic and lateral margins, the center being thinly sclerotized and bearing the float-hairs (Fig. 3, Fl). The center is reinforced by a pair of oblique antero-laterally projecting strongly sclerotized ridges and a heavily sclerotized bridge which extends from the cephalic margin to the caudal margin of the tergum.

The median caudal projection of the eighth tergite which overhangs the paddles probably represents the ninth segment fused immovably to the eighth.

The median caudal projection of the eighth sternite which lies ventrad of the paddles is interpreted as the tenth segment since it contains the developing external genitalia of the imago.

Thus, the paddles are attached to segment

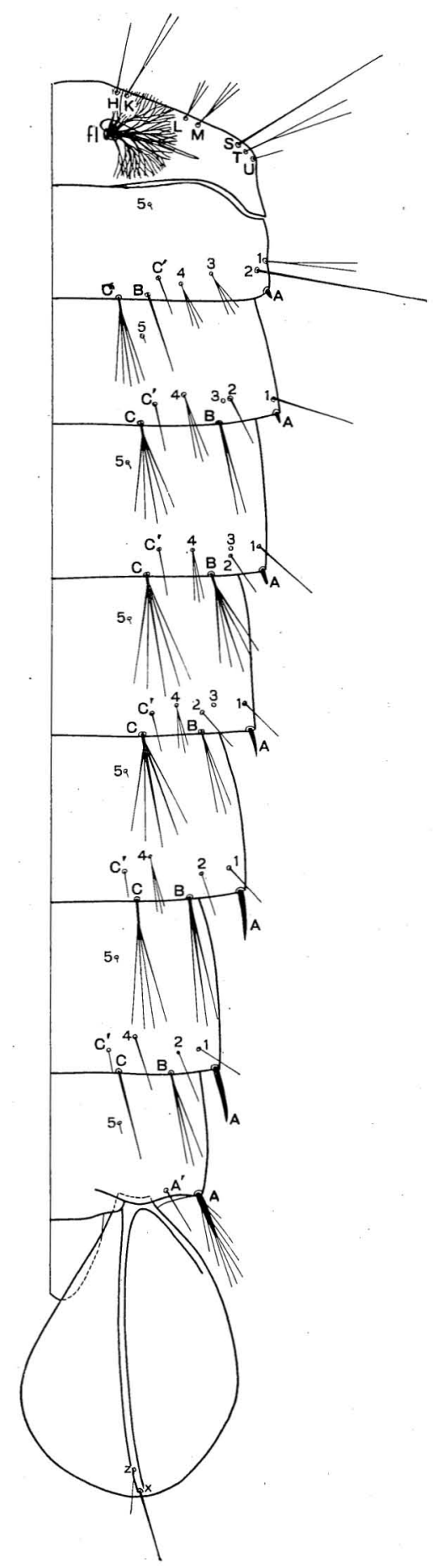

FIG. 3. Generalized abdomen of anopheline pupa in dorsal view (right half). 


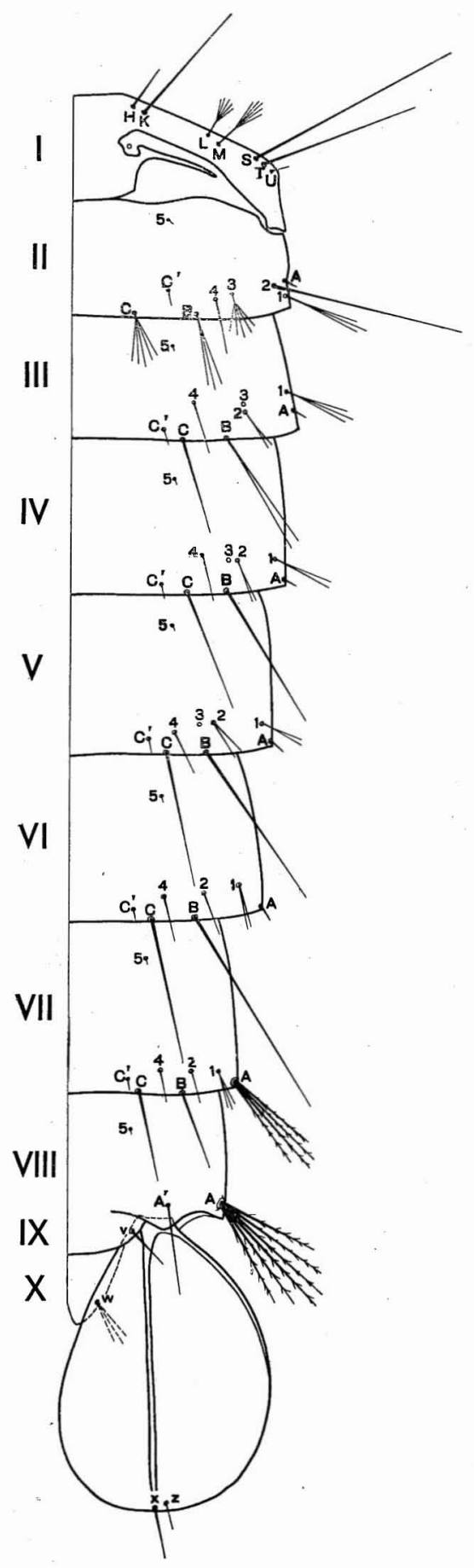

FIG. 4. Generalized abdomen of culicine pupa in dorsal view (right half).
VIII in a groove along the caudal edge of the segment. The paddles articulate freely only in a lateral direction, and as a rule are broadly oval, dorso-ventrally flattened plates. They are usually strengthened by a thickened outer buttress, which extends partially around the lateral margin from the base, and by a median thickened midrib which extends from the base to the apex; the medial and caudal margins are never reinforced by a buttress. These latter margins may, however, be either entire, denticulate, or fringed with hairs along part or all of their extent. The hairs forming the fringe are always mere processes from the edge of the paddle without articulated bases. Near the apex of the paddle one or two setae may be present. These are usually designated as the terminal seta (Figs. 3 and 4, x) and the accessory seta (Figs. 3 and $4, z$ ). The shape of the paddle, presence or absence of the terminal and accessory setae, and the nature of the margins have long been recognized and used as valuable features in taxonomic work.

\section{Chaetotaxy}

Macfie (1920: 161-169) stated that the pupa of Aedes aegypti is furnished with 100 pairs of setae, 12 pairs of which he found on the cephalothorax, and 88 pairs on the abdomen. In addition, Macfie determined that the chaetotaxy varies with right and left sides of the same individual, but that it is the same for pupae of different ages and that neither sex exceeds the normal variations of the species.

Several different systems of designating pupal setae have evolved since Macfie's paper. All of them, however, are based fundamentally on Macfie's system. These include the systems of Senevet (1930: 297-382), Baisas (1936: 6584; 1938: 175-232), and Edwards (1941: 354-428). Rozeboom and Knight (1946: 95131) recently originated an entirely new system for the abdominal setae only.

The following generalized description of pupal chaetotaxy follows mainly the modified system of Baisas. 
Cephalothorax. - There has been little deviation from Macfie's classification of the cephalothoracic setae, probably because they show so little variation in position among the genera of mosquitoes. The setae are illustrated in typical positions in Figure 1, and are described as follows:

Postocular (circum-ocular of Macfie): Three setae located on the head shield close to the posterior border of the eye; 1 upper, 2 median, 3 lower.

Anterothoracic: Four setae located in the triangular area between the anterior margin of the cephalothorax and the upper border of the antenna as it sweeps backwards; 4 lower anterior, 5 upper anterior, 6 lower posterior, 7 upper posterior.

Dorsal: A single seta (8) located between, a little behind, or far behind, the trumpets.

Supra-alar: A single seta (9) located above the root of the wing.

Metanotal (posterothoracic of Macfie): Three setae located on the bridge of the metanotum: 10 internal (o of Senevet, Baisas, and Edwards), 11 median ( $P$ of Senevet, Baisas, and Edwards), and 12 external ( $R$ of Senevet, Baisas, and Edwards).

ABDOMEN.-In attempting to homologize the setae of anopheline, culicine, megarhinine, and sabethine pupae I have been able to follow the reasoning of Baisas (1938: 175-232) almost completely for all except the dorsal setae of segment II. This is the most difficult segment to fit into the scheme of the abdomen as a whole because of the shifting in position of some of the setae. Rozeboom and Knight (1946: 95-131) considered that the setae of segment II were not entirely homologous to those of III-VII when they stated that not all segments have all the setae, and Baisas (1938: 175-232) and others apparently failed to find all of the setae on segment II. However, I have found the full complement of setae on segment II and consider the differences from other segments as of position only.

Seta $\mathrm{A}$ is present as a spine or simple hair on segments II through VI of all mosquito pupae with the exception of the tribe Megarhinini, the pupae of which will be discussed in a separate paper. On segment II, seta $\mathrm{A}$ is a minute simple spine or hair on the lateral margin usually somewhat anterior to the postero-lateral corner (Figs. 3, 4). With this as a starting point and working toward the mid-dorsal line of the tergite we find seven setae more or less near to the posterior margin, and one (seta 5) near the anterior margin. The larger two of the posterior seven, usually nearest the posterior margin, are designated as $\mathbf{B}$ and $\mathbf{C}$, and the others a little more anterior are taken in sequence from lateral side to mid-dorsal line as setae $1,2,3,4$, and $C^{\prime}$ respectively. The position of $C^{\prime}$ varies somewhat, but it is usually a small, simple, more or less, spine-like seta placed either just laterad of, or just mesad of, B.

There is usually no difficulty in interpreting the setae on segments III to V. However, seta 3 is represented only by its socket on these segments. Seta 3 is entirely absent from segment VI, but otherwise the setae of this segment are similar to those of III through V.

Segment VII presents some difficulties. Seta 3 is entirely absent as on segment VI, and the larger postero-lateral seta, which is usually a tuft in non-anopheline pupae, is considered homologous to seta $\mathrm{A}$ of other segments. The other setae fall fairly easily into line. In some species of Aedes, seta 1 may approach the size and importance of A; and in Armigeres seta B is so reduced in size that it is difficult to assign with certainty.

Segment. VIII has only three setae dorsally. These are difficult to homologize with those of the other segments, and hence are generally designated simply as A, the larger postero-lateral tuft; $A^{\prime}$, the smaller seta mesad of $A$; and 5, apparently the same seta as in the other segments.

Segments IX and X have one pair of small setae each in only a few genera. Seta $v$ on segment IX is present in Uranotaenia, Aedomyia, and Culex only, while seta $\mathrm{w}$ on segment $\mathrm{X}$ is present only in Megarbinus. 
Using Macfie's work as a basis, in Table 1 I have attempted to homologize as far as possible the various modifications of the system of classifying the dorsal abdominal setae which have been presented in the literature, and the slightly modified system used in this study.

TABLE 1

Homologies of Dorsal Abdominal Setae OF MOSQUITO PUPAE

\begin{tabular}{llllll}
\hline \hline Macfie & Senevet & \multicolumn{2}{c}{ Baisas } & Rozeboom & \\
(1920) & $(1930)$ & $(1936)$ & (1938) & \& Knight & Present \\
Culic. & Anoph. & Anoph. & Culic. & (1946) & Study \\
\hline
\end{tabular}

Segment I:

$\begin{array}{lcccrc}\left(C^{\prime \prime}\right) * & \mathrm{H} & \mathrm{H} & \mathrm{H} & 9 & \mathrm{H} \\ \left(\mathrm{C}^{\prime}\right) & \mathrm{K} & \mathrm{K} & \mathrm{K} & 6 & \mathrm{~K} \\ \left(\mathrm{~B}^{\prime}\right) & \mathrm{L} & \mathrm{L} & \mathrm{L} & 5 & \mathrm{~L} \\ (\mathrm{~B}) & \mathrm{M} & \mathrm{M} & \mathrm{M} & 4 & \mathrm{M} \\ \left(\mathrm{A}^{\prime \prime}\right) & \mathrm{S} & \mathrm{T} & \mathrm{S} & 2 & \mathrm{~S} \\ \left(\mathrm{~A}^{\prime}\right) & \mathrm{T} & \mathrm{S} & \mathrm{T} & 3 & \mathrm{~T} \\ (\mathrm{~A}) & \mathrm{U} & \mathrm{U} & \mathrm{U} & 1 & \mathrm{U} \\ (\mathrm{C}) & 1 & \mathrm{t} & \cdots & 10 & \begin{array}{c}\text { float- } \\ \text { hair }\end{array} \\ & & & & & \end{array}$

Segment II:

$\begin{array}{lcccrc}\text { A } & \ldots & \text { A } & \text { A } & 1 & \text { A } \\ \text { C }^{\prime} & \text { III } & 3 & \text { B } & 10 & \text { B } \\ \text { C } & \text { C } & \text { C } & \text { C } & 9 & \text { C } \\ \text { C }^{\prime \prime} & \text { IV } & 4 & 3 & 5 & C^{\prime} \\ \text { A }^{\prime} & \text { I } & 1 & \cdots & 3 & 1 \\ \text { A }^{\prime \prime} & \text { I } & 1 & 1 & 2 & 2 \\ \text { B } & \text { II } & 2 & 2 & 4 & 3 \\ \text { B }^{\prime} & \text { II' } & 2 & 4 & 6 & 4 \\ \text { D } & \text { V } & 5 & 5 & 7 & 5\end{array}$

Segment III:

$\begin{array}{lcccrc}\text { A } & 9 & \text { A } & \text { A } & 1 & \text { A } \\ \text { C }^{\prime} & \text { B } & \text { B } & \text { B } & 5 & \text { B } \\ \text { C } & \text { C } & \text { C } & \text { C } & 10 & \text { C } \\ \text { C' }^{\prime \prime} & \text { C }^{\prime} & \text { C' }^{\prime} & \text { C }^{\prime} & 9 & \text { C' }^{\prime} \\ \text { A }^{\prime} & \text { I } & 1 & 1 & 2 & 1 \\ \text { B } & \text { II } & 2 & 2 & 4 & 2 \\ \ldots . & \text { III } & \cdots . . & 3 & 3 & 3 \\ \text { B }^{\prime} & \text { IV } & 4 & 4 & 6 & 4 \\ \text { D } & \text { V } & 5 & 5 & 7 & 5\end{array}$

Segments IV-VII:

$\begin{array}{llllrl}\text { A } & 9 & \text { A } & \text { A } & 1 & \text { A } \\ \text { B } & \text { B } & \text { B } & \text { B } & 8 & \text { B } \\ \text { C } & \text { C } & \text { C } & \text { C } & 10 & \text { C } \\ \text { C }^{\prime \prime} & \text { C' }^{\prime} & C^{\prime} & C^{\prime} & 9 & C^{\prime} \\ \text { A }^{\prime} & \text { I } & 1 & 1 & 2 & 1 \\ B^{\prime} & \text { II } & 2 & 2 & 4 & 2 \\ \cdots C^{\prime} & \text { III } & \cdots & 3 & 3 & 3 \dagger \\ \text { D } & \text { IV } & 4 & 4 & 6 & 4 \\ & \text { V } & 5 & 5 & 7 & 5\end{array}$

Segment VIII:

\begin{tabular}{llcccc}
$\mathrm{A}$ & 6 & $\mathrm{~A}$ & $\mathrm{~A}$ & 1 & $\mathrm{~A}$ \\
$\mathrm{P}$ & 7 & $\mathrm{~A}^{\prime}$ & $\mathrm{A}^{\prime}$ & 8 & $\mathrm{~A}^{\prime}$ \\
$\mathrm{D}$ & 8 & 5 & 5 & 7 & 5 \\
\hline
\end{tabular}

* These setae are not actually designated by Macfie, but their possible homologies to those of the following segments are so indicated.

$\dagger$ Seta 3 not present on segments VI and VII.
No attempt has been made to utilize the ventral abdominal setae in the descriptions, hence no comment concerning them is called for here.

\section{SYSTEMATIC TREATMENT}

All of the species recorded in this paper belong to the subfamily Culicinae, as no species of the subfamily Chaoborinae have been recorded from New Guinea. However, it is possible that the latter have been overlooked and a key separating the pupae of the two subfamilies is included. The subfamily key was taken with slight change from Edwards (1932: 8). The key to genera and subgenera of Culicinae is largely original, but based somewhat on a key to Ethiopian pupae in Edwards (1941); all other keys are original.

\section{Key to Subfamilies}

1. Paddles fused basally, not movable; spiracle beyond middle of respiratory trumpet Genus Coretbrella of Chaoborinae

Paddles free, movable 2

2. Respiratory trumpet either almost closed apically or with the spiracle near its middle Chaoborinae

Trumpet open at tip, internal spiracle at base Culicinae

Key to Genera and Subgenera of Culicinae 1. Paddles relatively small, without setae; seta A-VIII as long as or longer than the paddles

Paddles relatively large, with or without setae; seta A-VIII never as long as the paddles

2. Trumpets with inner wall well separated from outer wall; seta K-I long, other setae on segment I small.

Harpagomyia p. 27.

Trumpets with inner and outer wall in contact; $\mathrm{K}, \mathrm{S}$, and $\mathrm{T}$ of segment I all long

3. Seta B-VII very long, extending well beyond posterior margin of segment VIII, usually beyond apex of paddles Tripteroides (Tripteroides) p. 25.

Seta B-VII at most extending to about middle of segment VIII, usually much shorter 
4. Seta 2 the most conspicuous seta on segment II, usually about twice as long as seta B; upper postocular seta (1) of cephalothorax two- or three-branched ....Tripteroides (Mimeteomyia) p. 23.

Seta 2 smaller, or equal to, $\mathbf{B}$ which is the most conspicuous seta on segment II; upper postocular seta (1) of cephalothorax simple, not branched. .......Tripteroides (Rachisoura) p. 23.

5. Anal segment (X) with a pair of setae; paddles broad, lateral face longer than medial face, with hair-like fringe and without terminal setae.

Megarhinus p. 23.

Anal segment (X) without setae; paddles with lateral and medial faces approximately equal in length, if fringed with hairs then they also have terminal setae

6. Setae A-III-VI stout, peg-like (apex pointed or rounded), always on posterior margin at or near to posterolateral corner of segments.

Setae A-III-VI small, simple spines on lateral margin above postero-lateral corners of the segments. 8

7. Float-hair on segment I dendritic; paddles with both terminal and accessory setae. Anopheles p. 11.

Bironella p. 21.

Float-hair on segment I with eight to ten short simple branches; paddles with only the simple terminal seta......

Aedomyia p. 38.

8. Trumpets divided to base into two movable leaflets, no meatus.

Hodgesia p. 28.

Trumpets undivided, with well-marked meatus

9. Trumpets long, with basal half or more tracheoid

Trumpets short, or only moderately long; tracheoid area when present usually occupying much less than half the meatus

10. Trumpet with tip highly modified for piercing plants; paddles narrowed and notched apically, without setae; no float-hair on segment I.

Trumpet not modified for piercing; segment I with normal float-hair or at least a seta in its place.
11. All abdominal setae very small and weak Mansonia (Coquillettidia) p. 37. Setae B and C forming long stout bristles .......Mansonia (Mansonioides) p. 37.

12. Paddles very narrow, over four times as long as wide; trumpets very long, tracheoid for more than three-fourths of their length; float-hair reduced to a single stout seta .......Ficalbia (Etorleptiomyia) p. 35.

Paddles not more than twice as long as broad; trumpets not so extremely long, and tracheoid for not more than two-thirds of their length; float-hair not a single seta.

13. Dorsal seta placed far behind trumpets; paddles fringed or strongly denticulate and often with light or dark spots......

Ficalbia (Mimomyia) p. 35.

Dorsal setae placed between or scarcely behind the trumpets; paddles with margins smooth or finely serrate but never fringed Uranotaenia (Uranotaenia) p. 29.

14. Paddles without terminal setae Culex (Acallyntrum) p. 76

Paddles with at least the terminal seta ( $\mathrm{x})$

15. Paddles nearly always with accessory seta placed beside the terminal seta; segment IX nearly always with seta $\mathrm{v}$

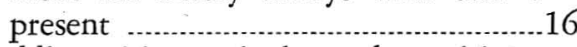

Paddles with terminal seta but without accessory seta; segment IX without seta $\mathrm{v}$

16. Paddles with serrate margins; seta $\mathrm{v}$ at least equal to the length of segment IX

Uranotaenia (Pseudoficalbia) p. 29

Paddles with smooth margins; seta $\mathrm{v}$ minute, never more than one-fourth the length of segment IX

17. Seta A far anterior to the postero-lateral corners on segments III-VI; paddles slightly notched at apex; large species Culex (Lutzia) p. 68

Seta A near to the postero-lateral corners on segments III-VI; paddles not notched at apex; size variable. 18

18. Seta $\mathrm{K}$ on segment I usually simple; all cephalothoracic setae small and inconspicuous Culex (Mochthogenes) p. 69. 
Seta $\mathrm{K}$ on segment I usually twobranched; at least some of cephalothoracic setae conspicuous.

19. Seta C-II always more than fifteenbranched....Culex (Culiciomyia) p. 72.

Seta C-II never more than fourteenbranched, usually much less.

20. Trumpet long, length more than nine times the greatest diameter of meatus; pinna short, less than one-fifth of the total length of trumpet.

Culex (Lophoceraomyia) p. 69.

Trumpet short, length never more than five times the greatest diameter of meatus; pinna long, more than onefourth of total length of trumpet........ Culex (Culex) p. 78.

21. Paddles elorigate, length more than twice greatest width

Aedes (Macleaya) p. 54.

Paddles more or less rounded, length never more than one and one-half times the greatest width.

22. Dorsal seta (8) of cephalothorax set well behind the bases of the trumpets........23

Dorsal seta (8) of cephalothorax set between or only slightly behind the bases of the trumpets.

23. Seta $S$ on segment I a small tuft; seta $C^{\prime}$ II absent. Armigeres p. 64 .

Seta $S$ on segment I long, simple or twobranched, but never a tuft; seta $C^{\prime}$-II present........Aedes (Stegomyia) p. 55.

24. Setae $H$ and $K$ wide apart, $K$ as near to $\mathrm{L}$ as to H.......Aedes (Banksinella) p. 61.

Setae $\mathrm{H}$ and $\mathrm{K}$ near together and well apart from $L$ and $M$.

25. Seta B very long, exceeding posterior margin of following segment on at least segments IV and V.

Seta B smaller, not reaching posterior margin on any segments.

26. Seta C-II separated from B-II by nearly the length of segment II; trumpets long with fairly well-developed tracheid area, though the rings are not complete..........Aedes (Mucidus) p. 40.

Seta C-II usually rather close to B-II, separated by not more than half the length of segment II; trumpets short, tracheoid area obsolete, or at most represented by one or two incomplete rings
27. Seta C-II a medium-length, ten- to fifteen-branched, often dendritic tuft...... Aedes (Aedes) p. 62.

Seta C-II of various lengths, not over sixbranched, never dendritic. 28

28. Paddles with smooth or serrate margins, never with a fringe of hairs Aedes (Finlaya) p. 42.

Paddles with a marginal fringe of long fine hairs............Aedes (Skusea) p. 54

29. Setae B and C simple on most of the segments

Aedes (Leptosomatomyia) p. 63.

Setae $B$ and C branched or forked on most of the segments.

Aedes (Aedimorphus) p. 60.

\section{Genus ANOPHELES Meigen}

DiAgnosis: Trumpets short and widely open. Abdomen with seta A spine-like, stout, and placed at or close to the postero-lateral corners of segments III to VI. Paddles with a terminal seta at end of midrib and a smaller accessory seta subapically.

\section{Key to Species of Anopbeles}

1. Setae B and C on IV-VII multi-branched with central branch nearly twice as long and stout as other branches; terminal seta of paddles short, straight, and with two to four side branches (Fig. 5)

A. (A.) barbirostris barbirostris

Setae $B$ and $C$ on IV-VII never multibranched, at most four- to fivebranched and all branches subequal; terminal seta of paddles longer, straight or hooked.

2. Paddle with a series of strong denticles on the lateral margin....................... 3

Paddle without denticles, fringe consisting of fine hairs only

3. Seta $A-V$ approximately equal to $A-I I I$ in length; terminal seta of paddle straight A. (M.) lungae

Seta $A-V$ approximately two or three times the length of A-III; terminal seta of paddle hooked.

\section{4}

4. Seta A-VI no more than a third longer than seta $\mathrm{A}-\mathrm{V}$; terminal seta of paddle weak (Fig. 6) ............... (M.) karwari

Seta A-VI more than twice as long as seta $\mathrm{A}-\mathrm{V}$; terminal seta of paddle strong (Fig. 7)

A. (M.) subpictus subpictus 
5. Seta B-II with thirteen or more branches; dorsal seta (8) of cephalothorax over 105 microns long.

Seta B-II with less than thirteen branches; dorsal seta (8) less than 105 microns long

6. Seta A-VII smooth, slender, averaging 153 microns in length; seta B-II branched from near base (Fig. 8) ......

A. (M.) punctulatus

Seta A-VII stout, with a distinct rugose constriction near base, averaging about 82 microns long; seta B-II with main branching arising at basal third from a stout stalk. A. (M.) clowi

7. Seta A-IV less than one-half the length of seta $A-V$ (Fig. 9) ....A. (M.) farauti

Seta A-IV one-half or more the length of seta $\mathrm{A}-\mathrm{V}$ (Fig. 10)

A. (M.) koliensis

Anopheles (Anopheles) barbirostris barbirostris Van der Wulp 1884

Fig. 5

Pupa fully described by Senevet (1932: 209) from Karwar, India, and by Crawford (1938: 39) from near Singapore, Malaya. The figure and the following description have been taken largely from Crawford's paper.

DiAGNOSIs.--Separable from all other known anophelines of New Guinea in having setae B and $\mathrm{C}$ on segments IV to VII multi-branched with the central branch nearly twice as long and stout as the other branches of the tuft. Terminal seta of paddles short, straight, and with two to four side branches.

CePhalothoraX.-Postocular: 1 fairly long, two- to four-branched; 2 long, two- to fivebranched; 3 long, two- to five-branched.

Anterothoracic: 4 medium, two- to threebranched; 5 long, two-branched or occasionally three-branched; 6 longer, two-branched or simple; 7 long, two-branched or simple.

Dorsal: 8 medium, simple, stout.

Supra-alar: 9 long, simple or two-branched.

Metanotum: 10 medium, two- to four-branched; 11 fairly long, two- to three-branched or occasionally simple; 12 long, two- to three-branched or simple.
Trumpet: Dark brown, expanded, somewhat boat-like.

ABDOMEN.-Segment I: H fairly short, twoto three-branched or simple; $\mathrm{K}$ medium length, two- to four-branched; L fairly short, four- to six-branched; $M$ long, two- to three-branched from near base; $s$ fairly long, two- to fivebranched from proximal fourth; $T$ long, about one and one-half times s, simple or occasionally two-branched; U short, simple or two-forked. Segment II: A minute; B medium, simple or occasionally two-branched; C long, four- to tenbranched from near base or higher; $C^{\prime}$ fairly long, five- to eleven-branched; 1 long, simple;

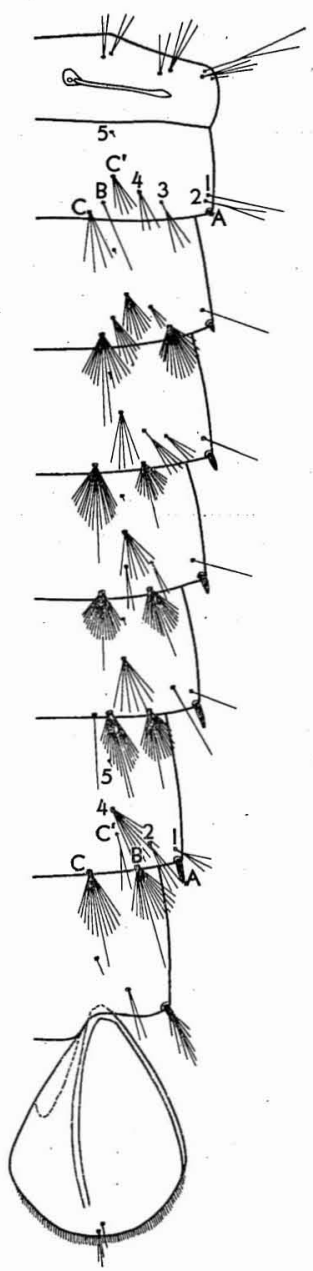

FIG. 5. Anopbeles barbirostris barbirostris: dorsal aspect of right half of abdomen of male (after Crawford, 1938). 
2 slightly shorter, simple or two- to fourbranched; 3 medium, two- to three-branched; 4 fairly short, two- to six-branched, commonly three- to four-branched.

Segment III: A short peg about twice the length of A-II; B fifteen- to forty-branched tuft; C a tuft of twelve to thirty-eight branches with long central branch; $C^{\prime}$ long, three- to seven-branched; 1 long, simple; 2 fairly short, two- to fourbranched or rarely simple; 3 represented only by its socket; 4 long, five- to twelve-branched. Segment IV: A short spine, yellow, beak-like, little or no curve, pointed; B twenty-two- to fifty-branched tuft with long central branch; C eighteen- to fifty-branched tuft with long central branch; 1 long, simple; 2 short, two- to four-branched; 3 represented only by its socket; 4 medium, four- to seven-branched; $c^{\prime}$ medium, two- to five-branched, commonly three-branched. Segment $V$ : A similar to and slightly longer than A-IV; B twenty- to fifty-branched tuft with one or two long central branches; $\mathrm{C}$ similar to $\mathrm{B}$, with thirty-three to fifty branches; $C^{\prime}$ fairly long, two-branched or simple; 1 long, simple; 2 medium length, two- to four-branched; 3 represented only by its socket; 4 fairly long, four- to eight-branched.

Segment VI: A similar to and slightly longer than $\mathrm{A}-\mathrm{V}$; B twenty- to forty-branched strong tuft with a long central branch; $C$ similar to and same length as B with twenty-nine to fifty branches; $C^{\prime}$ long, simple or two-forked near base or higher; 1 long, simple; 2 long, simple or twobranched; 3 absent; 4 long, three- to sevenbranched.

Segment VII: A similar to A-VI, about one-tenth of the segment; B fairly strong seventeen- to forty-branched tuft with long central branch; C medium, strong seventeen- to fifty-branched tuft with long central branch; $C^{\prime}$ long, two- to threeforked from proximal one-fourth; 1 fairly short, two- to five-branched; 2 fairly long, simple or two-branched; 4 slightly shorter, five- to eightforked from near base or higher.

Segment VIII: A medium length, stalk long with ten to fifteen inconspicuous branches; $A^{\prime}$ slightly longer than A, two- to three-forked from proximal one-third or simple; 5 short, two- to three-branched or simple.

Paddles: Broadly ovoid; lateral margin with small teeth proximally, replaced by short hairs distally; medial margin with similar short hairs almost to level of genital pouches; base of paddle pigmented; terminal seta short, with one to four fine side branches on its distal half, or bifid; accessory seta almost as long as terminal seta, two-branched or simple.

Anopheles (Myzomyia) lungae Belkin and Schlosser 1944

This pupa has not been fully described or figured, but Belkin, Knight, and Rozeboom (1945: 251) gave a diagnostic description from which the following notes have been taken.

DiAgNosis.-Paddle with a series of strong denticles on the lateral margin; seta $\mathrm{A}-\mathrm{V}$ approximately equal to A-III in length; terminal seta of paddle straight.

ABDOMEN.-Segment I: $\mathrm{H}$ averages sixbranched, range from five to seven; $\mathrm{K}$ usually simple, occasionally two-branched.

Segment II: C averages seven-branched, range from five to ten; $c^{\prime}$ averages three-branched, range from one to four.

Segment III: A short, simple; $\mathrm{C}$ averages fourbranched, range from three to six; $C^{\prime}$ averages two-branched, range from simple to two.

Segment IV: A short, about equal to A-III; C averages three-branched, range from two to five; 1 averages two-branched, range from simple to three.

Segment $V$ : A short, about equal to A-III; C averages three-branched, range from two to four; 1 averages two-branched, range from simple to three.

Segment VI: A much longer, at least three times $\mathrm{A}-\mathrm{V}$, extremely slender and pale, frequently branched or apically frayed; $\mathrm{C}$ averages twobranched, range from simple to four; 4 averages four-branched, range from three to five. Segment VII: A slightly longer, similar, with 
one or more branches in over 80 per cent of the specimens examined; B averages four-branched, range from three to six; 4 averages fourbranched, range from two to six.

Segment VIII: A a little longer, usually simple, occasionally two-branched; $\mathrm{A}^{\prime}$ averages twobranched, range from two to three.

\section{Anopheles (Myzomyia) karwari (James) 1903}

Fig. 6

This pupa was fully described and figured by Senevet (1932:223) from Cochin-Chine, French Indo-China; by Baisas (1936: 74, 212) from the Philippine Islands; and by Crawford (1938: 89) from near Singapore, Malaya. The figure and the following description have been taken largely from Crawford's paper.

Diagnosis.-Together with A. subpictus subpictus the pupa of this species can be distinguished from all other known anophelines of New Guinea by the following characters: seta $\mathrm{A}-\mathrm{V}$ approximately two or three times as long as A-III; terminal paddle seta long and hooked, the lateral margin with denticles proximal to the fringe of hairs. Seta A-VI is no more than a third longer than $\mathrm{A}-\mathrm{V}$ in karwari, but $\mathrm{A}-\mathrm{VI}$ is more than twice as long as A-V in subpictus.

CephalothoraX.-Postocular: 1 medium, two- to three-branched; 2 medium, two- to fourforked from proximal one-third; 3 medium, two- to four-branched.

Anterothoracic: 4 medium, three- to sixbranched; 5 medium, two- to six-branched; 6 fairly long, two- to four-branched; 7 long, twoto three-forked from near base or simple.

Dorsal: 8 fairly short, simple.

Supra-alar: 9 medium, two- or three-branched. Metanotum: 10 fairly long, simple or occasionally two-forked; 11 fairly short, two- to fourforked at proximal fourth; 12 long, two- to five-branched near middle.

Trumpet: Tubular.

ABDOMEN. - Segment I: H short, simple; $\mathrm{K}$ medium, four- to six-branched; L fairly short, two- to six-branched; $\mathrm{M}$ fairly long, three- to four-branched; $s$ fairly long, two- to sixbranched; T long, two- to three-branched; U very short, simple.

Segment II: A minute, colorless; B medium, simple or occasionally two-forked, stout; C fairly long, six- to twelve-forked, usually eight- to nine-forked from near base and higher; $c^{\prime}$ short, two- to three-branched; 1 fairly long, two- to three-branched, rarely simple; 2 about same length, three- to seven-branched; 3 short, twoto three-branched; 4 long, simple or twobranched.

Segment III: A minute, colorless; B fairly long, three- to six-branched; $C$ long, almost equal to

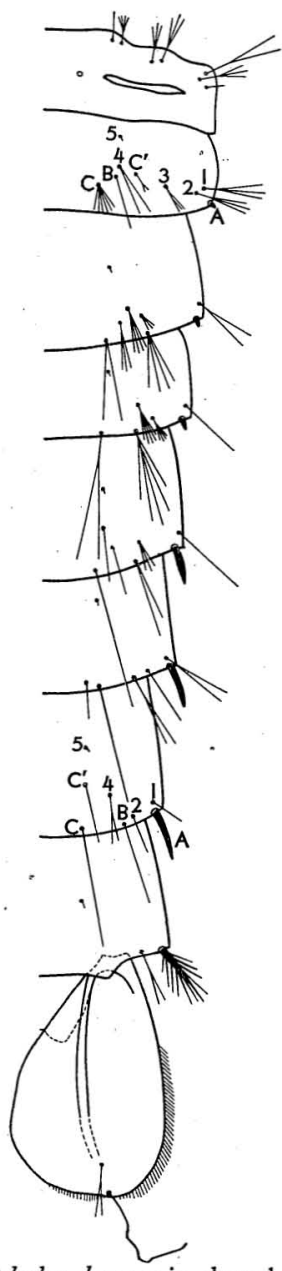

Fig. 6. Anopheles karwari: dorsal aspect of right half of abdomen of male (after Crawford, 1938). 
tergite, three- to six-branched; 1 fairly long, two- to four-forked from proximal third; 2 short, three- to six-branched; 3 represented only by its socket; 4 fairly long, two- to five-forked from near base or higher; $c^{\prime}$ fairly long, two- to three-branched or simple.

Segment IV: A minute; B long, three- to fivebranched; $\mathrm{C}$ long, about length of tergite, simple or two- to three-branched; $C^{\prime}$ medium, threeto four-branched; 1 long, simple or occasionally two- to three-forked from middle; 2 short, twoto seven-forked from proximal one-half; 3 represented only by its socket; 4 fairly long, simple or two- to three-branched.

Segment $V$ : A long, curved, tapered to a fine point, about one-third length of tergite; B long, simple or bifurcated; c long, simple or occasionally with one side branch; $C^{\prime}$ fairly long, two- to three-branched or occasionally simple; 1 long, simple or two-branched; 2 medium, twoto four-branched; 3 represented only by its socket; 4 fairly long, simple or two-branched.

Segment VI: A similar to A-V but a little longer; B long, commonly with two unequal branches from proximal one-fourth, or simple with one to two fine side branches, about two-thirds length of tergite; c long, longer than tergite, generally simple, occasionally with two unequal branches about middle, or with one side branch; $\mathrm{C}^{\prime}$ medium, one-third to one-half of $\mathrm{C}$, twobranched or occasionally simple or threebranched; 1 long, two-forked from middle one-third, occasionally three-forked or simple; 2 slightly shorter, simple or two-branched, occasionally three-branched; 3 absent; 4 fairly long, simple or two-branched.

Segment VII: A long, curved, tapered to a fine point, a little less than half of tergite in length; B long, simple or with one to two small side branches; C long, slightly longer than tergite, generally simple but may be bifurcate or have a fine side branch; $C^{\prime}$ short, two- to threebranched, occasionally simple; 1 short, two- to three-branched or simple; 2 slightly longer, simple or two-forked from middle one-third; 4 medium, two-branched or simple.
Segment VIII: A long, stalk about one-third total length, with seven to fifteen stout branches, three to five being terminal; $A^{\prime}$ fairly long, twoto three-branched, occasionally simple; $5 \mathrm{mi}$ nute, simple.

Paddle: Base of lateral margin with small pointed teeth, distally their apices taper into hairs which form a fringe extending a short distance around the apex to the medial margin; midrib stout, not reaching accessory seta; terminal seta long, hook-like; accessory seta fairly short, two- to three-branched, well removed from apex of paddle.

Anopheles (Myzomyia) subpictus subpictus Grassi 1899

\section{Fig. 7}

This pupa was fully described by Senevet (1931: 38) from Kasauli, India. The figure and the description which follow have been taken from Senevet's paper.

DIAGNOSIS.-Together with $A$. karwari the pupa of this species is set apart from all other anophelines known from New Guinea by the denticulated lateral margin of the paddle, the long seta A-IV, and the long hooked terminal seta on the paddle. From karwari it can be distinguished by the length of seta $\mathrm{A}$-VI which is more than twice as long as A-V in subpictus while it is no more than a third longer than $\mathrm{A}-\mathrm{V}$ in karwari.

Cephalothorax. - Metanotum: 10 long, strong, bifurcate; 11 medium, very fine, threebranched; 12 long, three-forked.

ABDOMEN.-Segment I: H medium, simple; $\mathrm{K}$ medium, four-branched; L short, five- to sixbranched; $M$ fairly long, three-branched; $\mathrm{S}$ medium, three- to four-branched; $\mathrm{T}$ and $\mathrm{U}$ long, simple.

Segment II: A minute; B fairly long, simple; $C$ with central short stem bearing three to four branches on each side, about one-half the length of the segment; $c^{\prime}$ medium, three- to fourbranched near apex; 1 fairly long, simple; 2 medium, three- or four-branched; 3 medium, three- to four-branched; 4 fairly long, five- to six-branched; 5 short, simple. 
Segment III: A a little longer, rounded; B fine, six- to seven-branched, one-half the length of the segment; $\mathrm{C}$ one-third length of segment, four- to six-branched; $C^{\prime}$ fairly long, strong; 1 fairly long, bifurcate; 2 medium, four- to fivebranched; 3 represented only by its socket; 4 fairly long, five- to six-branched.

Segment IV: A a little longer, apex rounded; B two-thirds length of segment, four- to fivebranched; $\mathrm{C}$ about as long as the segment, twoto three-branched; $c^{\prime}$ medium, four- to fivebranched; 1 long, simple; 2 medium, four- to five-branched; 3 represented only by its socket; 4 fairly long, four- to six-branched.

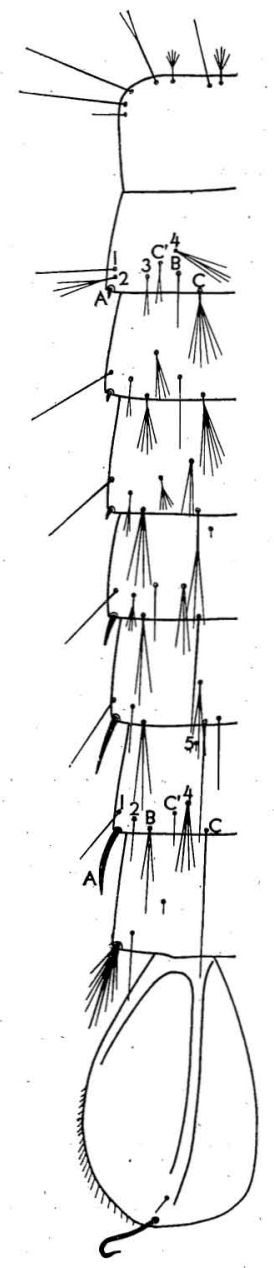

FIG. 7. Anopbeles subpictus subpictus: dorsal aspect " of left half of abdomen of male (after Senevet, 1931).
Segment $V$ : A longer, less than one-third of segment, apex not very pointed; B about two-thirds length of segment, two- to three-branched; C simple, strong, slightly longer than segment; $\mathrm{C}^{\prime}$ fairly long, simple; 1 long, simple; 2 medium, three- to four-branched; 3 represented only by its socket; 4 fairly long, three- to four-branched. Segment VI: A longer, about one-half the length of segment; В about same as B-V; C simple, strong, longer than segment; $C^{\prime}$ long, simple, half as long as C; 1 fairly long, bifurcate; 2 fairly long, simple; 3 absent; 4 long, three- to four-branched.

Segment VII: A slightly longer than one-half of segment VIII; B about same as B-VI; C simple, strong, slightly longer than segment; 1 medium, simple; 2 fairly long, simple; 4 long, fivebranched.

Segment VIII: A with fairly long central stalk, having two or three fairly strong branches on each side, and terminating in two long and strong branches, total length about one-fourth of the paddle; $A^{\prime}$ slightly longer than $A$, simple. Paddle: Little elongated; external margin bare on its anterior one-fourth, presenting on the following one-fourth a few small triangular, short, pointed spines in two to four rows; these spines are elongated on the next onefourth, and the margin becomes almost serrated; these spines are curved to the rear on the posterior one-fourth and abruptly replaced by hairs which are much longer, but which decrease rapidly and do not reach the terminal seta; terminal seta long, simple and hooked; accessory" seta small, simple, not reaching apex of paddle.

\section{Anopheles (Myzomyia) punctulatus Dönitz 1901}

Fig. 8

The pupa of this species was partially described and figured by Belkin, Knight, and Rozeboom (1945: 253) from the Solomon Islands, and by Rozeboom and Knight (1946: 108), who also compared it in many details with $A$. farauti and $A$. koliensis from the Solomon Islands and New Guinea. 
Diagnosis.-Very similar to $A$. clowi, together with which it can be separated from all other species of the punctulatus complex in having seta B-II with thirteen or more branches and the dorsal seta (8) of the cephalothorax over 105 microns long. The differences between punctulatus and clowi as reported by Rozeboom and Knight seem to be very minor and may not hold when more specimens of clowi have been examined.

Cephalothorax. - Postocular, anterothoracic and supra-alar setae similar to those in $A$. farauti.

Dorsal: 8 long, usually more than 105 microns in length.

Metanotum: 10 long, simple; 11 medium, twoforked; 12 medium, two-forked.

Trumpet: Similar to that of $A$. farauti in proportions, but paler and not offering much contrast to the general color of the cephalothorax.

ABDOMEN.-Segment I: H medium, simple; $\mathrm{K}$ medium, three- to eight-forked; $\mathrm{L}$ small, twoto four-forked; $\mathrm{M}$ long, three-forked; $\mathrm{s}$ very long, three- to four-forked; T long, six-forked; U small, simple.

Segment II: A small, stout peg; в long, simple; C long, averages eighteen-branched, usually more than thirteen but ranging from seven to thirty-eight; $C^{\prime}$ small, simple or three-forked; 1 small, four- or five-forked; 2 long, simple to three-forked; 3 medium, three- or four-forked; 4 long, five- to eight-forked; 5 minute, simple on this and all following segments.

Segment III: A small, slightly longer than A-II; B medium, six- to nine-branched; $c$ long, averages ten-forked, range from four- to sixteenforked; ' ' medium, simple to three-forked; 1 medium, two-forked near apex, range from simple to five-forked; 2 small, simple or fiveforked; 3 represented only by its socket; 4 medium, four- to seven-forked.

Segment IV: A small, roughl $j$ equal to A-III; B long, four- or five-branched; $C$ long, four- to eight-forked; c' medium, four- to six-forked; 1 medium, simple or two-forked; 2 small, threeor four-forked near apex; 3 represented only by its socket; 4 medium, five- to six-forked.
Segment V: A long, approximately four or five times as long as A-IV; B long, three- to fiveforked; c long, two- to four-forked; $c^{\prime}$ medium, simple; 1 medium, simple to three-forked; 2 small, simple to three-forked; 3 represented only by its socket; 4 medium, four-forked.

Segment VI: A longer than A-V; B long, fourbranched; C long, simple or three-forked; C' medium, simple; 1 medium, simple or twoforked; 2 small, simple; 3 absent; 4 medium, three- to five-forked.

Segment VII: A longer than A-VI, nearly twice as long as $\mathrm{A}-\mathrm{V}$; B long, two- to five-forked; C long, simple; $\mathrm{C}^{\prime}$ small, three-forked near apex; 1 small, simple; 2 small, simple; 4 medium, three- to five-forked.

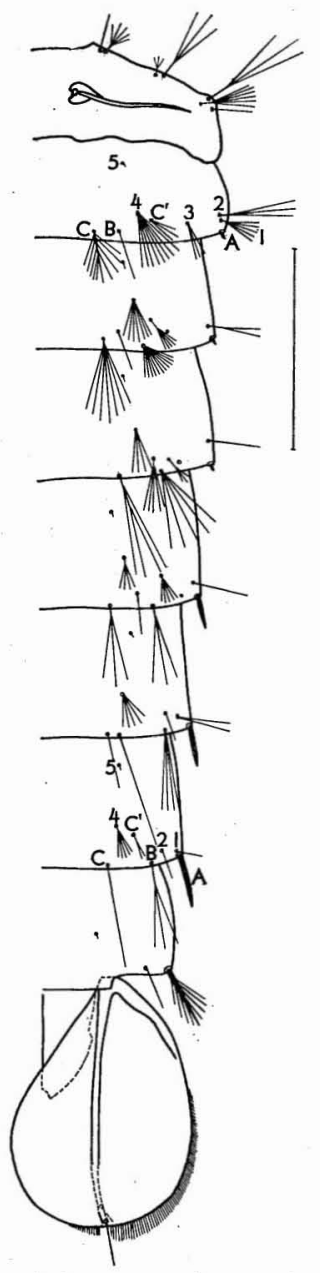

FIG. 8. Anopbeles punctulatus: dorsal aspect of right half of abdomen of male from Hilimoi, Papua. 
Segment VIII: A about equal to A-VII, with ten to twelve small side branches; $A^{\prime}$ medium, simple to three-forked.

Paddle: Roundly oval in shape, about one-fourth longer than wide; margin without denticles but produced into a fringe of fine hairs around the apex to a point mesad of the terminal seta; midrib strong, dividing the paddle unequally, the lateral face wider than the medial face; terminal seta medium, usually straight; accessory seta small, simple.

SPECIMENS EXAMINED.-The pupal exuviae of five males and two females from Hilimoi, Milne Bay, Papua.

\section{Anopheles (Myzomyia) farauti Laveran 1902}

\section{Fig. 9}

The pupa has been rather completely described and figured by several authors. Buxton and Hopkins (1927: 67) gave a brief description and figures of the terminal abdominal segments and paddles as $A$. punctulatus from the New Hebrides; Senevet (1930: 337) gave a complete detailed description and figures of the abdomen, paddles, and trumpet as $A$. punctulatus from the New Hebrides; Belkin, Knight, and Rozeboom (1945: 258) gave a complete description of specimens from the Solomon Islands; and Rozeboom and Knight (1946: 108) compared farauti with punctulatus and koliensis from the Solomon Islands and New Guinea in many details and gave a complete set of figures of the abdomen and cephalothorax.

Diagnosis. - Similar to A. koliensis with which it differs from others of the punctulatus complex in having seta B-II with less than thirteen branches and dorsal seta (8) of cephalothorax less than 105 microns long. It differs from koliensis in having seta A-IV less than one-half the length of $\mathrm{A}-\mathrm{V}$.

Cephalothorax. - Postocular: 1 small, three- to four-branched; 2 medium, four-forked; 3 small, three forked.

Anterothoracic: 4 small, four- to six-forked; 5 small, three- to five-forked; 6 medium, twoforked; 7 medium, two-forked.
Dorsal: 8 medium, simple or two-forked (less than 105 microns in length according to Belkin, et al.).

Supra-alar: 9 medium, two- to three-forked.

Metanotum: 10 medium, simple or two-forked near apex; 11 medium, three- to five-forked near middle; 12 long, two- to four-forked near middle.

Trumpet: Orange-brown, contrasting noticeably with the color of the cephalothorax, pigmented area extending basally from the apex at least to the base of the pinna.

ABDOMEN.-Segment I: H medium, simple or rarely two-forked; $\mathrm{K}$ medium, five-forked near basal one-fourth, occasionally simple or four-forked; L small, three-forked near middle; M long, three-forked near middle, rarely fourforked; $s$ very long, three-forked near basal onefourth; $\mathrm{T}$ long, five- to six-forked near basal third; U small, two-forked near apex or simple.

Segment II: A very small, stout peg; B long, simple; C long, three- to sixteen-forked, usually less than thirteen-forked; $c^{\prime}$ medium, three- to five-forked; 1 long, four-forked near basal third; 2 very long, simple or occasionally two- or three-branched; 3 medium, four- or threeforked; 4 medium, five- to seven-forked; 5 minute, simple on this and all following segments.

Segment III: A small, about twice length of A-II; B long, six-forked; C long, five- to elevenbranched; ' $\mathrm{C}$ ' long, simple; 1 very long, simple or occasionally three-forked; 2 small, simple or rarely three-forked; 3 represented only by its socket; 4 medium, four- or five-forked.

Segment IV: A about twice the length of A-III, averaging 29 microns in length according to Rozeboom and Knight; B long, six-forked; C long, usually șix-forked, range from three- to eight-forked; C' small, five-forked; 1 long, simple; 2 small, simple; 3 represented only by its socket; 4 medium, four- to five-forked.

Segment $V$ : A longer, more than twice the length of $\mathrm{A}-\mathrm{V}$; B medium, from four- to fiveforked; C long, usually three-forked, range from 
two- to six-forked; $C^{\prime}$ medium, three-forked from near middle; 1 long, simple or rarely twoforked; 2 small, simple or two-forked; 3 represented only by its socket; 4 medium, fourforked.

Segment VI: A longer than A-V; slightly plumose or frayed; B long, three- or four-forked; C long, two- to four-forked; $C^{\prime}$ medium, simple or rarely three-forked at apex; 1 medium, simple; 2 small, simple; 3 absent; 4 medium, threeto six-forked.

Segment VII: A about equal to and similar to A-VI; B long, three-forked, range from two- to four-forked; C long, simple; $C^{\prime}$ small, simple or rarely two-forked at apex; 1 small, simple or

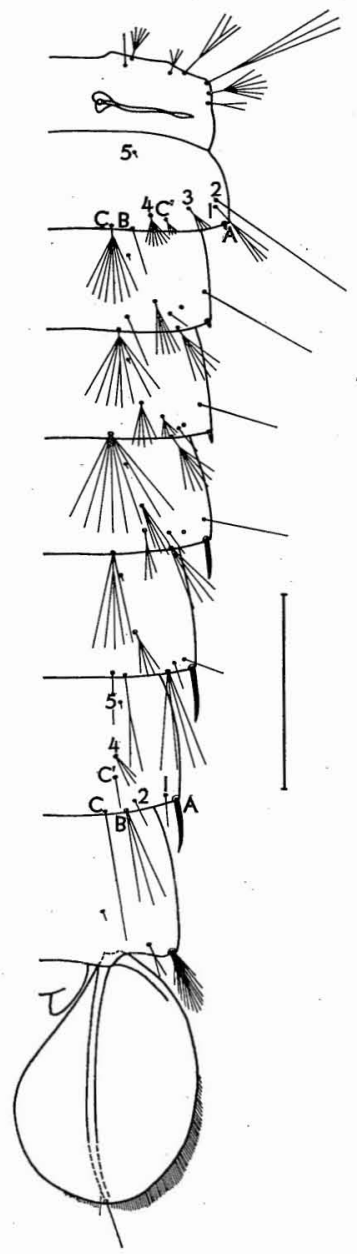

FIG. 9. Anopheles farauti: dorsal aspect of right half of abdomen of female from Amsterdam Island, Dutch New Guinea. rarely three-forked near middle; 2 small, simple; 3 absent; 4 small, three- to six-forked.

Segment VIII: A about equal in length to A-VII, with eight to eleven fine side branches; $A^{\prime}$ small, two-forked, occasionally simple or three-forked. Paddle: Roundly oval in shape, about onefourth longer than wide; margin without denticles but produced into a fringe of fine hairs around the apex to a point a little mesad of the terminal seta; midrib strong, dividing the paddle unequally, lateral face wider than medial face; terminal seta long, simple, usually hooked; accessory seta small, simple.

SPECIMENS EXAMINED.-The pupal exuviae of four males and six females from Gamadodo, WagaWaga, Hilimoi, and KanaKope, Milne Bay, Papua, and Amsterdam Island, Dutch New Guinea.

Anopheles (Myzomyia) clowi Rozeboom and Knight 1946

The pupa was described from the single type specimen by Rozeboom and Knight (1946: 114) from Hollandia, Dutch New Guinea. This constitutes the lone record of this species. The following descriptive notes were taken from this paper; no figures were given.

Diagnosis.-Very similar to $A$. punctulatus from which it can be distinguished by the structure of seta A-VII, this seta having a distinct rugose constriction near its base and averaging about 82 microns in length; and by seta B-II with its main branching arising at the basal one-third from a stout stalk.

Cephalothorax.-Dorsal: 8 long, 153 to 167 microns.

Metanotum: 10 longer, 177 to 180 microns.

Trumpet: Palely pigmented over entire length, offering only slight contrast to rest of cephalothorax; ratio of depth of basal notch to length of trumpet approximately $1: 1.4$.

ABDOMEN. - Segment I: $\mathrm{H}$ two- to fourbranched; K simple.

Segment II: C distinctive in possessing a dark, stout, basal stalk which is approximately onethird the total length of the seta, seventeen- to eighteen-branched; $C^{\prime}$ long, stout, simple. 
Segment III: A short, 14 to 17 microns; B elevenbranched; c nine-branched; $C^{\prime}$ two-branched.

Segment IV: A darkly pigmented, stout, smoothly and acutely tapered, about twice the length of A-III; $\mathbf{B}$ four-branched; $C$ three- to four-branched; $C^{\prime}$ external to $\mathrm{B}$ in position; 1 simple.

Segment $V$ : A similar to and about twice the length of A-IV; B two- to four-branched; $C$ twobranched; 1 simple.

Segment VI: A similar to and about the same length as $\mathrm{A}-\mathrm{V}$; B three-branched; C simple to three-branched; 4 four-branched.

Segment VII: A similar to and about same length as A-VI; B three-branched; C long, simple or two-branched; C' four-branched.

Segment VIII: $\mathrm{A}^{\prime}$ three-branched.

Paddle: Midrib with external margin distinct to posterior two-thirds; buttress well developed, external margin of padidle distinct to posterior half and possessing minute, clear spinules that increase in size posteriorly to beginning of fringe; fringe of fine pale hairs extending from center of external margin to the beginning of anterior curve internal to terminal seta, longest just external to this seta. Terminal seta straight, rather stout, darkly pigmented.

\section{Anopheles (Myzomyia) annulipes Walker 1856}

This pupa is undescribed except for a brief note of doubtful value given by Cooling (1924: 21) which reads, "The pupa is distinguished by the broad triangular breathing trumpets; they are pale and rather mottled."

\section{Anopheles (Myzomyia) koliensis Owen 1945}

Fig. 10

This pupa has not been fully described or figured previously, but Belkin, Knight, and Rozeboom (1945: 261) gave a diagnostic description, and Rozeboom and Knight (1946: 108111 ) included a few notes in their work on the punctulatus complex.

DiAgNosis.-Very similar to $A$. farauti but separable on the basis of the relative lengths of setae A-IV and A-V. Rozeboom and Knight
(1946: 110) examined a large series and found that in koliensis seta A-IV was more than onehalf the length of $A-V$ in 97.7 per cent of the specimens, while in farauti seta A-IV was less than one-half the length of $\mathrm{A}-\mathrm{V}$ in 89.4 per cent of the specimens.

Cephalothorax. - Postocular: 1 small, usually simple; 2 small, two-forked near middle; 3 small, three-forked near middle.

Anterothoracic: 4 small, three- to six-forked; 5 medium, three- or four-forked near middle; 6 medium, simple or two-forked near middle; 7 long, two-forked near basal one-third.

Dorsal: 8 small, two-forked near base, less than 105 microns in length, averages 69 microns.

Supra-alar: 9 small, four-forked near middle.

Metanotum: 10 medium, simple; 11 medium, three- or four-forked near middle; 12 medium, three- or four-forked near middle.

Trumpet: Similar to that of $A$. farauti.

ABDOMEN,-Segment I: H medium, always simple; $\mathrm{K}$ medium, averages five-branched, range from three to six; I small, three-forked near middle; $M$ long, three- or four-forked near basal one-third; "s long, three- or four-forked near basal one-third; $\mathrm{T}$ medium, three-branched; $\mathrm{U}$ small, simple.

Segment II: A very small, transparent; B long, always simple; $C$ usually six-branched, range from two to eleven; $C^{\prime}$ small, four-branched; 1 long, simple; 2 medium, four-branched; 3 medium, four-forked near basal one-third; 4 medium, six-branched; 5 small, simple, on this and all following segments.

Segment III: A small, transparent, about twice the length of A-II; B medium, six-branched; $C$ medium, averages ten-branched, range from seven to thirteen; $C^{\prime}$ medium, usually simple, occasionally two-branched; 1 long, equal to 1-II, usually simple, range from one- to threebranched; 2 small, three-forked near middle; 3 represented by a socket only on this and segments IV and V; 4 medium, similar to 4-II.

Segment IV: A short, stout, light brown color, less than twice the length of A-III; B long, averages six-branched; $C$ long, averages sevenbranched, range from five to nine; $C^{\prime}$ medium, 
six-branched; 1 long, though a little shorter than 1-III, usually simple, occasionally twobranched; 2 small, two-forked; 4 medium, fourforked near base.

Segment V: A slightly longer than A-IV and similar; B long, four-branched; $C$ averages fourbranched, range from three to six; $C^{\prime}$ medium; three-forked near middle; 1 long, equal to 1-IV, always simple; 2 small, two-forked near middle; 4 medium, five-branched.

Segment VI: A almost twice the length of A-IV; B long, three-branched; C long, averages twobranched, range from one to three; $C^{\prime}$ medium, mesad of $\mathrm{C}$, simple; 1 long, equal to 1-IV; 2

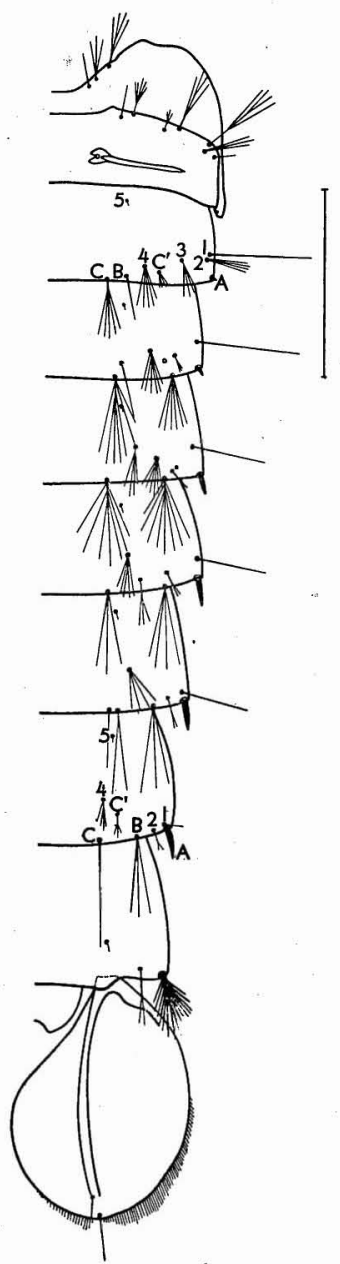

FIG. 10. Anopbeles koliensis: dorsal aspect of right half of abdomen of female from Lake Sentani, Dutch New Guinea. small, two-forked near middle; 4 medium, averages four-branched, range from two to five. Segment VII: A twice the length of A-IV, stout, acutely tapered from base, only rarely branched; B long, averages three-branched, range from two to four; $C$ very long, simple; $C^{\prime}$ small, three- to four-forked; 1 small, simple; 2 small, twoforked near apex; 4 small, averages fourbranched, range from three to five.

Segment VIII: A tufted, ten- to fifteenbranched; $A^{\prime}$ medium, averages three-branched, range from two to four.

Paddle: Midrib strong, nearly reaching apex; lateral margin and apex of medial margin with a fringe of fine hairs; terminal seta medium, simple; accessory seta small, simple.

SPECIMENS EXAMINED.-The pupal exuviae of six females from Lake Sentani, Dutch New Guinea, collected by Rozeboom, Knight, and Laffoon, USNM No. 2594.

\section{Genus BIRONELLA Theobald}

Since only two species of this genus have been completely described in the pupal stage it is impossible at the present time to formulate a diagnosis of the genus which will successfully separate it from Anopbeles. Bironella (Brugella) bollandi Taylor is of doubtful occurrence in New Guinea; its pupa was completely figured and described by Belkin, Knight, and Rozeboom (1945: 244).

Bironella (Bironella) soesiloi sensu Swellengrebel and Rodenwaldt 1932, as designated by Lee and Woodhill (1944: 65)

\section{Fig. 11}

Cephalothorax.-Postocular: 1 medium, three- or five-forked near base; 2 medium, sixto seven-forked near middle; 3 medium, six- to seven-forked near base.

Anterotboracic: 4 medium, four- to sixbranched; 5 long, four- to six-forked near basal third; 6 medium, four-forked near middle; 7 long, six- to eight-forked near basal fourth. Dorsal: 8 medium, simple or two-forked near apex.

Supra-alar: 9 long, three- to four-forked near middle. 
Metanotum: 10 medium, simple; 11 small, three-forked near base; 12 long, five- to sixforked near basal one-third.

ABDOMEN.-Segment $I: \mathrm{H}$ small, three- to six-forked near base; $\mathrm{K}$ small, three- to fourforked near basal one-third; L medium, fourforked near base; M small, averages five-forked, range from four to six; $s$ long, four- to fiveforked near basal one-third; T medium, four- to six-forked near basal one-third; U small, twoto five-branched.

Segment II: A very small, blunt-tipped, transparent; B medium, stout, with three or four fine side branches; C medium, averages twelvebranched, each branch of which may be split

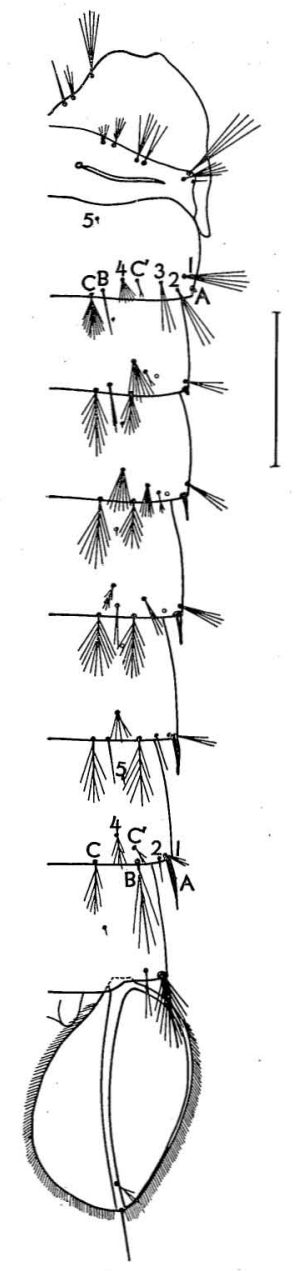

FIG. 11. Bironella soesiloi: dorsal aspect of right half of abdomen of male from Hilimoi, Papua. into three or four smaller branches; $c^{\prime}$ small, two- to six-forked near apex; 1 long, averages five-branched, range from four to seven; 2 long, averages six-branched; 3 medium, seven- to nine-branched; 4 small, averages nine-branched; 5 minute, simple on this and all following segments.

Segment III: A small, about one and one-half times the length of A-II, blunt-tipped; B medium, eight- to twelve-branched; $C$ long, tento eighteen-branched; $C^{\prime}$ medium, stout, with six to ten small side branches; 1 medium, fivebranched; 2 small, with several small side branches or two-forked near apex; 3 represented only by its socket on this and segments IV and V; 4 medium, seven- to nine-branched. Segment IV: A long, slightly curved and tapered to a fine point, about eight times as long as A-III; B medium, nine-branched; C long, averages ten-branched; $C^{\prime}$ small, six- to ten-branched; 1 medium, three-branched; 2 small, simple to three-forked near apex; 4 medium, six- to ninebranched.

Segment V: A as A-IV, about one and one-half times as long as A-IV; B long, averages elevenbranched; c long, averages eleven-branched; $C^{\prime}$ medium, two-branched; 1 medium, fourbranched; 2 medium, three-branched; 4 small, six-branched.

Segment VI: $\mathrm{A}$ as $\mathrm{A}-\mathrm{V}$, but twice as long as A-IV; B long, averages eight-branched; C long, averages seven-branched; $C^{\prime}$ medium, simple; 1 medium, three-branched; 2 small, simple; 4 small, four- or five-branched.

Segment VII: A as A-VI, same length as A-VI; B long, averages five-branched; C medium, averages seven-branched; $C^{\prime}$ small, three-forked near middle; 1 small, three-branched; 2 small, simple; 4 small, six-branched.

Segment VIII: A slightly longer than A-VII, with eleven to nineteen side branches; $A^{\prime}$ medium, two- to four-forked near basal one-third. Paddle: Midrib strong, reaching apex; almost the entire lateral and medial margins fringed with fine hairs; terminal seta long, simple, slightly hooked at apex; accessory seta small, three- to six-forked near middle. 
SPECIMENS EXAMINED.-The pupal exuviae of one male and two females from Hilimoi, Milne Bay, Papua.

\section{Bironella (Bironella) gracilis Theobald 1905}

The pupa of this species has not been described, but rather unsatisfactory figures of the paddles and trumpet were published by Hill (1925: 66).

\section{Genus MEGARHINUS Robineau-Desvoidy}

A diagnosis of the genus and a discussion of the species which occur in New Guinea are being reserved for a later study of the pupae of the tribe Megarhini.

\section{Megarhinus (Toxorhynchites) inornatus Walker 1865}

The pupa of this species remains undescribed, but Hill (1925: 67) published figures of its terminal abdominal segments, the paddles, and the trumpet.

\section{Megarhinus (Toxorhynchites) splendens (Wiedemann) 1819}

Brief superficial notes and figures of the pupa of this species were published by Banks (1908: 233 ) but are probably of no diagnostic value. Barraud (1931: 1131) included a few notes and figures of the paddle and part of segment VII based on specimens from India. Since Barraud was interested only in distinguishing among the Indian species of the genus, his key characters and descriptive notes which are quoted below are probably of little significance in New Guinea.

Paddle wide and rounded, less than 11/2 times as long as greatest width; one of the five inner hairs near the posterior margin of tergite 7 very long and stout, reaching beyond the posterior margin of tergite 8 . The larger lateral hair on segment 7 long and stout, usually much longer than tergite 8 , and often as long as greatest width of paddle. Of the sub-median and sublateral hairs, one is long and black on tergites 2, 6 and 7, and two on tergites 3, 4 and 5; the larger hair on segments 2 to 7 is long.

\section{Genus TRIPTEROIDES Giles}

DiAgNosis.-Trumpets short with tracheoid portion reduced to a very small fraction of the base of the meatus. On segment I, setae $\mathrm{H}, \mathrm{K}$, and $\mathrm{L}$ placed about equidistant from each other. On segments II-VI, seta A a small lateral spine; A-VII and A-VIII large, fan-shaped plumose tufts. Seta B a long simple seta on segments II to VI. Paddles short, not exceeding the apices of setae A-VIII posteriorly; midrib weak; paddles without terminal setae; lateral face at least twice the width of medial face.

\section{Subgenus RACHISOURA Theobald}

The pupae of none of the fourteen New Guinean species of this subgenus are represented in our collections. However, Belkin (manuscript) completely described and figured two species from Guadalcanal, Solomon Islands, and thus provides us with at least a temporary diagnosis of the subgenus.

DiAgnosis.-Seta B-VII short, not more than one-half the length of segment VIII; seta B the most conspicuous seta on segment II, equal to or longer than seta 2-II; upper postocular seta (1) of cephalothorax simple.

\section{Subgenus Mimeteomyia Theobald}

DiAgNOSIS.- Seta B-VII short, not more than one-half the length of segment VIII; paddles tapering to a narrow blunt apex; seta 2 the most conspicuous seta on segment II, usually twice as long as B; upper postocular seta (1) of the cephalothorax two- or three-branched.

\section{Tripteroides (Mimeteomyia) argenteiven-} tris (Theobald) 1905

$$
\text { Fig. } 12
$$

Cephalothorax. - Postocular: 1 long, usually two-branched, occasionally threebranched; 2 very long, two-branched; 3 small, simple or two-forked.

Anterothoracic: 4 medium, usually two-forked near base, occasionally simple; 5 medium, twoforked; 6 medium, simple; 7 long, simple.

Dorsal: 8 long, usually simple, occasionally twoforked. 
Supra-alar: 9 long, simple.

Metanotum: 10 two- or three-forked, occasionally simple or four- to five-forked; 11 simple; 12 simple.

Trumpet: short, funnel-shaped, greatest diameter equal to a little less than half the length; pigmentation uniform; pinna equal to about two-fifths of total length; no definite tracheoid portion present.

AвDOMEN.-Segment I: $\mathrm{H}$ small, simple; $\mathrm{K}$ long, simple; L medium, usually two-forked from near base, occasionally three- or fourforked; $M$ very small, usually simple, ranges from simple to four-forked; $\mathrm{s}$ and $\mathrm{T}$ long, subequal to each other, simple; $U$ minute, simple.

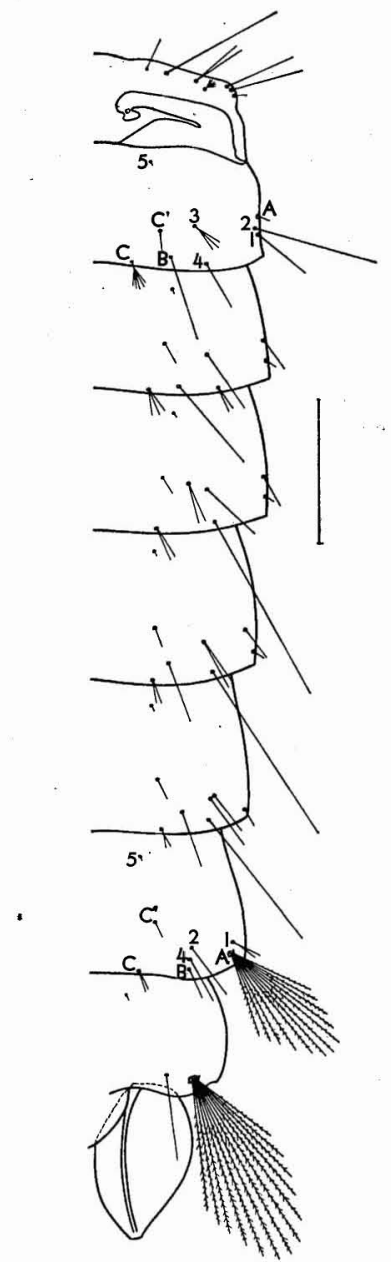

FIG. 12. Tripteroides argenteiventris: dorsal aspect of right half of abdomen of female from Hilimoi, Papua.
Segment II: A small, simple spine; в long, simple; C small, three- to seven-forked near base; $\mathbf{C}^{\prime}$ small, simple; 1 medium, simple or twoforked; 2 longest seta on segment, simple; 3 small, two- to five-forked; 4 medium, usually simple, occasionally two- or three-forked.

Segment III: A small, simple spine; B long, simple; C small, usually three-forked near base, occasionally simple or four- to five-forked; $\mathrm{C}^{\prime}$ small, simple; 1 small, simple; 2 small, two- or three-forked, rarely simple; 3 represented only by its socket; 4 medium, simple.

Segment IV: A small, simple spine; B very long, exceeding posterior margin of segment $\mathrm{V}$, simple; C small, two- to three- forked near base, or occasionally four-forked; $C^{\prime}$ small, simple; 1 small, simple; 2 medium, simple; 3 represented only by its socket; 4 medium, usually twoforked from near base, occasionally simple or three-forked.

Segment $V$ : A small, simple spine; B very long, equal to B-IV, simple; C small, usually twoforked near base, or occasionally simple or three-forked; $C^{\prime}$ small, simple; 1 small, simple; 2 medium, usually two-forked near base, occasionally three-branched; 3 represented by its socket; 4 medium, simple.

Segment VI: A small, simple spine; в long, not quite reaching posterior margin of segment VII, simple; C small, usually simple, occasionally two- to three-forked from middle; $C^{\prime}$ small, simple; 1 medium, well removed from the lateral margin, simple; 2 medium, simple; 3 absent; 4 medium, simple.

Segment VII: A large, black, conspicuous nineto fourteen-branched, plumose tuft, usually twelve-branched, about equal to B-VI in length; B small, simple; C small, either simple or twoforked; $C^{\prime}$ small, simple; 1 small, simple or twoto three-forked near apex; 2 medium, simple; 4 medium, simple.

Segment VIII: A very large, black, conspicuous thirteen- to twenty-two-branched, plumose tuft, averages seventeen-branched, exceeding the paddles in length; $A^{\prime}$ long, reaching to about the middle of the paddle, simple. 
Paddle: Small, less than seta A-VIII in length, tapering to a blunt apex which is very finely serrate; without terminal or accessory setae; midrib weak, dividing the paddle unequally, the lateral face being about twice the width of the medial face.

SPECIMENS EXAMINED.-The pupal exuviae of eleven males and eight females from Hilimoi, Milne Bay, Papua, and Draeger Harbor, Northeast New Guinea.

\section{Subgenus TRIPTEROIDES Giles}

Diagnosis.-Seta B as long as, or longer than, the following tergite on "segments II through VII. Paddles with blunt, almost squared apices.

\section{Key to Species of Tripteroides (Tripteroides)}

Seta C on segments II, III, V, and VII simple; seta 1 on segments II through VI simple (Fig. 13) T. bimaculipes

Seta C on segments II, III, V, and VII threeor four-branched; seta 1 on segments II through VI two- or three-branched (Fig. 14) T. brevipalpis

\section{Tripteroides (Tripteroides) bimaculipes}

(Theobald) 1905

\section{Fig. 13}

Cephalothorax.-Postocular: 1 very long, twice length of trumpet, two-branched, slightly plumose; 2 long, two-branched; 3 long, twobranched.

Anterothoracic: 4 medium, two-branched; 5 medium, two-branched; 6 small, simple; 7 medium, two-branched.

Dorsal: 8 long, two-thirds length of trumpet, two-branched.

Supra-alar: 9 medium, simple or two-forked.

Metanotum: 10 small, two-forked; 11 long, stout, simple; 12 long, stout, plumose, simple or occasionally two- or three-forked near apex.

Trumpet: Short, length about four times its greatest diameter; pinna about one-fourth of total length; tracheoid area represented by only two or three rings at base; darkest pigment near center, both ends lighter.
ABDOMEN.-Segment I: $\mathrm{H}$ small, simple; $\mathrm{K}$ long, stout, simple; L small, two-branched, rarely simple or three-forked; M small, usually twobranched, range from simple to four-branched; $S$ and $T$ long, simple, subequal to each other; U small, simple.

Segment II: A small, simple; B long, stout, simple; c small, two-branched, occasionally simple or three-branched; $C^{\prime}$ small, simple; 1 small, simple; 2 long, stout, simple, subequal to B in length; 3 small, two-branched or rarely threebranched; 4 small, two-branched, occasionally simple or three-branched; 5 minute, simple on this and all following segments.

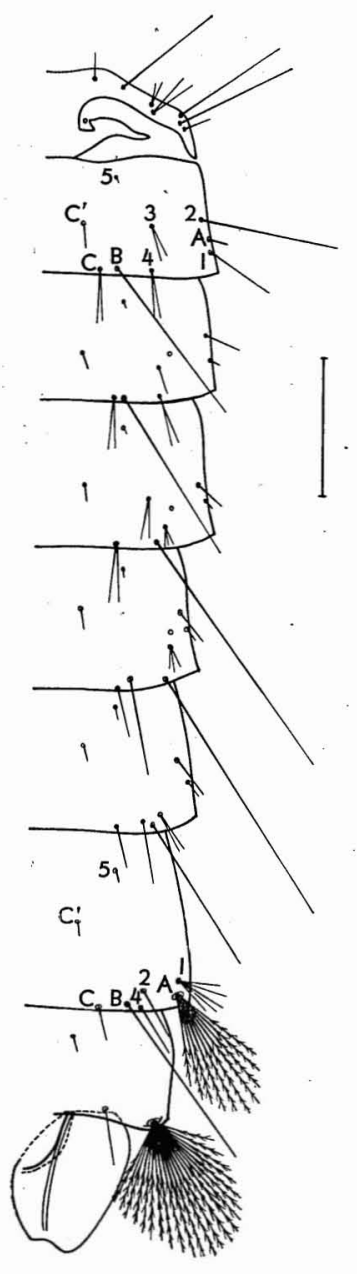

FIG. 13. Tripteroides bimaculipes: dorsal aspect of right half of abdomen of female from Amsterdam Island, Dutch New Guinea. 
Segment III: A small, simple; в long, stout, simple; C small, simple; 1 small, simple, rarely twobranched; 2 small, two-branched or occasionally simple or three-branched; 3 represented only by its socket on this and segments IV and V; 4 small, two-branched, occasionally threebranched.

Segment IV: A small, simple; B long, stout, simple; C small, two-branched, rarely threebranched; $C^{\prime}$ small, simple; 1 small, simple or two-branched; 2 small, two-branched, or occasionally three-branched; 4 small, two- or threebranched, or occasionally simple or fourbranched.

Segment V: A small, simple; в long, stout, simple; C small, two-branched or occasionally simple or three-branched; $C^{\prime}$ small, simple; 1 small, simple or occasionally two-branched; 2 small, three-branched, range from simple to fourbranched; 4 small, simple, rarely two-forked.

Segment VI: A small, simple; B long, stout, simple; $C$ small, two-branched, range from simple to three-branched; $C^{\prime}$ small, simple; 1 small, simple or rarely two-branched; 2 small, twobranched or occasionally simple or threebranched; 3 absent; 4 small, simple or rarely two-forked.

Segment VII: A large, conspicuous, fan-like, eight- to thirteen-branched, plumose tuft, usually nine- or ten-branched;" B long, about twice the length of A, stout, simple; C small, simple, rarely two-branched or three-forked; $C^{\prime}$ small, simple; 1 small, stout, four-branched, occasionally three- or five-branched; 2 small, simple, rarely two-branched; 4 small, simple.

Segment VIII: A large, conspicuous, fan-like, ten- to twenty-branched, plumose tuft exceeding the apices of the paddles in length, averages seventeen-branched; $A^{\prime}$ small, simple.

Paddles: Short, generally blunt-tipped, almost squared; not exceeding the branches of A-VIII in length; margins smooth, lacking terminal setae; midrib not quite reaching apex, dividing paddle unequally, the lateral face being about three times as wide as the medial face.

SPECIMENS EXAMINED.-The pupal exuviae of four males and six females from Hilimoi and
KanaKope, Milne Bay, Papua, and Amsterdam Island, Dutch New Guinea.

\section{Tripteroides (Tripteroides) brevipalpis Brug 1934}

Fig. 14

Cephalothorax.-Postocular: 1 very long, about twice length of trumpet, two-branched; 2 long, two-branched; 3 long, three-branched.

Anterothoracic: 4 medium, two- or threebranched; 5 long, three-branched; 6 small, simple; 7 medium, two-branched.

Dorsal: 8 long, slightly longer than trumpet, two-branched.

Supra-alar: 9 medium, two-branched.

Metanotum: 10 small, two-branched, occasionally simple or three-branched; 11 long, simple; 12 long, two- or three-forked, occasionally simple, usually slightly plumose.

Trumpet: Funnel-shaped, length about four and one-half times the greatest diameter of the meatus; pinna about one-fourth of the totai length; tracheoid area represented by only two or three rings at base; darkest pigment near middle, both ends lighter.

ABDOMEN.-Segment I: $\mathrm{H}$ small, simple; $\mathrm{K}$ long, stout, simple; L small, simple or rarely twoor three-forked; M small, usually two- or threebranched, range from simple to four-branched; $\mathrm{S}$ and $\mathrm{T}$ long, simple, subequal in length; $\mathrm{U}$ minute, simple.

Segment II: A very small, simple; B long, stout, simple; C small, three-branched, occasionally two- to five-branched; $\mathrm{C}^{\prime}$ small, simple on this and all following segments; 1 small, simple; 2 long, stout, simple, subequal to $\mathbf{B} ; 3$ small, threebranched, range from simple to four-branched; 4 small, two- or three-branched, range from two- to four-branched.

Segment III: A very small, simple; в long, stout, simple; C small, three-branched, range from two- to four-branched; 1 small, two-branched or rarely three-branched; 2 small, two-branched, occasionally simple or three-branched; 3 represented only by its socket on this and segments IV and V; 4 small, two- or three-branched, range from two- to five-branched. 
Segment IV: A very small, simple; B long, stout, simple; C small, three- or four-branched, rarely five-branched; 1 small, two- or three-branched; 2 small, two-branched or occasionally simple or three-branched; 4 small, two- or threebranched, range from simple to four-branched.

Segment V: A very small, simple; B long, stout, simple; C small, three- or four-branched; 1 small, two- or three-branched; 2 small, threebranched, range from two- to four-branched; 4 small, simple.

Segment VI: A very small, simple; B long, stout, simple; C small, three-branched or occasionally two- or four-branched; 1 small, two- or three-

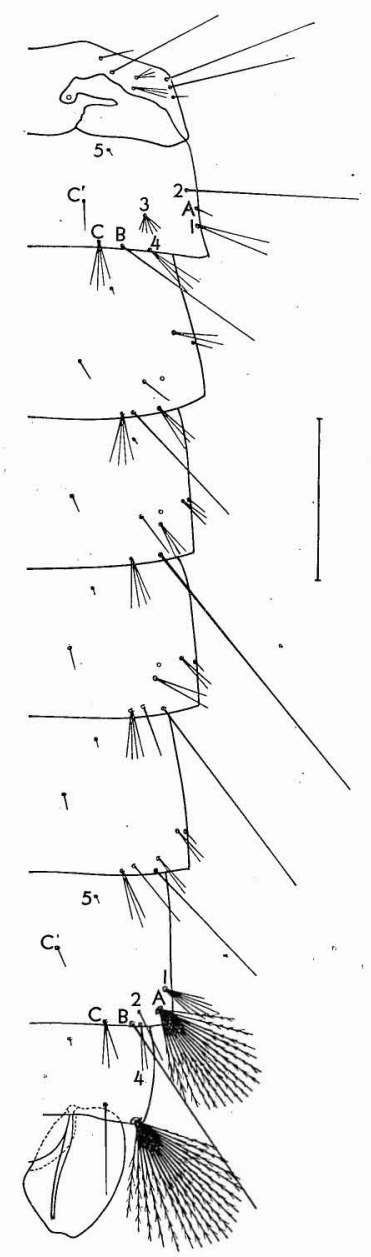

FIG. 14. Tripteroides brevipalpis: dorsal aspect of right half of abdomen of female from Mios Woendi, Dutch New Guinea. branched; 2 small, three-branched, range from simple to three-branched; 3 absent; 4 small, simple.

Segment VII: A large, conspicuous, fan-like, tento seventeen-branched, plumose tuft, usually thirteen-branched; B very long, stout, simple; C small, two- to four-branched; 1 small, stout, four- or five-branched, occasionally three- or six-branched; 2 small, simple or occasionally two-branched or forked; 4 small, simple or occasionally two-branched or forked.

Segment VIII: A large, conspicuous, fan-like, fifteen- to twenty-one-branched, plumose tuft exceeding the apices of the paddles in length, usually twenty-branched; $A^{\prime}$ small, simple.

Paddles: Short, generally blunt-tipped and not exceeding the branches of A-VIII in length; margins smooth; without terminal setae; midrib not quite reaching apex, dividing the paddle unequally, the lateral face being about three times the width of the medial face.

SPECIMENS EXAMINED.-The pupal exuviae of four males and four females from Mios Woendi, Dutch New Guinea.

\section{Genus HARPAGOMYIA De Meijere}

DIAGNOSIS.--Trumpet very short, with small, almost circular opening; outer wall wholly reticulate, the thin inner wall more obviously separated from the outer wall than usual, its basal part with some annular ridges. Upper postocular seta (1) of cephalothorax very long, split to the base into two equally stout branches; dorsal seta (8) placed well behind trumpets. Abdomen with setae $\mathrm{H}$ and $\mathrm{K}$ not far apart, $\mathrm{K}$ long and simple, all the other setae (including S) quite small. Setae A and B on segment II long and simple; $\mathrm{C}$ not quite so long, forked above base. Setae A and C on III-VI small; B long and simple, increasing in length from segment III to VI. Setae A-VII and A-VIII forming large fan-shaped tufts, largest on VIII and slightly shorter than paddle in length. Paddles small, broad at base and pointed at tip, without terminal setae, medial face rather narrow. 


\section{Harpagomyia genurostris (Leicester) 1908}

Our pupal specimens of this species from Saidor, Northeast New Guinea, were lost due to breakage in shipment, hence a complete description cannot be given. However, this is the only species of the genus known from New Guinea so the generic diagnosis should be sufficient to place any specimens from the island.

The species has been partially described but inaccurately figured by Jacobson (1911: 161) and De Meijere (1911: 164) from the Dutch East Indies and partially figured but not described by Bohart and Ingram (1946: 54) from Okinawa. The following descriptive notes have been translated and rewritten from $\mathrm{De}$ Meijere.

Cephalothorax.-Behind the upper eyespot stands a long double hair (median postocular seta), which beyond the middle shows a strong bending; under the eye one finds a much shorter, simple or double seta (upper postocular). The thorax also bears in front two short double hairs, one behind the other (upper and lower anterothoracic). On the middle, also, are the respiratory trumpets. These are long, in the upper half almost entirely of equal width, straight truncate at the end, and with a few deep incisions on the inner side.

ABDOMEN.-On the last abdominal segment are the customary, well-developed, multifid fanhairs (A-VIII). The dorsum always shows more hairs close to the corner, which are mostly sessile, those lying on the lateral sides (evidently seta B) are particularly long and surpass the next following segment in length. The next to the last and the last segments always bear a multifid fan-hair on the posterior outer corner. The paddles are little pigmented, with an inconspicuous midrib, long and acuminate apically, terminal seta missing, the margin is extremely fine-toothed on the medial side only, the rest smooth. The abdomen is yellow-white, while on the back it has a characteristic black pattern.

\section{Genus HODGESIA Theobald}

DiAgnosis.-Readily distinguished from all other mosquito pupae by the form of the trumpets, which are described by Wigglesworth (1929: 60) as follows:

Trumpets small and of highly characteristic structure, being cleft almost to the base in the form of two leaflets. Outer leaflet four times as long as its average width, with more or less longitudinal strigulae and with numerous minute scale-like denticles on the outer surface. Inner leaflet only half the width of the outer and with a bifid tip; it has the same longitudinal or oblique strigulation, but is without the minute denticles of the outer leaflet; its anterior margin and tip are clothed with fine hairs and the posterior margin is reflected inwards away from the outer leaflet.

The cephalothoracic and almost all the abdominal setae are small and inconspicuous. The dorsal seta (8) of the cephalothorax is placed in front of the trumpets.

The pupa of none of the three New Guinean species has been described.

\section{Genus URANOT AENIA Lynch-Arribalzaga}

DiAGNOSIs.-As in culicine genera the inner wall of the trumpet is not separated from the outer (in contrast to Harpagomyia), and the following features are found in the abdominal chaetotaxy. Setae $\mathbf{H}$ and $\mathbf{K}$ close together, but well apart from $\mathrm{L}$ and $\mathrm{M}$; $\mathrm{S}$ somewhat larger than these; the float-hair usually large and dendritic. Seta 2-II long, markedly longer than other setae of the segment. Setae A-III through VI small and spine-like; A-VII and A-VIII very variable according to the species. Segment IX always with a small seta on its posterolateral corners.

Discussion.-As noted by Edwards (1941: 364) it is surprising that the pupal stage of Uranotaenia is not better defined in view of the distinctive position of the genus on adult characters. Perhaps the readiest means of diagnosis is the pair of setae on segment IX which are always at least equal to the length of that segment; these setae are also present in Aedo- 
myia and in most, if not all, Culex, but in these genera they are shorter, stout, and often difficult to see. The paddles of Uranotaenia usually have the medial face much wider than the lateral face, but this is not a constant feature. The dorsal setae (8) of the cephalothorax are placed between the trumpets in most Uranotaenia as in most Aedes, not behind them as in Megarbinus, Harpagomyia, Ficalbia, and, usually, Culex, but this feature is not quite constant either. In most of the species, one of the anterothoracic setae (seta 6 in the known New Guinean species) is lengthened and thickened.

Key to Species of Uranotaenia

1. Trumpets short, their total length less than three times the greatest diameter of the meatus; tracheoid area greatly reduced, comprising less than one-fifth the total length of the trumpet

(Subgenus Pseudoficalbia) .... 2

Trumpets moderate to very long, their total length more than four times the greatest diameter of the meatus; tracheoid area not reduced, comprising more than two-fifths of the total length of the trumpet.

(Subgenus Uranotaenia).... 4

2. Setae A-VII and A-VIII long, at least equal to the length of their respective segments, two- or three-branched; seta B on segments IV-VII long, more than one-half the length of the segments; with an irregular line of black pigment on base of paddle (Fig. 15) ......U. papua

Setae A-VII and A-VIII short; not more than one-half as long as their respective segments, always simple; seta B on segments IV-VII short, always less than one-half the length of the segments; paddle without pigment. 3

3. Seta 1 on segment II three- or fourbranched (Fig. 16)

Seta 1 on segment II simple. U. quadrimaculata

4. Seta B on segments V-VII very long, greatly exceeding length of segments, two- or three-branched (Fig. 17)

U. albescens

Seta B on segments V-VIII long, exceeding length of segment only slightly on $\mathrm{V}$, not exceeding segment on VI and VII, usually three- or four-branched (Fig. 18) U. argyrotarsis
Uranotaenia (Pseudoficalbia) papua Brug .1924

\section{Fig. 15}

DiAgNosis.-With the typical characteristics of the subgenus. Readily separated from other known Pseudoficalbia from New Guinea in having setae A-VII and A-VIII longer and two- to three-branched and seta B 'on segments IV-VII more than one-half the length of the segment.

Cephalothorax.-Postocular: 1 medium, simple; 2 small, two-branched; 3 small, twobranched.

Anterothoracic: 4 small, simple; 5 small, fourbranched; 6 long, greater than length of trumpet, stout, simple; 7 small, three-branched.

Dorsal: 8 long, three-fifths length of trumpet, two-branched.

Supra-alar: 9 small, simple or two-branched.

Metanotum: 10 long, simple; 11 long, simple; 12 medium, simple.

Trumpet: Short, total length about two and onethird times the greatest diameter of the meatus; pinna short, less than one-fourth of the total length; tracheoid area reduced to basal one-fifth of trumpet, with a small spot of dark pigment.

ABDOMEN.-Segment I: $\mathrm{H}$ small, simple; $\mathrm{K}$ long, stout, simple; L small, simple or twoforked; $\mathrm{M}$ small, two-forked or branched, occasionally simple or three-branched; s long, simple; $\mathrm{T}$ small, two-branched or forked, occasionally simple or three-branched; U small, simple.

Segment II: A small, simple spine; B long, simple; C medium, simple; $C^{\prime}$ medium, simple or rarely two-branched; 1 medium, twobranched; 2 long, simple; 3 small, simple or occasionally three-branched or forked; 4 medium, simple; 5 medium, simple on this and all following segments.

Segment III: A small, simple; B medium, simple; C medium, simple or occasionally two-forked; $C^{\prime}$ small, simple on this and all following segments; 1 medium, simple; 2 small, simple or two-forked near base; 3 represented only by its socket on this and segments IV and V; 4 small, simple. 
Segment IV: A medium, simple; в long, simple; C medium, simple or occasionally two-branched; 1 medium, simple; 2 small, two-branched or forked near base, occasionally simple; 4 small, simple or two-forked, occasionally three- or four-forked.

Segment V: A medium, simple; в long, simple; C small, simple; 1 medium, simple or twoforked, occasionally three- or four-forked; 2 small, simple or two-branched, occasionally three-forked; 4 small, simple or two-forked, occasionally three-forked.

Segment VI: A long, simple or occasionally with a small side branch; B long, simple; c small,

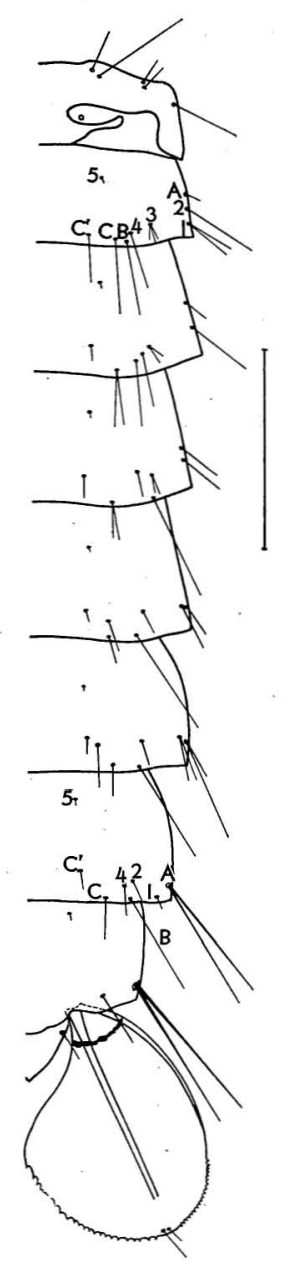

FIG. 15. Uranotaenia papua: dorsal aspect of risht half of abdomen of male from Mios Woendi, Dutch New Guinea. simple; 1 medium, two-branched or forked near base, occasionally simple or three-branched; 2 small, simple or two-branched; 3 absent; 4 medium, simple or two-branched, occasionally three-branched.

Segment VII: A very long, reaching posterior margin of segment VIII, usually two-branched, only rarely simple; B long, simple; C medium, simple; 1 very small, well removed from lateral margin, usually simple, occasionally twobranched; 2 small, simple or two-forked; 4 small, simple or two-forked.

Segment VIII: A very long, strong, two-branched or rarely three-branched; $A^{\prime}$ medium, simple or occasionally two- to four-forked.

Segment IX: v medium, stout, simple.

Paddle: Roughly oval, length greater than width; margin of apical one-half finely serrate laterally, coarsely serrate medially;" midrib strong, dividing the paddle unequally, the lateral face being about two-thirds the greatest width of the medial face; with an irregular line of black pigment across the base of the paddle; terminal seta medium, simple; accessory seta small, about onehalf length of terminal seta, simple.

SPECIMENS EXAMINED.-The pupal exuviae of twelve males and seven females from Hilimoi, Milne Bay, Papua; Draeger Harbor, Northeast New Guinea; and Mios Woendi, Dutch New Guinea.

\section{Uranotaenia (Pseudoficalbia) nigerrima Taylor 1914}

Fig. 16

Diagnosis.-With the typical characteristics of the subgenus Pseudoficalbia: trumpets short, their total length about two and one-fourth times the greatest diameter of the meatus; tracheoid area reduced to only a few basal rings; with both terminal and accessory setae on paddles. Setae A-VII and A-VIII, as well as seta B on segments IV-VII, short, less than one-half the length of their respective segments. Very similar to $U$. quadrimaculata, but separable from it in having seta 1 on segment II three- or fourbranched while on quadrimaculata this seta is simple. 
Cephalothorax.-Postocular: 1 medium, simple; 2 small, three-forked; 3 medium, twobranched.

Anterotboracic: 4 medium, two- or three-forked near apex; 5 medium, four-branched; 6 long, stout, simple; 7 small, two- or three-forked.

Dorsal: 8 long, two-thirds length of trumpet, three- or four-branched.

Supra-alar: 9 long, simple.

Metanotum: 10 medium, stout, simple or twoforked; 11 long, stout, simple; 12 long, slender, simple.

Trumpet: Short, length about two and onefourth times the greatest diameter of the meatus; pinna short, about one-third of total length; tracheoid area reduced to three or four basal rings; with a small spot of dark pigment in the tracheoid area.

AвDomen.-Segment I: H medium, simple; $\mathrm{K}$ long, stout, simple; L small, simple; $\mathrm{M}$ small, two- or threè-branched or only rarely simple or four-branched; s small, simple; $\mathrm{T}$ small, two- to four-branched; u minute, simple.

Segment II: A small, simple spine; B medium, stout, simple; C medium, stout, two-forked or occasionally simple or three-forked; $C^{\prime}$ medium, simple spine; 1 medium, three-branched or occasionally two- to four-branched or rarely simple; 2 small, stout, simple; 3 very small, two-branched or occasionally simple or three-branched; 4 medium, stout, simple; 5 minute, simple on this and all following segments.

Segment III: A small, simple spine; B medium, stout, simple; C small, two-branched or occasionally simple or three-branched; $C^{\prime}$ small, simple on this and all following segments; 1 small, simple or occasionally two-branched or forked; 2 small, two-forked, occasionally simple or twobranched; 3 represented only by its socket on this and segments IV and V; 4 medium, stout, simple.

Segment IV: A small, simple spine; B medium, stout, simple; C small, two-branched or occasionally simple to four-branched; 1 small, simple or two-branched; 2 small, two-branched or occasionally simple; 4 small, three-branched, range from two- to four-branched.
Segment V: A small, stout, simple spine; B medium, stout, simple; c small, two-branched or occasionally simple or three-branched; 1 small, simple or occasionally two-branched or twoforked; 2 small, two- or three-branched; 4 small, two-branched or occasionally three-branched.

Segment VI: A small, stout, simple spine; B medium, stout, simple; C small, two-branched or occasionally simple to four-branched; 1 small, simple; 2 small, two-branched, range from simple to three-branched; 3 absent; 4 small, twobranched or forked, range from simple to threebranched.

Segment VII: A small, stout, simple; B medium, stout, simple; C small, two-branched or occasion-

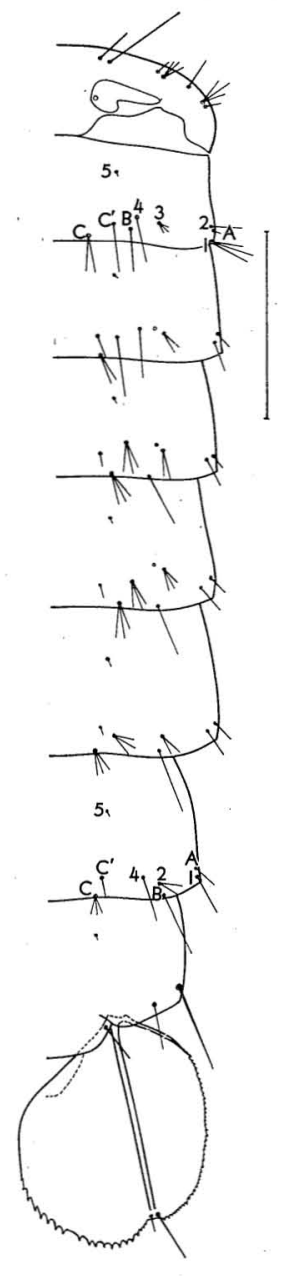

FIG. 16. Uranotaenia nigerrima: dorsal aspect of right half of abdomen of male from Hilimoi, Papua. 
ally simple or three-branched; 1 small, simple; 2 small, simple or two-branched; 4 small, simple or two-branched.

Segment VIII: A medium, stout, simple; $\mathrm{A}^{\prime}$ small, simple or rarely two-branched.

Segment IX: v small, stout, simple.

Paddle: Rounded, length slightly exceeding greatest width; margin finely serrate laterally, more coarsely serrate medially; apex notched at end of midrib; midrib strong, almost reaching apex, dividing paddle unequally, the lateral face approximately two-thirds the width of the medial face; without pigment; terminal seta very small, simple; accessory seta medium, stout, simple.

SPECIMENS EXAMINED.-The pupal exuviae of nine males and twelve females from Gamadodo and Hilimoi, Milne Bay, Papua, and Draeger Harbor, Northeast New Guinea.

Uranotaenia (Pseudoficalbia) quadrimaculata Paine and Edwards 1929

Pupa described diagnostically without figures by Paine and Edwards (1929: 313) from Guadalcanal, Solomon Islands. Since we have no New Guinean specimens in our collections the following descriptive notes have been taken entirely from the above paper.

DiAgnosis.-With the typical characters of the subgenus. Very close to $U$. nigerrima, but apparently separable from it in having seta 1 on segment II simple.

CePhalothoraX.-Dorsal: 8 three- to fourbranched, placed behind trumpet.

Trumpet: Short, only about twice as long as its greatest breadth; on the middle of inner margin is a small, semicircular emargination.

ABDOMEN.-Segment II: 1 and 2 strong, simple, placed close together near lateral margin. Segments III-VII: "Each with short stiff bristle laterally, somewhat behind the posterior corner, and a simple sublateral bristle, about two-thirds as long as the segment on posterior margin; remaining bristles on segment minute and inconspicuous, except that segment VII has additional simple bristle at posterior corner." Segment VIII: A simple or bifid.
Paddle: "With the part within midrib much longer than the outer part, also more extended apically, where it is provided with a loose fringe of spinules; on outer part of paddle the spiny fringe is much shorter and closer." Terminal seta small, simple; accessory seta longer, simple.

Uranotaenia (Uranotaenia) albescens Taylor 1914

Fig. 17

Cephalothorax.-Postocular: 1 medium, eleven-forked; 2 medium, six-forked; 3 medium, five-forked.

Anterothoracic: 4 medium, four- to five-forked; 5 long, three-branched; 6 very long, stout, simple; 7 medium, three-forked.

Dorsal: 8 very long, plumose, simple or twobranched.

Supra-alar: 9 missing from specimen.

Metanotum: 10 fairly long, three-branched; 11 fairly long, three-forked; 12 fairly long, five- to seven-branched.

Trumpet: Long, tubular, length about ten times the greatest diameter of the meatus; pinna short, expanded at tip; tracheoid portion dark, remainder of trumpet pale.

ABDOMEN.--Segment I: $\mathrm{H}$ long, simple; $\mathrm{K}$ long, two-forked near middle; L very small, three- to five-forked near middle; $M$ small, simple or two-forked; s long, two-forked near base; $\mathrm{T}$ medium, simple; U small, two-forked.

Segment II: A medium or small, simple; B long, two-forked near middle; $\mathrm{C}$ long, eight-branched; $\mathrm{C}^{\prime}$ small, three- or four-forked near apex; 1 medium, three-forked near middle; 2 long, twobranched, most conspicuous seta on the segment; 3 medium, three-forked near base; 4 long, simple; 5 minute, simple on this and all following segments.

Segment III: A small, simple spine; B medium, three-forked near middle or simple; $\mathrm{C}$ long, with eight branches; $C^{\prime}$ very small, simple or twobranched; 1 long, three-branched; 2 small, simple; 3 represented only by its socket on this and segments IV and V; 4 small, five-branched. Segment.IV: A small, simple spine; в long, fourbranched; c long, five- to six-branched; $C^{\prime}$ very 
small, simple; 1 medium, three-branched; 2 small, simple; 4 medium, four- or five-forked near middle.

Segment V: A small, simple spine; B very long, exceeding posterior margin of segment VI, threebranched; C similar to B but shorter, fourbranched; $C^{\prime}$ very small, simple; 1 medium, three-branched; 2 small, three- or four-forked near apex; 4 small, simple.

Segment VI: A small, simple spine; B very long, equal to $\mathrm{B}-\mathrm{V}$, three-branched; $\mathrm{C}$ long, equal to $\mathrm{C}-\mathrm{V}$, four-branched; $\mathrm{C}^{\prime}$ very small, simple; 1 medium, three-branched; 2 medium, simple or three-forked near apex; 3 absent; 4 medium, simple.

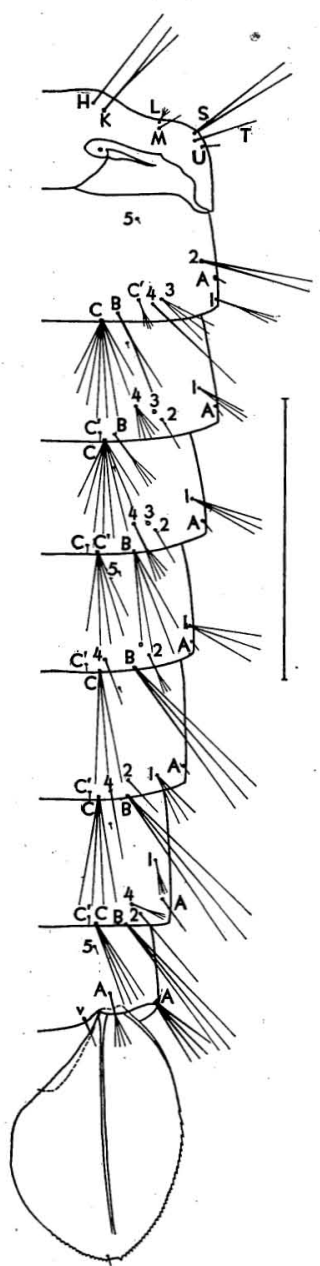

FIG. 17. Uranotaenia albescens: dorsal aspect of right half of abdomen of male from WagaWaga, Papua.
Segment VII: A medium, simple; B very long, similar to B-VI, two- or three-branched; C long, four-branched; $C^{\prime}$ very small, simple; 1 small, four-forked near middle; 2 long, simple or threeforked near apex; 4 small, three- or four-forked near apex.

Segment VIII: A medium, stout, four- or fivebranched; $A^{\prime}$ medium, four-forked near middle. Segment IX: v small, stout, simple.

Paddle: Long, oval; margin of apical two-thirds serrate laterally, only apical one-third serrate medially; midrib strong, dividing paddle unequally, the lateral face a little more than onehalf as wide as the medial face; terminal seta minute, simple; accessory seta absent.

SPECIMEN EXAMINED.-The pupal exuvium of a single male from WagaWaga, Milne Bay, Papua.

\section{Uranotaenia (Uranotaenia) argyrotarsis Leicester 1908}

Fig. 18

This pupa was partially described, without figures, by Paine and Edwards (1929: 312) from the Solomon Islands.

Cephalotionax. - Postocular: 1 long, seven- or eight-forked near base, rarely less; 2 long, slightly shorter than 1 , usually eightforked near base, rarely six-forked; 3 long, usually six-forked near base, rarely three-forked.

Anterothoracic: 4 long, six- or five-forked near base; 5 medium, four-forked near base; 6 very long, stout, exceeding length of trumpet, simple; 7 medium, two- or three-forked near middle.

Dorsal: 8 very long, about equal to trumpet in length, five- to eight-forked near base.

Supra-alar: 9 small, three- to five-forked near base.

Metanotum: 10 small, three- to four-forked near base; 11 small, two-forked near middle; 12 long, three- to five-forked near base.

Trumpet: Moderately long, total length about four and one-half times greatest diameter of meatus; uniformly dark pigmented.

ABDOMEN.-Segment I: H medium, simple; K medium, three-forked near base; L small, 
simple or two- to three-forked at apex; $M$ small, three- to four-forked near base, rarely fiveforked; s long, usually three-forked near base, rarely simple or two-forked; $\mathrm{T}$ medium, two- to four-forked near basal one-fourth; U very small, simple.

Segment II: A small, simple spine; B medium, usually three-forked near base, rarely simple or two-forked; C medium, three- to five-forked basally, each branch itself being forked further out; $C^{\prime}$ medium, three- to four-forked; 1 medium, two- or three-forked near basal onefourth; 2 long, two-forked near base; 3 small, two- or three-forked near apex, rarely simple; 4

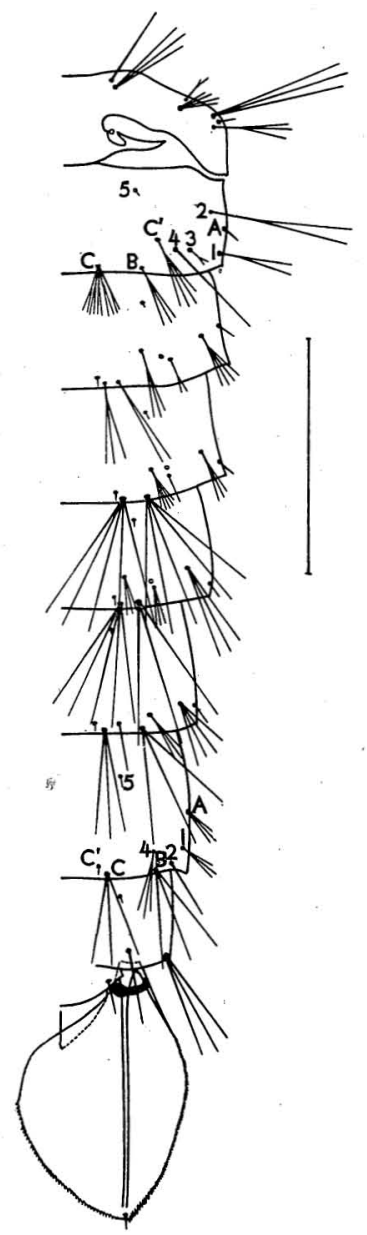

FIG. 18. Uranotaenia argyrotarsis: dorsal aspect of right half of abdomen of male from WagaWaga, Papua. long, simple; 5 minute, simple on this and all following segments.

Segment III: A small, simple spine; B medium, two- or three-forked near base, rarely simple; $C$ medium, three- to six-forked near base; $\mathrm{C}^{\prime}$ small, simple on this and all following segments except VIII from which it is absent; 1 medium, usually two-forked, occasionally three- or four-forked; 2 small, two-forked near apex; 3 represented only by its socket; 4 medium, four- to fiveforked near base.

Segment IV: A small, simple spine; B long, reaching to anterior part of segment VI, fouror five-branched, rarely three-branched; $C$ similar to $\mathrm{B}$, five- or six-branched; 1 small, three- or four-forked near base; 2 very small, simple or rarely three-forked near apex; 3 represented only by its socket; 4 small, two- to five-forked near basal one-fourth.

Segment V: A small, simple spine; B similar to в-IV, thiree- or four-branched; C similar to C-IV, three- to six-branched, usually five; 1 long, three- or four-forked near base; 2 small, threeto five-forked near base; 3 represented only by its socket; 4 small, two- or three-forked near base.

Segment VI: A small, simple spine; B similar to $\mathrm{B}-\mathrm{V}$, but not quite as long, three- or fourbranched; C similar to $\mathrm{C}-\mathrm{V}$ but not as long, threeor four-branched; 1 medium, three- or fourforked near base; 2 small, two- to four-forked near basal one-fourth; 3 absent; 4 small, usually simple, occasionally two- or three-forked near apex.

Segment VII: A small, three-branched; B similar to B-VI, two- to five-branched; C similar to C-VI, two- to four-branched; 1 small, three-forked near base; 2 medium, usually simple, occasionally two-forked near apex; 4 medium, three- to five-forked near base.

Segment VIII: A medium-long, two- or threebranched; $A^{\prime}$ medium, two-forked near apex or simple.

Segment IX: v small, simple.

Paddle: Elongate, more or less pointed; margin very finely serrate laterally, becoming coarser 
apically and medially; midrib strong, dividing paddle unequally, the lateral face about one-half the „width of the medial face; with an irregular bar of black pigment across the base of the paddle; terminal seta minute, very difficult to see on some specimens, simple; accessory seta absent.

SPECIMENS EXAMINED.-The pupal exuviae of six males and eleven females from Gamadodo, WagaWaga, and Hilimoi, Milne Bay, Papua.

\section{Uranotaenia (Uranotaenia) neotibialis King} and Hoogstraal 1947

Pupal trumpet described and figured by King and Hoogstraal (1947: 590) from Hollandia, Dutch New" Guinea, as follows: "Moderatelỳ long, length $.46 \mathrm{~mm}$., diameter .043 at narrowest point, pigmented apically and on basal half."

Uranotaenia (Uranotaenia) setosa King and Hoogstraal 1947

Pupal trumpet described and figured by King and Hoogstraal (1947: 585) from Hollandia, Dutch New Guinea, as follows: "Long and slender (length $.58 \mathrm{~mm}$; width at narrowest point $.028 \mathrm{~mm}$.), somewhat flared at tip, pigmented apically and on basal two-fifths."

Uranotaenia (Uranotaenia) tibioclada King and Hoogstraal 1947

Pupal trumpet described and figured by King and Hoogstraal (1947: 593) from Dobodura, Northeast New Guinea, as follows: "Very long and slender, length $1.05 \mathrm{~mm}$., diameter .05 at narrowest point; pigmented on basal half and at apex."

\section{Genus FICALBIA Theobald}

DIAGNOSIS.-According to Edwards (1941: 374) the species of Ficalbia are so diverse in the pupal stage that it is difficult to give an adequate generic diagnosis that will apply to all of them. Two characters common to all known species are: trumpets with at least the basal one-half (usually much more) tracheoid; paddles narrow at the base and without buttress.

\section{Subgenus Miмомyia Theobald}

DiAgNosis. - The following characters are common to all known species. Trumpets long, with more than proximal one-half tracheoid. Float-hair fully developed or reduced but always branched. Dorsal seta (8) of cephalothorax not stout, usually multiple and always inserted far behind the trumpets. Main abdominal setae sometimes forming large tufts but not conspicuously black. On segments III-VII, seta $\mathrm{C}^{\prime}$ is on the margin internal to C; on VII, setae 2 and 4 are both absent. Segment VIII is longer than in most culicine pupae, being almost as long as broad; seta A-VIII very small and inconspicuous.

The pupae of the two species recorded from New Guinea remain unknown.

\section{Subgenus ETORLEPTIOMYia Theobald}

DiAgnosis.-In. all the four known species of this subgenus the trumpets are very long, slender, and flexible, and are tracheoid for more than three-fourths of their length. The dorsal seta (8) of cephalothorax is placed far behind the base of the trumpets as in the subgenus $M i$ momyia, but it is stout or very stout in Etorleptiomyic. The float-hair is reduced to a small, stout, simple seta. The abdomen has many strong black tufts, including A-VIII. The paddles are at least five times às long as their greatest width with both margins strongly denticulate and with no setae at tip. On segments IVVI, seta $C^{\prime}$ is on the posterior margin between B and $\mathrm{C}$.

\section{Ficalbia (Etorleptiomyia) elegans (Taylor) 1914}

Fig. 19

The pupa was described without figures by Taylor (1929: 271) from Townsville, Australia.

CePhalothorax.-Postocular: 1 medium, simple; 2 small, simple; 3 long, simple.

Anterothoracic: 4 small, simple; 5 small, simple; 6 very long, simple; 7 small, simple.

Dorsal: 8 medium, stout, black, far behind trumpets. 
Supra-alar: 9 small, two- or three-forked near middle.

Metanotum: 10 very long, black, simple; 11 long, simple; 12 small, two-forked near middle, pale.

Trumpet: Very long, tubular, equal to length of abdominal segments I-VIII; tracheoid portion extending over three-fourths of the length of the trumpet, darkly pigmented; pinna short, slightly flared, pale colored along with reticulate portion.

ABDOMEN.-Segment I: H very long, simple; $\mathrm{K}$ very long, simple; L small, two-forked; M long, simple; $s$ long, simple; T small, simple; U small, simple; float-hair small, stout, simple.

Segment II: A short, simple spine; B very long, simple; C very long, two-branched; 1 medium, simple; 2 small, three-forked; 3 long, twobranched; 4 long, simple.

Segment III: A short, simple spine; B very long, simple; C very long, four-branched; $C^{\prime}$ short, simple; 1 medium, simple; 2 long, simple; 3 represented only by its socket on this and segments IV and V; 4 long, two-branched.

Segment IV: A short, simple spine; B very long, three-branched; $C$ very long, five-branched; $C^{\prime}$ small, simple; 1 medium, simple; 2 long, simple; 4 long, simple.

Segment V: A short, simple spine; B very long, three-branched; C very long, four-branched; $C^{\prime}$ small, simple; 1 a little longer than 1-IV, simple; 2 small, simple; 4 small, simple.

Segment VI: A short, simple spine; в very long, three-branched; C very long, four-branched; $C^{\prime}$ small, simple; 1 medium-long, simple; 2 small, simple; 3 absent; 4 small, simple.

Segment VII: A short, simple spine; B very long, three-branched; $C$ exceedingly long, reaching to middle of paddle, three-branched; $C^{\prime}$ small, simple; 1 medium, three-branched; 2 small, simple; 4 small, simple.

Segment VIII: A very long, eight-branched; $A^{\prime}$ small, two-forked.

Paddle: Long and narrow, length about seven times greatest width; with a pale brownish tint except on the apical third; midrib well developed; without terminal setae; margin with a

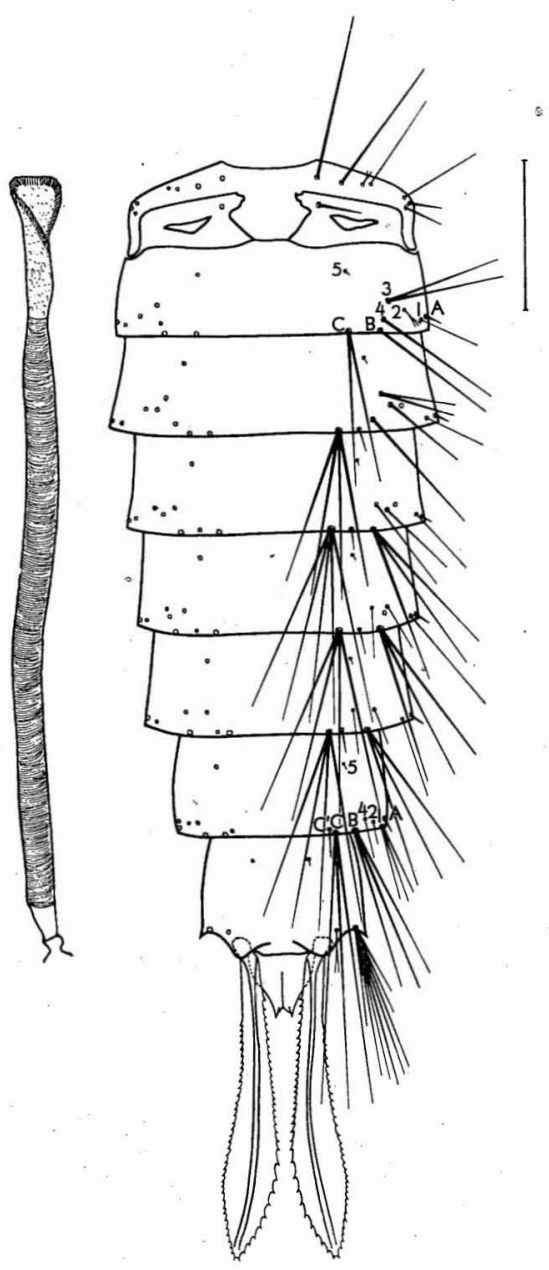

FIG. 19. Ficalbia elegans: pupal trumpet and dorsal aspect of abdomen of male from Chacon Swamp, Guadalcanal, Solomon Islands.

fringe composed of tooth-like processes extending right around the apex, the processes increasing in size from the base to the apex, especially on the medial margin.

SPECIMENS EXAMINED.-The pupal exuviae of one male and one female from Chacon Swamp, Guadalcanal, Solomon Islands, collected by John N. Belkin.

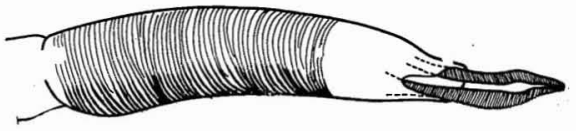

FIG. 20. Mansonia, subgenus Coquillettidia: characteristic trumpet (after Edwards, 1941). 


\section{Genus MANSONIA Blanchard}

Diagnosis. - The two main features by which pupae of Mansonia differ from those of other mosquitoes are the modification of the tip of the trumpet for the purpose of piercing plant roots and the replacement of the floathairs by minute simple setae. Also, all setae of the body are simple; setae $\mathrm{H}$ and $\mathrm{K}$ wide apart, $\mathrm{K}$ much nearer to $\mathrm{L}$ and $\mathrm{M}$ than to $\mathrm{H}$ on segment I. Paddles narrow and deeply notched at the tip, without setae; both lateral and medial margins with small denticles.

\section{Subgenus CoQuilletTidia Dyar} Fig. 20

DiAGNOSIs.-Trumpet long, mainly cylindrical, but the meatus narrowed for a short distance before base of pinna, and with a line of weakness at this point, so that the pinna can very readily be broken off; meatus tracheoid for the greater part of its length; pinna entire, with numerous ridges which presumably serve to hold it firmly in the plant root after insertion. Abdomen shagreened with minute points, except on more or less circular areas occupying the middle one-third of each tergite, these areas being practically smooth but outlined with an irregular series of fine wrinkles; on the posterior margins of the tergites the points are a little larger and produce a finely serrated edge. All the abdominal setae, including A, B, and C, minute, pale, and often difficult to find.

\section{Mansonia (Coquillettidia) xanthogaster (Edwards) 1924}

\section{Fig. 21}

The pupa has not been described, but Taylor (1944: 126) published figures of the paddles and trumpet of specimens from Cairns, Australia. The figure of the paddles has been redrawn and included here.

\section{Subgenus MansonioIDES Theobald}

DiAgNOSIS.-Trumpets differing from those of Coquillettidia in having the meatus tracheoid for only about one-half its length, and very little narrowed distally, without any line of

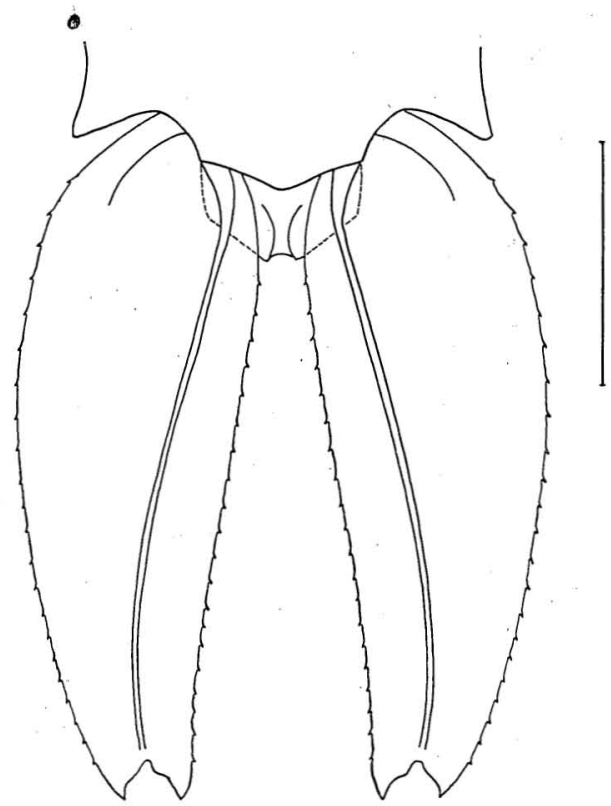

FIG. 21. Mansonia xantbogaster: dorsal aspect of terminal abdominal segment arid paddles (after Taylor, 1944).

weakness separating it from the pinna; pinna deeply divided into two parts, one pale and very delicately feathered, the other strongly sclerotized and almost spine-like, though feathered on one side. Abdomen with the basal part of each tergite coarsely reticulate, without shagreen, posterior margin prominent but smooth. Setae C-II, C-III, B, and C-IV-VII forming long, stout, dark bristles extending to or beyond posterior margin of the following segments; remaining setae small and obscure as in Coquillettidia. Paddles about twice as long as broad.

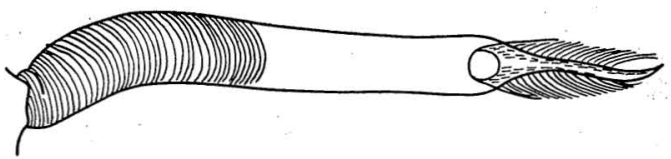

FIG. 22. Mansonia africana: pupal trumpet (after Edwards, 1941).

Mansonia (Mansonioides) africana

(Theobald) 1901

Figs. 22, 23

Photographs of the whole pupa in lateral view and notes on its habits were given by Connal (1928: 293) and figures of the whole 


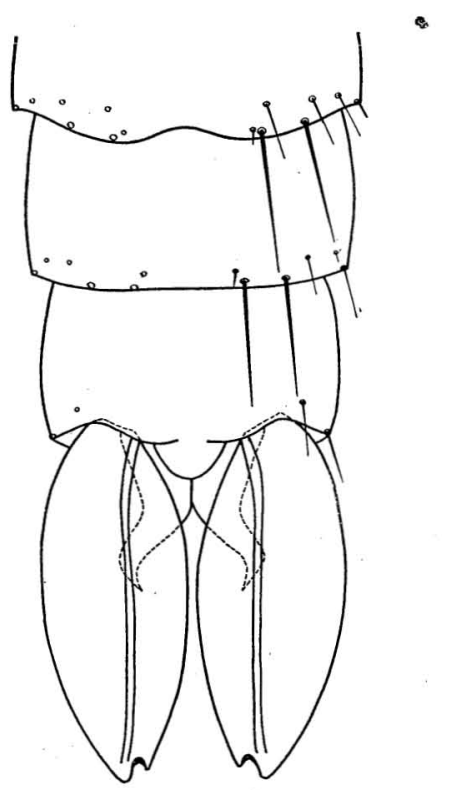

FIG. 23. Mansonia africana: dorsal aspect of terminal abdominal segments of male (after Edwards, 1941).

abdomen and paddles in dorsal view and of the trumpets were given by Edwards (1941: 384). The latter reference is the source of the figures and notes included here.

Since all the setae are simple and no other species of the subgenus except $M$. uniformis from New Guinea have been described, it seems unnecessary to attempt a complete and detailed description at this time. According to Edwards the trumpets are long, with the meatus about six times as long as broad.

\section{Mansonia - (Mansonioides) uniformis (Theobald) 1901}

A few notes on the pupa by Edwards and Given (1928: 346) based on specimens from Singapore and without figures are scarcely of diagnostic value. However, Edwards (1941: 384) included a brief note on separating this species from $M$. africana, but no figures.

All that is known may be stated as follows: Abdominal segments II to VII each with four strong setae on the hind margin. Trumpets shorter than in $M$. africana, the terminal chitinized spine of the pinna being about one-third of the total length, its margin smooth; meatus only about four times as long as broad.

\section{Genus AEDOMYIA Theobald}

DiAgnosis.-Trumpet short, with large and very oblique opening; a short tracheoid area at base. Cephalothoracic setae mostly small and inconspicuous, but dorsal seta (8) and median metanotal seta (10) large, similar to the floathair. $H, K, L$, and $M$ all small and grouped close together; float-hair composed of simple branches, not dendritic, similar to seta $\mathrm{C}$ on the following segments. Seta B very long, stout, and dark with some small basal side branches on segments IV to VI. Paddles narrow at base, widened distally, with a long terminal seta; midrib dividing paddle about equally.

\section{Aedomyia catasticta Knab 1909}

Fig. 24

Pupa partially described and fully figured by Baisas (1938: 181) from the Philippine Islands.

DIAGNOSIS.-In addition to the characters of the genus, $A$. catasticta has the following features which distinguish it from the other species. Setae A on segments II-VIII present as a graduated series of stout spines resembling seta $\mathrm{A}$ in Anopheles; seta v on segment IX is present as a small stout spine as in the genus Culex, but much smaller than found in Uranotaenia.

Discussion.-Both Baisas (loc. cit.) and Edwards (1941: 372) point out that seta B is absent from segments II and III. . Realizing that the setae of segment II of most culicines are subject to great variation in position, one might assume that the medium-length stout one mesad of $C$ is $B$, but this seta conforms in size and form, if not position, to seta $C^{\prime}$ of the following segments. The only logical conclusion, therefore, is that seta B-II is absent. However, on segment III, if seta B is really absent, there remains a small three- or four-forked seta anterior to and between $\mathrm{C}^{\prime}$ and $\mathrm{C}$ to which no designation will be assigned. Therefore, although this seta is not obviously homologous, I am tentatively designating it as B-III.

Cephalothorax. - Postocular: 1 small, simple; 2 small, four-branched; 3 small, fourbranched. 
Anterothoracic: 4 small, simple or two-forked; 5 small, four- or five-forked; 6 small, two- or three-forked; 7 small, simple.

Dorsal: 8 medium, similar to float-hair, eightor nine-branched.

Supra-alar: 9 small, simple or two-forked.

Metanotum: 10 medium, similar to float-hair, twelve- to fourteen-branched; 11 medium, simple; 12 medium, four-forked.

Trumpet: Medium-long, length about four and one-half times greatest diameter of meatus; pinna long, about one-third of total length; tracheoid area darkly pigmented, restricted to basal one-fifth of trumpet.

ABDOMEN.-Segment $I: \mathrm{H}$ very small, simple; $\mathrm{K}$ very small, simple; $\mathrm{L}$ very small, two- to four-forked; $M$ very small, four-branched; $S$ medium, three- to five-branched; $\mathrm{T}$ medium, simple or two-forked; U medium, two-branched; float-hair medium, nine- to fourteen-branched, not dendritic.

Segment II: A small, simple spine; B absent; C medium, ten- or eleven-branched; $C^{\prime}$ medium, simple spine; 1 medium, simple or occasionally four-branched; 2 medium, four- to sevenbranched; 3 small, simple or two-forked near apex; 4 medium, six- or seven-branched; 5 small, simple.

Segment III: A medium, stout simple spine, exactly on the postero-lateral corner of the segment; B (?) small, three- or four-forked near middle; C medium, ten- to fifteen-branched; $\mathrm{C}^{\prime}$ medium, stout simple spine; 1 medium, fiveto seven-branched; 2 small, simple to threebranched; 3 represented only by its socket; 4 medium, six-branched; 5 minute, simple on this and all following segments:

Segment IV: A similar to A-III; B long, stout, with a few short simple branches near base, otherwise plumose and simple; c long, a little less than half of $\mathrm{B}$, seven- to nine-branched; $C^{\prime}$ smaller than $C^{\prime}$-III, stout, simple spine on this and all following segments; 1 medium, seven-branched; 2 small, two-branched or forked; 3 represented only by its socket; 4 small, three- to five-branched.

Segment V: A similar to A-IV; B very long, similar to B-IV; C medium, seven- to ninebranched; 1 medium, six- or seven-branched; 2 small, simple to four-forked; 4 small, simple; 3 represented only by its socket.

Segment VI: A similar to A-V; B very long, similar to B-V; C medium, five-branched; 1 medium, three- or four-branched; 2 small, simple; 3. absent; 4 small, simple.

Segment VII: A medium, stout, two-branched; B long, about two-thirds length of B-VI, plumose but without basal side branches; $\mathrm{C}$ medium, four- or five-branched; 1 very small, fourbranched; 2 very small, simple; 4 very small, simple to three-branched.

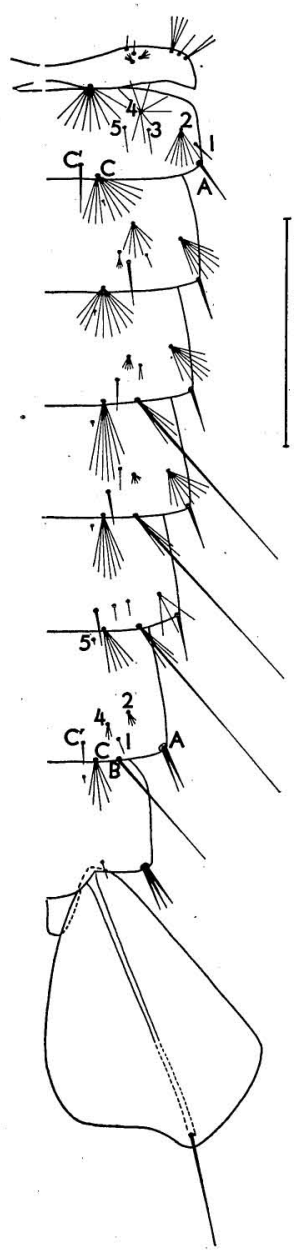

FIG. 24. Aedomyia catasticta: dorsal aspect of right half of abdomen of male from Caminawit Point, Mindoro, Philippine Islands. 
Segment VIII: A medium, stout, three-branched; $A^{\prime}$ small, simple or two-forked near apex.

Segment IX: v small, simple spine.

Paddle: Roughly triangular, narrow basally with apex expanded; midrib strong basally, fading at apical one-third into an oval area of light-brown pigment; terminal seta very long, simple, slightly plumose; accessory seta absent.

SPECIMENS EXAMINED.-The pupal exuviae of ten males and ten females from Caminawit Point (near San José), Mindoro Island, Philippine Islands, collected by the writer.

\section{Genus $A E D E S$ Meigen}

DiAgNosis.-According to Edwards (1941: 384) no single feature has been found which will separate all pupae of Aedes from all others, but most species of the genus have the following features in common: Trumpets short, without definite tracheoid portion except in the subgenus Mucidus. Float-hairs always well developed and normally dendritic. Seta A on II-VI usually minute; A-VII not forming a conspicuous tuft; A-VII and A-VIII very near to corners of segments. Paddles with terminal seta only, no accessory seta.

It is more satisfactory to treat the species of Aedes strictly by subgenera because of the divergences of the genus as a whole.

\section{Subgenus Mucidus Theobald}

Diagnosis.-In New Guinea the two species known in the pupal stage differ markedly in the length of the trumpet, and, in contrast to all other Aedes, have a rather definite tracheoid area. Otherwise, except for its large size, the pupal stage of Mucidus is not particularly outstanding although the great distance between setae C-II and B-II holds promise of being unique.

\section{Key to Species of Aedes (Mucidus)}

Trumpet moderately long with straight sides, total length not over five times greatest diameter of meatus; tracheoid area restricted to basal one-fifth of trumpet (Figs. 25, 26). A. alternans
Trumpet about ten times as long as greatest diameter of meatus; tracheoid area occupying at least basal one-third of trumpet (Figs. 27, 28). A. aurantius sspp.

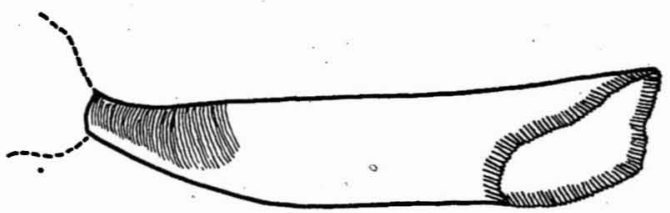

Fig. 25. Aedes alternans: pupal trumpet of female from Brisbane, Australia.

\section{Aedes (Mucidus) alternans (Westwood)} 1835

Figs. 25, 26

Pupa not described, but figures of the paddles and trumpet of specimens from North Queensland, Australia, were included by Hill (1925: 70). The figures and diagnosis included here are based on a single denuded specimen from Brisbane, Australia, collected by Mr. F. A. Perkins of the University of Queensland.

Diagnosis.-Readily separated from $A$. awrantius sspp. by the trumpet, which is moderately long with straight sides; total length about five times greatest diameter of the meatus; tracheoid area with almost complete rings,

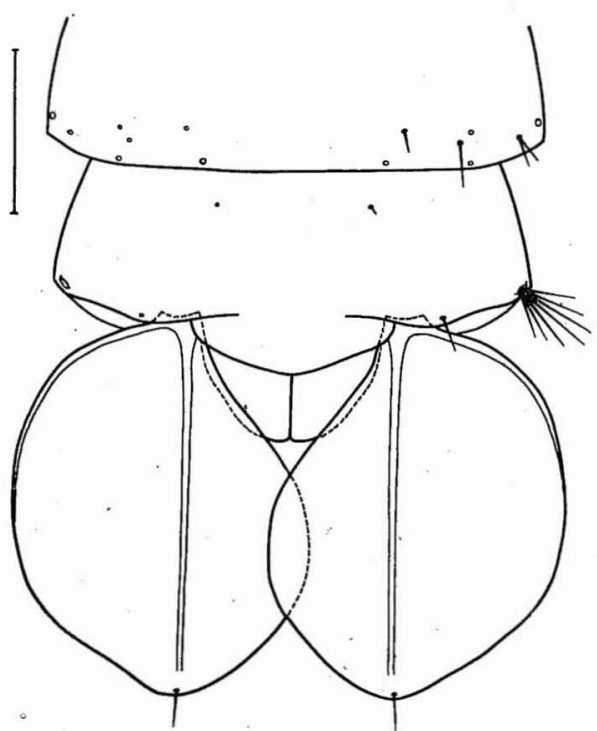

FIG. 26. Aedes alternans: dorsal aspect of terminal abdominal segments of female from Brisbane, Australia. 
restricted to the basal one-fifth of the trumpet; pinna not flared at apex.

Since the only specimen available for study was almost bare of all setae no attempt was made to describe its chaetotaxy.

\section{Aedes (Mucidus) aurantius aurantius (Theobald) 1907}

Pupa partially described and figures of the trumpet and paddles given by Edwards and Given (1928: 341) from Singapore specimens. The descriptive notes, quoted verbatim below, are too brief to be of value in separating this subspecies from chrysogaster.

Respiratory horns about half as long as the thorax; basal third or rather more blackish, as is the expanded tip, the rest pale and rather more slender. A small three-branched tuft behind the horn. First abdominal segment with a pair of large tufts; $2-7$ with long single sublateral hairs, the other hairs inconspicuous; 8 with small 4-branched apical lateral tufts. Paddles rounded, without fringe; a small simple apical bristle; midrib strong.

Aedes (Mucidus) aurantius chrysogaster (Taylor) 1927

Figs. 27, 28

DiAgnosis.--The long trumpets, which are about ten times as long as their greatest diameter; the long tracheoid area, which is about one-third of the total length of the trumpet; and the position of seta C-II, which is removed from B-II by a distance nearly equal to the length of the segment, should readily distinguish this species from all other Aedes.

Cephalothorax.-Postocular: 1 medium, two- or three-forked; 2 medium, two-forked or occasionally simple or three-forked; 3 medium, simple to four-forked.

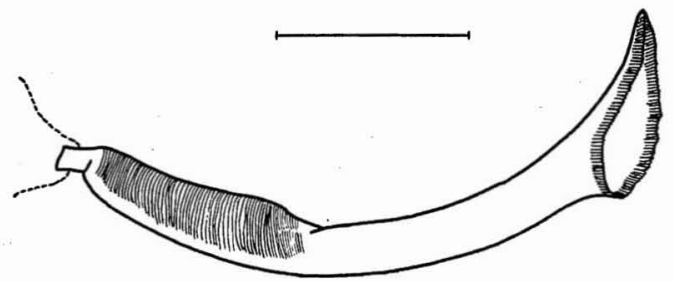

FIG. 27. Aedes aurantius chrysogaster: pupal trumpet of male from Aoeki Island, Dutch New Guinea.
Anterothoracic: 4 medium, usually four-forked, may be simple or two-forked; 5 medium, simple to five-forked; 6 minute, two- to sixbranched; 7 medium, simple to three-forked.

Dorsal: 8 very long, almost equal to length of trumpets and placed almost between them, two-branched or simple.

Supra-alar: 9 small, three- to six-forked.

Metanotum: 10 small, usually five-branched, rarely six-branched; 11 medium, three- to sixforked near base; 12 medium, usually threeforked near apex, range from three to seven. Trumpet: Long, narrow, length about ten times the greatest diameter of meatus; pinna expanded, less than one-twelfth of the total length; tracheoid area with nearly complete rings and occupying about one-third of the total length of the trumpet; tracheoid and pinna dark pigmented, the rest pale.

ABDOMEN.-Segment I: $\mathrm{H}$ very small, twoforked; $\mathrm{K}$ long, two- or three-branched; $\mathrm{L}$ very small, four- to six-forked near middle; $M$ very small, seven- to ten-branched; s long, simple; T long, slightly shorter than s, four-branched; U minute, simple.

Segment II: A small, simple spine; B small, fourforked near middle; $C$ very large, black, threeor four-branched from proximal one-third; $c^{\prime}$ very small, simple; 1 long, five-forked from near base; 2 very long, simple; 3 long, fourforked from near base; 4 very 'small, twobranched with each branch apically threeforked; 5 minute, simple on this and all following segments.

Segment III: A small, simple spine; B small, four-forked near base; c long, three-branched; $C^{\prime}$ very small, simple on this and all following segments; 1 long, simple or two-forked; 2 very small, four- to six-forked; 3 represented only by its socket; 4 small, six- or seven-branched.

Segment IV: A small, simple spine; B very long, simple; C long, two-branched; 1 long, twoforked; 2 very small, two- to four-forked; 3 represented only by its socket; 4 very small, six-forked from near base.

Segment V: A small, simple spine; B very long, reaching posterior margin of VII, simple; $C$ 
long, simple or two-branched; $\mathrm{C}^{\prime}$ very small, simple or two-forked near apex; 1 long, simple or three-forked near apex; 2 very small, five- to seven-forked near base; 3 represented only by its socket; 4 long, two- or three-forked near base.

Segment VI: A small, simple spine; B very long, simple; C long, two- or three-branched; 1 long, simple, well removed from lateral margin; 2 long, three- or four-forked near base; 4 long, two-branched.

Segment VII: A medium length, stout, twobranched, plumose; B very small, three-forked near base; C long, simple; 1 very small, twobranched, each branch two- or three-forked near

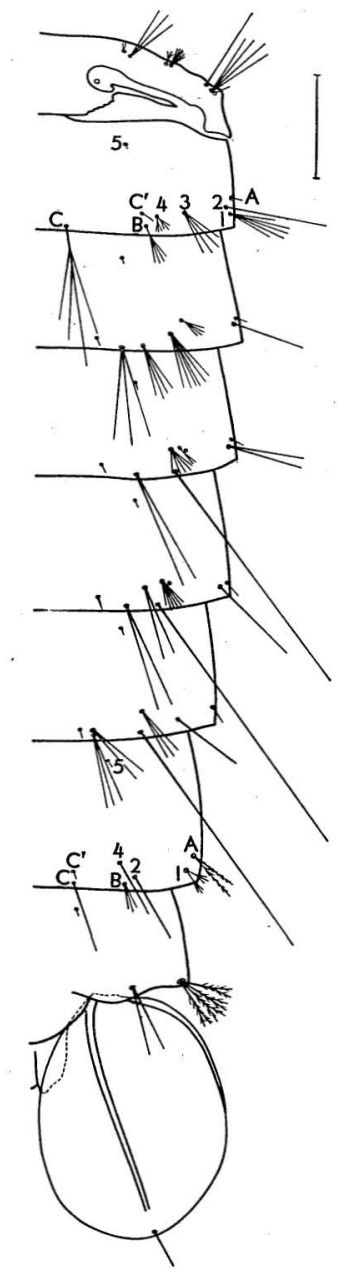

FIG. 28. Aedes aurantius chrysogaster: dorsal aspect of right half of abdomen of male from Aoeki Island, Dutch New Guinea. apex; 2 long, simple or two-forked near apex; 4 long, simple.

Segment VIII: A medium length, stout, plumose, three- or four-branched, each branch forked near apex; $A^{\prime}$ longer than $A$, two-forked near base.

Paddle: Roughly oval-shaped, margin smooth for the most part, but with very fine inconspicuous serrations near apex; terminal seta small, simple; midrib strong, not reaching apex, dividing the paddle unequally, the lateral face a little wider than medial face.

SPECIMENS EXAMINED.-One pupal exuvium and two pupae of males from Aoeki Island, Dutch New Guinea, collected by Dr. Arthur G. Humes.

Subgenus OCHLEROTATUS Lynch-Arribalzaga

The pupa of only one species of this subgenus has been described in detail, hence the preparation of a diagnosis of Ochlerotatus must wait for further study, especially of the numerous North American species. From what little is known about them it is probable that species of this subgenus will key down to the subgenus Aedes.

Aedes (Ochlerotatus) vigilax (Skuse) 1889 Fig. 29

Pupa undescribed, but Hill (1925: 71) included figures of the posterior margin of segment VIII, the paddles, and trumpet which have been redrawn and included here. Cooling (1924: 19) included a few notes on the pupae but gave nothing which is of any diagnostic value.

\section{Subgenus Finlaya Theobald}

DiAGNOSIs.-The eight species which are described in this paper have the following features in common. Seta $\mathrm{H}$ small, $\mathrm{K}$ much longer and stronger, subequal to or longer than $s$ and T. Seta 2 on segment II long, various in its length relations to B-II; C-II not more than sixbranched, each branch simple, medium length; $\mathrm{B}$ and C on III rather close together, B anterior to $\mathrm{C}$ in some species. Paddle with margin either smooth or finely serrate, never with a fringe of fine hairs. 


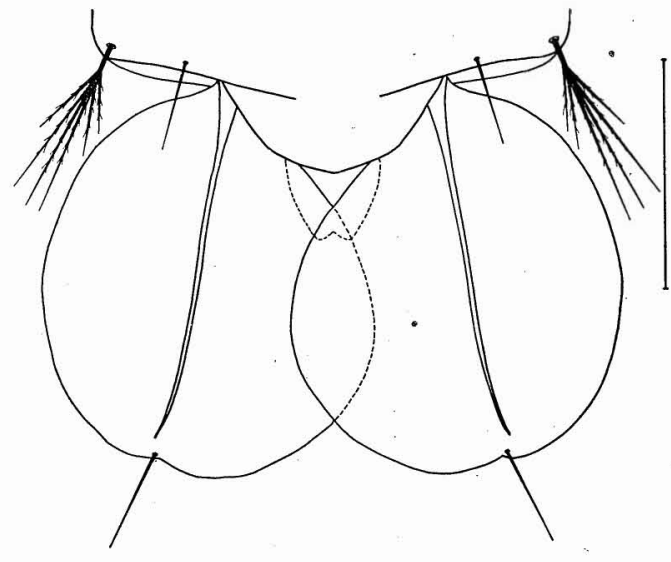

Fig. 29. Aedes vigilax: paddles (after Hill, 1925).

\section{Key to Species of Aedes (Finlaya)}

1. Paddles with serrate margins.

Paddles with smooth margins.

2. Seta A-VIII with no more than five stout branches; seta C-II two- to six-branched..3 Seta A-VIII normally. a tuft of more than seven branches; seta C-II simple.

3. Seta B exceeding the posterior margin of the following segment on segments IV-V only; paddles rounded apically with a notch at tip of midrib (Fig. 30 )

Seta $\mathrm{B}$ exceeding the posterior margin of the following segment on segments III through VI; paddles more or less pointed apically, never notched (Fig. 31)

A. keefei

4. Seta 2 on segment II very long, longer than B-II; paddles long and narrow, rounded apically; setae B-IV-VI slightly plumose apically (Fig. 32) A. wallacei

Seta 2 on segment II medium, not longer than B-II; paddles shorter and more rounded, apex with a notch at end of midrib; setae B-IV-VI not plumose (Fig. 33).

A. kochi

5. Seta B exceeding posterior margin of following segment on segments IV and V only; dorsal seta (8) of cephalothorax large, dendritic (Fig. 34)

A. candidoscutellum

Seta B exceeding posterior margin of following segment on at least segments IV, V, and VI; dorsál seta of cephalothorax medium or large but not dendritic
6. Seta A-VIII with six to eleven stout, simple, plumose branches (Fig. 35)

A. papuensis

Seta A-VIII with five to ten stout branches, each branch two- or four-branched apically (dendritic)

7. Seta C-II with four to eight branches; seta C-III with four to six branches; setae B-III-VI not plumose apically (Fig. 36) A. hollandius

Seta C-II with two to five branches; seta C-III with two to four branches; setae B-III-VI slightly plumose apically (Fig. 37) …............ novalbitarsis

Aedes (Finlaya) notoscriptus (Skuse) 1889 Fig. 30

Pupa undescribed by Hill (1925: 72), who included figures of the paddles and trumpet, but Graham (1929: 205) included a description and figures of specimens from New Zealand.

Cephalothorax.-Postocular: 1 long, simple or occasionally two-forked near middle; 2 long, simple; 3 long, simple.

Anterotboracic: 4 medium, simple or two-forked; 5 long, simple; 6 small, simple or rarely twoforked near apex; 7 long, two-forked near middle or simple.

Dorsal: 8 long, three-fourths length of trumpet, simple or two- to three-forked.

Supra-alar: 9 medium, simple.

Metanotum: 10 long, thin, two-forked or simple; 11 long, stout, simple; 12 long, thin, simple.

Trumpet: Funnel-shaped, length roughly three times the greatest diameter of meatus; pinna about one-third of total length; uniformly darkpigmented.

ABDOMEN.-Segment I: $\mathbf{H}$ small, stout, simple; $\mathrm{K}$ long, simple; L small, two- or three-forked near apex, rarely simple; $\mathrm{M}$ medium, two- or three-forked near basal third; $s$ long, simple; $T$ long, simple; U small, simple.

Segment II: A small, simple spine; B long, simple; C medium, three- to six-branched, rarely more; $C^{\prime}$ small, simple spine on this and all following segments; 1 medium, simple or rarely two-forked; 2 long, simple; 3 medium, simple or rarely two-forked at apex; 4 small, three- or two-forked near middle, rarely four- or five- 
forked; 5 minute, simple on this and all following segments.

Segment III: A small, simple spine; B long, simple; C medium, simple or occasionally two- or three-forked; 1 medium, simple or rarely twoforked near apex; 2 small, two-forked or occasionally three-forked or simple; 3 represented only by its socket; 4 medium, simple.

Segment IV: A small, simple spine; B very long, stout, simple; C long, simple or two-forked; 1 medium, simple or rarely two-forked near apex; 2 small, simple or two-forked; 3 represented only by its socket; 4 medium, three- or twoforked.

Segment V: A small, simple spine; B very long,

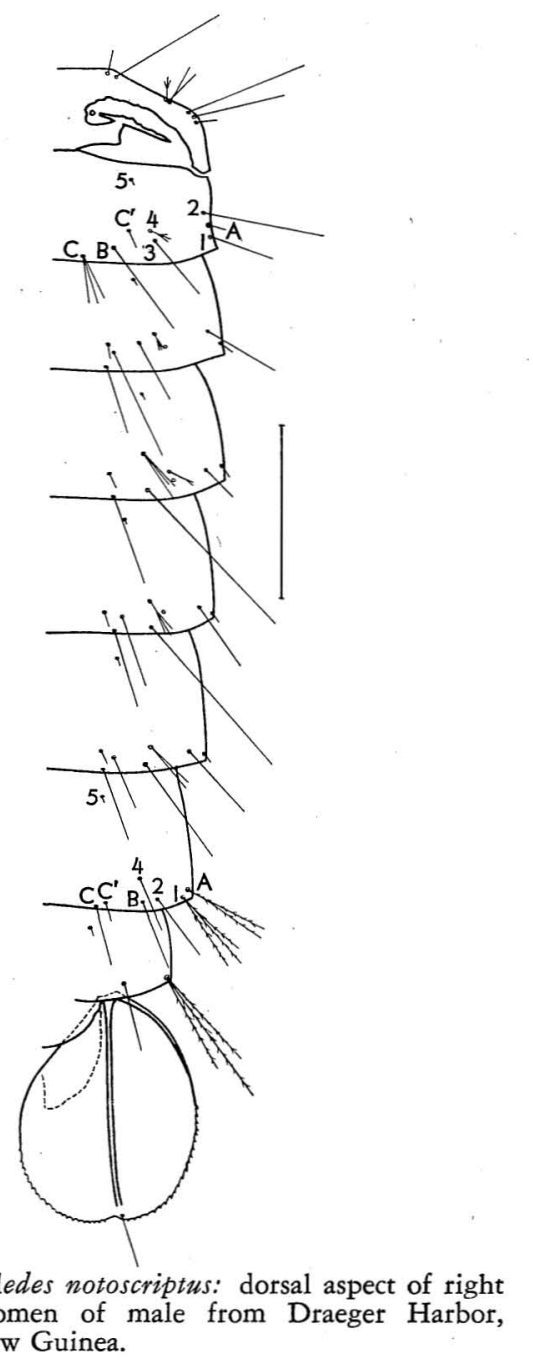
half of abdomen of male from Draeger Harbor, Northeast New Guinea.
FIG. 30. Aedes notoscriptus: dorsal aspect of right stout, simple; c long, simple or occasionally two-forked; 1 long, simple or rarely two-forked; 2 small, usually three-forked near middle, occasionally two- or four-forked or simple; 3 represented only by its socket; 4 long, simple or twoforked near apex.

Segment VI: A small, simple spine; B long, simple; C medium, simple or occasionally twoforked; 1 long, simple or occasionally twoforked; 2. medium, usually two-forked, occasionally simple or three-forked; 3 absent; 4 medium, simple.

Segment VII: A medium, stout, plumose, twobranched or rarely three-forked near base; B medium, simple; C medium, simple or rarely two-forked; 1 medium, stout, plumose, usually two-branched, occasionally simple or threebranched; 2 medium, simple; 4 medium, simple or rarely two-forked.

Segment VIII: A long, stout, plumose, three- to five-branched; $A^{\prime}$ medium, simple.

Paddle: Roughly oval, a little longer than wide, with a notch at the end of the midrib; margin serrate around apical half excepting the notch; midrib strong, dividing the paddle almost equally, but medial face slightly wider than lateral face; terminal seta medium, simple; one specimen with an irregular line of black pigment across the base of one paddle, all others non-pigmented.

SPECIMENS EXAMINED.-The pupal exuviae of nine males and fifteen females from Gamadodo, WagaWaga, and Hilimoi, Milne Bay, Papua; Draeger Harbor, Northeast New Guinea; and Amsterdam Island, Dutch New Guinea.

Aedes (Finlaya) keefei King and Hoogstraal 1946

Fig. 31

DiAgnosis,-Differing from all other New Guinean species of Finlaya, except perhaps quasirubrithorax, in having the paddles distinctly produced into an apical point.

Cephalothorax.-Postocular: 1 long, twoto four-forked; 2 long, simple or two-forked, rarely three-forked; 3 long, two-forked or occasionally three-forked. 
Anterothoracic: 4 medium, two- or three-forked near base; 5 long, two-forked near base; 6 small, two- or three-forked near base, rarely fourforked; 7 very long, exceeding length of trumpet, two- or three-forked near base.

Dorsal: 8 long, about three-fourths length of trumpet, three- or four-forked or branched.

Supra-alar: 9 long, two-forked near base, rarely simple.

Metanotum: 10 medium, seven- to elevenbranched; 11 long, simple; 12 medium, four- or five-forked near base.

Trumpet: Funnel-shaped, length usually about four times the greatest diameter of the meatus; pinna long, a little less than one-third of total length; uniformly dark pigmented.

AвDOMEN.-Segment I: $\mathrm{H}$ small, simple; $\mathrm{K}$ long, simple or two-branched; L small, simple; $\mathbf{M}$ medium, three- to five-branched; $\mathrm{s}$ very long, simple; $\mathrm{T}$ long, two-forked near base, or rarely simple; U small, simple.

Segment II: A small, simple; B long, simple; C long, two- to four-branched; $C^{\prime}$ small, simple on this and all following segments; 1 medium, twoor three-forked near base, rarely simple; 2 very long, simple; 3 medium, five- or six-branched, rarely more; 4 small, three- to seven-branched; 5 minute, simple on this and all following segments.

Segment III: A small, simple; B very long, simple; $\mathrm{C}$ long, three-branched or occasionally fiveor six-branched; 1 medium, three-branched or rarely four-branched; 2 small, two- or threeforked near middle, or simple; 3 represented only by its socket; 4 medium, four-branched, occasionally five- or six-branched.

Segment IV: A small, simple; B very long, almost reaching posterior margin of segment VI, simple; c long, two- or three-branched, rarely fivebranched; 1 medium, three- or four-branched, rarely five-branched; 2 small, simple; 3 represented only by its socket; 4 medium, four- or three-branched.

Segment V: A small, simple; B very long, almost reaching posterior margin of segment VII, simple; c long, two-branched, or occasionally threeor four-branched; 1 medium, two-branched or occasionally three- or four-branched; 2 small, five- or six-branched, or less frequently threeto eight-branched; 3 represented only by its socket; 4 medium, simple or two-forked near middle.

Segment VI: A small, simple; в very long, exceeding the posterior margin of segment VII, simple; C long, simple or two-branched; 1 medium, two-branched or rarely three-branched; 2 medium, usually two-forked, occasionally three-forked; 3 absent; 4 medium, usually simple, occasionally three-forked near apex.

Segment VII: A medium, two-branched or rarely three-branched; в long, simple; C long, simple or rarely two-forked; 1 small, various, range

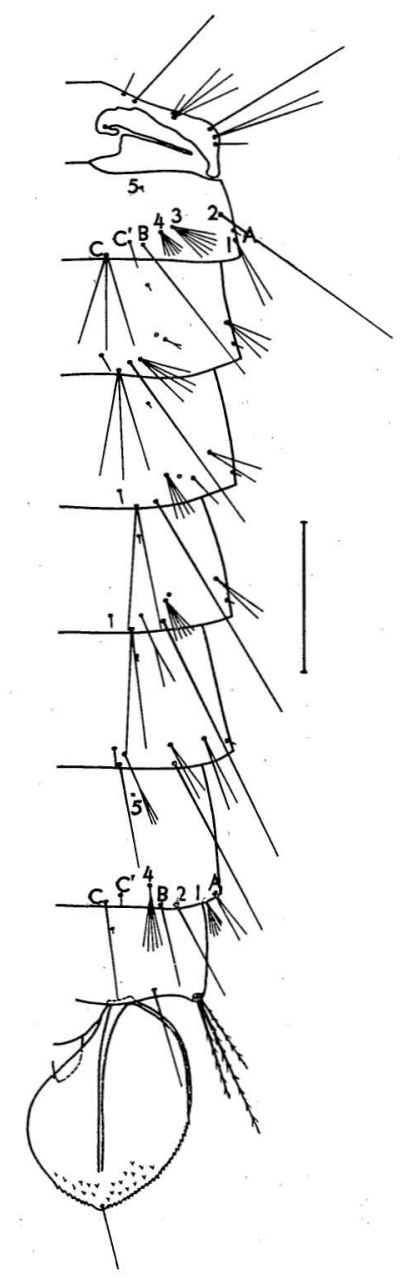

FIG. 31. Aedes keefei: dorsal aspect of right half of abdomen of female from Hilimoi, Papua. 
from three- to six-forked; 2 long, simple or twoforked; 4 medium, two- or three-forked, rarely five-forked near basal third.

Segment VIII: A very long, stout, plumose, three- to five-branched; $A^{\prime}$ long, simple or occasionally two-forked near apex.

Paddle: Elongate oval, pointed apically; margin finely serrate laterally from about middle around apex; apical dorsal face with a number of distinct fine spinules; midrib strong, ending before apex, dividing the paddle almost equally or with lateral face slightly wider than medial; terminal seta long, simple:

SPECIMENS EXAMINED.-The pupal exuviae of four males and six females from Hilimoi, Milne Bay, Papua.

\section{Aedes (Finlaya) quasirubrithorax}

(Theobald) 1918

This pupa is undescribed, but Hill (1925: 72 ) included figures of the paddles and trumpet of specimens from Townsville, Australia. They show similarities to those of $A$. keefei, but are not included here since there is some doubt as to the correctness of Hill's identification.

Aedes (Finlaya) wallacei Edwards 1926

Fig. 32

Cephalothorax.-Postocular: 1 medium, simple or two-forked; 2 medium, two-forked near base; 3 very long, two-branched.

Anterothoracic: 4 medium, two- to five-forked near base; 5 medium, two-forked; 6 small, simple or two- to three-forked; 7 medium, simple or two- to three-forked.

Dorsal: 8 medium, simple or three- to fourforked.

Supra-alar: 9 medium, simple or two- to threeforked.

Metanotum: 10 small, usually four- or fiveforked; 11 long, stout, simple; 12 long, usually six-forked, or occasionally three- to five-forked. Trumpet: Short, funnel-shaped; lightly pigmented except for the obsolete tracheoid portion which is dark; length about three times greatest diameter of meatus; pinna short, less than one-third of length of trumpet.
ABDOMEN.-Segment I: H small, simple or two-forked; $\mathrm{K}$ long, simple; L small, simple; $\mathrm{M}$ small, two- to four-forked near base; s very long, simple; $\mathrm{T}$ long, two- or three-forked; U very small, simple.

Segment II: A small, simple spine; в long, simple; C small, simple; $\mathrm{C}^{\prime}$ small, simple on this and all following segments; 1 medium, simple or two-forked near apex; 2 very long, simple or two-forked near middle; 3 small, two- or threeforked near middle; 4 small, simple or two- to three-forked; 5 minute, simple on this and all following segments.

Segment III: A small, simple spine; B very long, simple, plumose apically; C medium, two-forked near base; 1 medium, simple; 2 small, simple

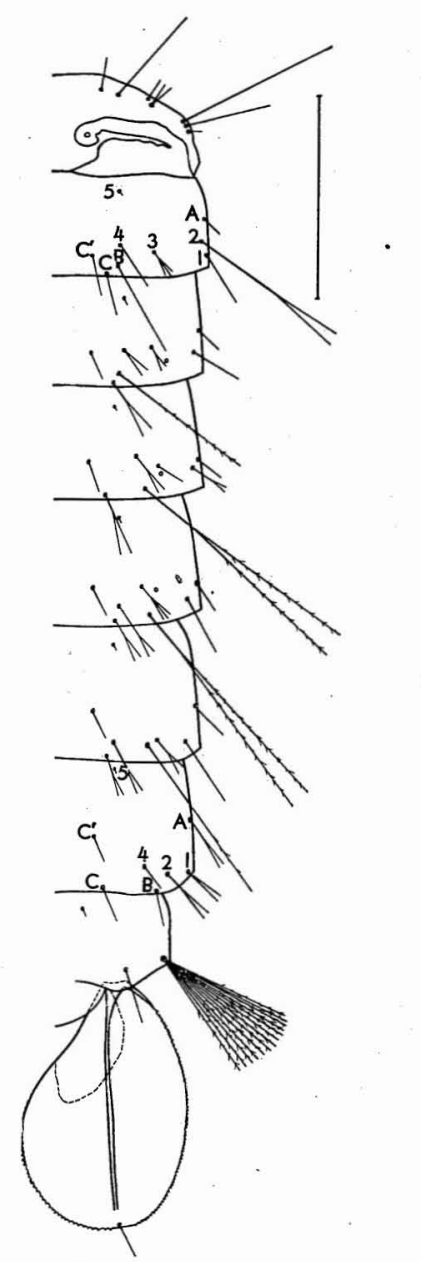

FIG. 32. Aedes wallacei: dorsal aspect of right half of abdomen of male from Hilimoi, Papua. 
or two-forked; 3 represented only by its socket; 4 small, two- or three-forked near base.

Segment IV: A small, simple spine; B very long, reaching to middle of segment VI, two-forked near basal one-third, plumose apically; $\mathrm{C}$ medium, two- or three-forked near base; 1. small, simple or two-forked near apex; 2 small, simple; 3 represented only by its socket; 4 small, twoor three-forked near apex.

Segment V: A small, simple spine; B very long, equal to B-IV in length, two-forked near basal one-third, plumose apically; $\mathrm{C}$ medium, two- or three-forked near middle; 1 medium, simple or two-forked; 2 small, three- or four-forked near middle; 3 represented only by its socket; 4 medium, two-forked near apex.

Segment VI: A small, simple spine; B very long, but shorter than $\mathrm{B}-\mathrm{V}$, simple or two-forked at apex, plumose apically; $\mathrm{C}$ small, two-forked near apex; 1 medium, simple; 2 small, two- or threeforked near middle; 3 absent; 4 medium, twoforked apically or simple.

Segment VII: A medium length, two- or threeforked apically; B small, simple or two- to threeforked; C small, simple; 1 small, simple or twoto three-forked near middle; 2 medium, simple or two-forked near middle; 4 small, simple.

Segment VIII: A long, large, conspicucous, plumose, eleven- to fifteen-branched tuft, most often thirteen-branched; $A^{\prime}$ medium, simple.

Paddle: Elongate oval; margin very finely serrate from extremity of buttress around to middle of medial margin; midrib strong, not reaching apex, dividing paddle almost equally; pigment present on only one specimen which had a small spot of black near the base of each paddle; terminal seta small, simple.

SPECIMENS EXAMINED.-The pupal exuviae of two males and three females from Hilimoi, Milne Bay, Papua.

\section{Aedes (Finlaya) kochi (Dönitz) 1901 Fig. 33}

Pupa partially described by Brug (1932: 22), who included figures of the trumpet and paddles as $A$. poicilia, and completely described and figured by Marks (1947a: 16).
DiAGNOSIS.-Distinct in having the paddle serrate and apically notched and most of the smaller abdominal setae simple.

CEPHALOTHORAX.-Postocular: 1 medium, two- or three-forked; 2 medium, two- to fourforked; 3 very long, two-branched.

Anterothoracic: 4 medium, two-forked; 5 medium, two-forked usually but eight-forked on one side of one of the specimens examined; 6 medium, two- or three-forked; 7 medium, twoto four-forked.

Dorsal: 8 medium, equal to greatest diameter of trumpet, two-forked.

Supra-alar: 9 medium, usually simple, occasionally two- or three-forked.

Metanotum: 10 long, two-forked; 11 long, simple, occasionally slightly plumose; 12 long, usually five-forked near base, occasionally twoor three-forked.

Trumpet: Funnel-shaped, length about three times the greatest diameter of meatus; pinna equal to about one-third of total length; tracheoid portion darker than rest.

Pigmentation: Abdominal segment I darkly pigmented overall, extending posteriorly, but lighter, to the center of segments II and III. Metanotum darkly pigmented overall, extending anteriorly onto dorsal thorax but fading before reaching trumpets.

ABDOMEN.-Segment I: $\mathrm{H}$ small, simple; $\mathrm{K}$ long, simple; L small, usually simple or occasionally two-, four-, or five-forked; M small, twoto five-forked near middle; $s$ long, usually simple, rarely three-forked near base; T long, twoforked near middle or simple; U small, simple. Segment II: A small, simple spine; в long, simple; c small, simple, rarely three-branched; $C^{\prime}$ small, stout, simple on this and all following segments; 1 medium, usually simple or occasionally two- or three-forked; 2 medium, usually simple, occasionally two- or three-forked; 3 small, three- or four-forked, occasionally simple or two-forked near base; 4 medium, two- or three-forked near base, occasionally simple; 5 minute, simple on this and all following segments. 
Segment III: A small, simple spine; B long, simple; C small, simple or two- to three-forked; 1 medium, simple; 2 small, two- or three-forked near middle, rarely simple; 3 represented only by its socket on this and segments IV and V; 4 medium, two- or three-forked just below middle.

Segment IV: A small, simple spine; B very long, two-branched; C small, simple or two-forked, rarely more; 1 small, usually simple, rarely twoforked near base; 2 small, simple or two-forked; 4 medium, two- or three-forked just below middle.

Segment V: A small, simple spine; B very long, two-branched; C medium, simple or two-forked;

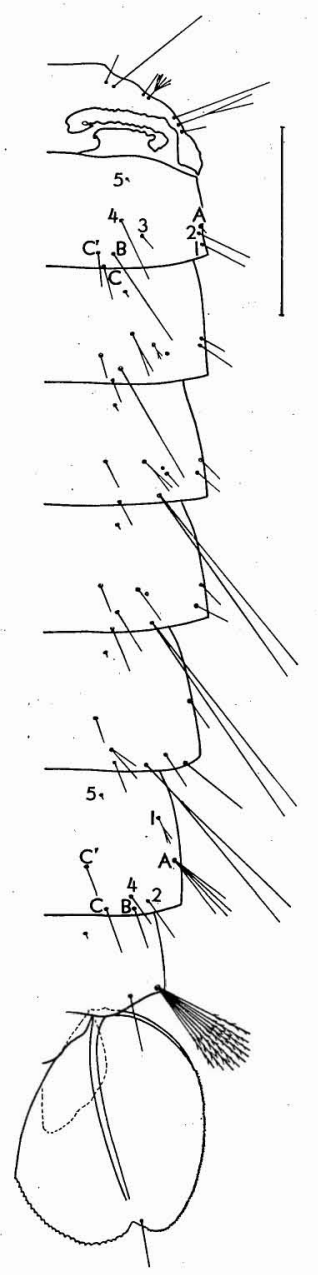

FIG. 33. Aedes kocbi: dorsal aspect of right half of abdomen of male from Hilimoi, Papua.
1 small, usually simple; 2 small, two- to fourforked, occasionally simple or five-forked; 4 medium, simple or two-forked.

Segment VI: A small, simple spine; B very long, two-forked near basal fourth; C small, simple or two-forked; 1 long, usually simple, occasionally two-forked; 2 small, simple or two-forked; 3 absent; 4 small, usually two-forked near base, rarely simple.

Segment VII: A long, two- to five-branched, usually four-branched; B small, usually simple, occasionally two- to four-forked; C small, simple or two-forked; 1 small, simple or two-forked, greatly displaced, being far anterior to its normal position; 2 small, simple or two-forked; 4 small, usually simple, occasionally two-forked. Segment VIII: A large, conspicuous, plumose, seven- to fifteen-branched, usually ten-branched; $A^{\prime}$ medium, usually simple, occasionally twoforked near apex.

Paddle: Rounded laterally, apex deeply notched; widest near apical one-third; margin finely serrate laterally, coarser medially to widest point; midrib strong, does not reach apical notch, divides paddle more or less equally, the medial face slightly wider than lateral face; terminal seta medium, simple, rarely two-forked apically.

SPECIMENS EXAMINED.-The pupal exuviae of thirteen males and seven females from Hilimoi, Milne Bay, Papua, and Amsterdam Island, Dutch New Guinea.

\section{Aedes (Finlaya) candidoscutellum Marks 1947}

Fig. 34

This pupa was partially described and figured by Marks (1947b: 8).

DiAgNosis.-Apparently distinct from other New Guinea Finlaya in having the dorsal seta (8) of the cephalothorax a well-developed dendritic tuft.

Cephalothorax. - Postocular: 1 small, four- or five-forked; 2 long, two-forked; 3 medium, three-forked.

Anterothoracic: 4 long, three-forked; 5 long, two- or three-forked; 6 small, two- or threeforked, or simple; 7 long, two- or three-forked. 
Dorsal: 8 large, dendritic, basally four-branched, each branch further branched two to four times, the number of ultimate branches thus ranging from eleven to seventeen.

Supra-alar: 9 medium, slightly plumose on some specimens, three- to five-forked near base.

Metanotum: 10 short, three- to nine-forked near base; 11 long, simple; 12 medium, fiveor six-forked near base.

Trumpet: Short, inflated near middle so that opening of pinna is less than the greatest diameter of the meatus; the tracheoid portion practically obsolete; uniformly black-pigmented.

ABDOMEN.-Segment I: $\mathrm{H}$ small, simple; $\mathrm{K}$ long, simple or three-forked near apex; L small, simple or two-forked; $\mathrm{M}$ medium, three- to fivebranched; S long, simple; $\mathrm{T}$ long, two-forked near apex; U very small, simple.

Segment II: A small, simple spine; B medium, simple; c long, six-branched; $C^{\prime}$ small, simple on this and all following segments; 1 medium, usually two-forked, or occasionally simple or three-forked; 2 long, simple or two-forked near apex; 3 medium, four- to six-forked near base; 4 small, three- to six-forked near base; 5 very small, simple on this and all following segments. Segment III: A small, simple spine; B long, simple; c long, four- to seven-branched; 1 medium, two-branched, each branch two- or three-forked near apex; 2 small, with two to four branches on one side only; 3 represented only by its socket; 4 medium, four- to six-branched.

Segment IV: A small, simple spine; B very long, reaching posterior margin of segment VI, simple; c medium, three- or four-branched; 1 similar to 1-III; 2 small, simple or two-forked; 3 represented only by its socket; 4 small, twoto five-forked near base.

Segment V: A small, simple spine; B very long, reaching posterior margin of segment VII, simple; $\mathrm{C}$ medium, two- or three-branched or forked near base; 1 small, two- to four-forked near base; 2 small, similar to 2-III; 3 represented only by its socket; 4 medium, two-forked near apex.

Segment VI: A small, simple spine; B medium, simple or two-forked near apex; C longer than
B, simple or two-forked near apex; 1 small, simple or two-forked near apex; 2 small, similar to 2-III; 3 absent; 4 medium, two-forked near middle, or simple.

Segment VII: A small, slightly plumose, usually two-branched, may be three- or four-branched; B small, simple or two-forked near base; c medium, simple or two-forked near apex; 1 small, three-forked near base or simple; 2 medium, two-forked near base; 4 small, two- to fourforked near base.

Segment VIII: A medium, plumose, three- to eight-branched, usually seven- or eight-branched; $A^{\prime}$ medium, two-forked near apex or simple. Paddle: Rounded, length barely exceeding greatest width; margin mostly smooth, but very

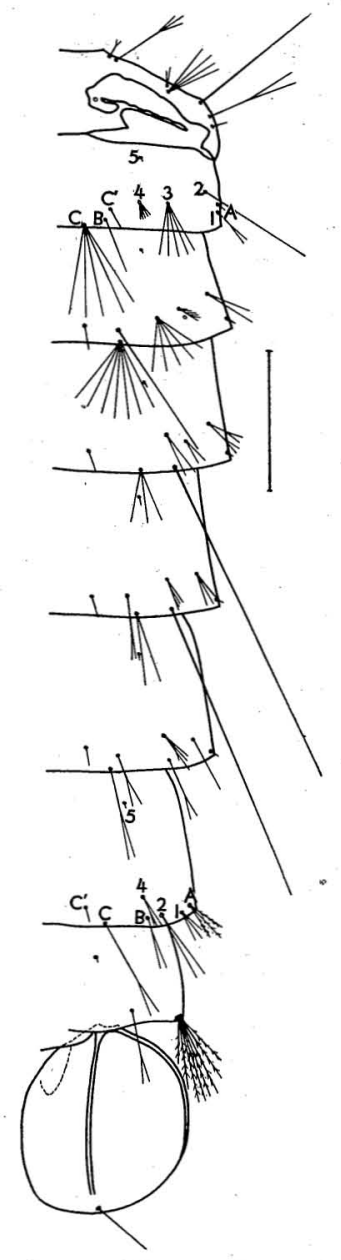

FIG. 34. Aedes candidoscutellum: dorsal aspect of right half of abdomen of female from Hilimoi, Papua. 
finely toothed near apex on some specimens; midrib strong, dividing paddle almost equally but lateral face may be slightly wider than medial face; terminal seta medium, simple.

SPECIMENS EXAMINED.-The pupal exuviae of two males and one female from Hilimoi, Milne Bay, Papua.

\section{Aedes (Finlaya) papuensis (Taylor) 1914 Fig. 35}

Cephalothorax.-Postocular: 1 small, twoor three-forked near base; 2 medium, twoforked near base; 3 small, two- or three-forked basally.

Anterothoracic: 4 medium, three- or four-forked near base, rarely two- or five-forked; 5 medium, two- to four-forked; 6 small, simple or two- to three-forked near base; 7 medium, two-forked near base or rarely three-forked.

Dorsal: 8 long, about three-fifths length" of trumpet, usually two-forked near base, less often three-forked or simple.

Supra-alar: 9 long, simple or infrequently twoforked near base.

Metanotum: 10 long, two- to five-forked near base; 11 long, simple; 12 medium, usually twoor three-forked, rarely simple or four-forked.

Trumpet: Short, funnel-shaped, the length being about two and one-half times greatest diameter of meatus; pinna long, slightly less than onehalf the length of the trumpet; uniformly darkpigmented.

ABDOMEN.-Segment I: $\mathrm{H}$ small, simple or rarely two-forked; $\mathrm{K}$ long, simple or two-forked, rarely slightly plumose; L small, usually twoforked near base or occasionally three- or fourforked; $M$ small, three- to six-forked near base; $\mathrm{s}$ medium, simple or rarely two-forked; $\mathrm{T}$ medium, usually two-forked near base, rarely simple or three-forked; U small, simple.

Segment II: A small, simple spine; B long, simple, stout; C medium, two- or three-branched, rarely simple or four-branched; $C^{\prime}$ small, simple on this and all following segments; 1 medium, simple or two- to three-forked, rarely fourforked; 2 medium, simple or rarely two-forked; 3 medium, simple or two-forked; 4 small, two- to five-branched; 5 minute, simple on this and all following segments.

Segment III: A small, simple spine; B long, reaching to posterior margin of segment.IV, simple; c medium, simple or two-branched; 1 medium, two-forked or simple; 2 small, twoor three-forked near base, rarely simple; 3 represented only by its socket; 4 medium, simple or two-forked.

Segment IV: A small, simple spine; B long, simple or rarely two-branched; C medium, twobranched or rarely simple; 1 medium, simple or two- to three-forked near apex; 2 small, two-forked near base or simple; 3 represented only by its socket; 4 small, two- or three-forked near base, rarely simple.

Segment V: A small, simple spine; в long, simple; C medium, two-forked near base or simple; 1 medium, simple or two-forked; 2 small, twoto five-forked; 3 represented only by its socket; 4 medium, two-forked or tarely simple.

Segment VI: A small, simple spine; B long, simple; C small, two-forked or simple; 1 medium, simple; 2 small, two- to four-forked near base or simple; 3 absent; 4 small, simple or rarely two-forked.

Segment VII: A medium length, stout, plumose, four- to six-branched, rarely two-branched; $\mathbf{B}$ medium, simple or rarely two- to three-forked near apex; C small, two-forked or simple; 1 medium, similar to A and subequal to it, plumose, three- to six-branched, rarely two-branched; 2 medium, simple or two-forked; 4 small, simple or two-forked.

Segment VIII: A medium length, stout, plumose, six- to eleven-branched, usually nine-branched; $\mathrm{A}^{\prime}$ medium, simple.

Paddle: Almost round, width usually slightly exceeding the length, apex rounded and appearing sometimes as a more or less blunt edge; margin sometimes very finely toothed laterally, smooth medially; midrib not strong, dividing paddle unequally, the lateral face being somewhat wider than medial face; terminal seta medium length, simple or rarely two-forked near basal one-fourth. 
SPECIMENS EXAMINED--The pupal exuviae of thirteen males and seventeen females from Gamadodo, WagaWaga, Hilimoi, and KanaKope, Milne Bay, Papua.

Aedes (Finlaya) hollandius King and Hoogstraal 1946

\section{Fig. 36}

DiAgNosis.-Very difficult to separate from A. novalbitarsis but apparently distinct from all other species of Finlaya in the character of seta A-VIII, which is dendritically branched.

Ceprhalothorax. - Postocular: 1 small, usually two-forked, occasionally three- to fiveforked; 2 long, two-forked; 3 long, two-forked or simple.

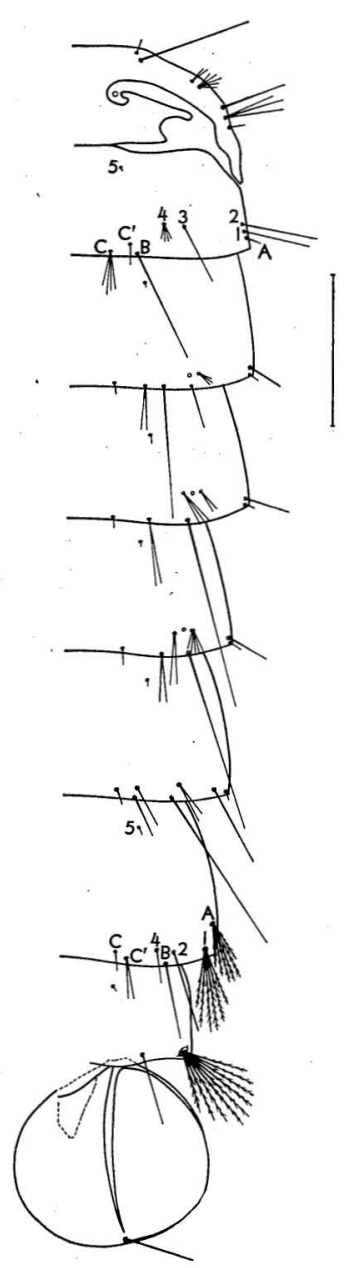

FIG. 35: Aedes papuensis: dorsal aspect of right half of abdomen of female from WagaWaga, Papua.
Anterothoracic: 4 small, two- or three-forked, rarely simple; 5 medium, two-forked; 6 very small, usually simple, occasionally two- or threeforked near apex; 7 long, two- or three-forked. Dorsal: 8 long, about one-half length of the trumpet, two- or three-forked, rarely simple. Supra-alar: 9 medium, two- or three-forked, rarely simple.

Metanotum: 10 medium, two- or three-forked near base, rarely simple; 11 long, simple; 12 medium, three- or four-forked, rarely two- or five-forked.

Trumpet: Funnel-shaped, length about four times greatest diameter of meatus; pinna long, about one-third of total length; uniformly darkpigmented.

ABDOMEN.-Segment I: H small, stout, simple; $\mathrm{K}$ long, stout, simple; L small, usually simple, occasionally two- or three-forked near apex; M small, usually four-forked near middle, occasionally three- or five-forked; $\mathrm{s}$ long, simple; $\mathrm{T}$ long, usually two-forked near basal one-fourth, rarely simple; U small, simple.

Segment II: A small, simple spine; B very long, stout, simple; C long, usually five-branched, range from four- to eight-branched; $C^{\prime}$ small, simple spine on this and all following segments; 1 long, three- or four-forked near base, rarely two-forked; 2 long, usually simple, occasionally two-forked; 3 medium, usually three-forked near base, range from simple to five-forked; 4 small, two- to five-forked near base, usually four-forked; 5 minute, simple on this and all following segments.

Segment III: A small, simple spine; B very long, stout, simple; c long, four- or five-branched, rarely six; 1 medium, three- or four-forked near basal one-fourth, occasionally simple or twoforked; 2 small, two- or three-forked near middle; 3 represented only by its socket; 4 medium, three- or four-forked, rarely five-forked.

Segment IV: A small, simple spine; B very long, stout, simple; C long, three- or four-branched, occasionally two-branched; 1 medium, three- or four-forked near basal one-fourth; 2 small, twoto four-forked near middle; 3 represented only 
by its socket; 4 long, three- to six-forked near base.

Segment V: A small, simple spine; B very long, stout, simple; C medium, two- or three-forked near base; 1 medium, two- to four-forked, rarely simple; 2 small, two- to four-forked; 3 represented only by its socket; 4 medium, two- or three-forked near base.

Segment VI: A small, simple spine; B very long, stout, simple; C medium, two- or three-forked near base, rarely simple; 1 medium, two-forked near base, rarely simple; 2 medium, usually three-forked near middle, occasionally two- to five-forked; 3 absent; 4 medium, two- or threeforked at basal one-third, rarely simple.

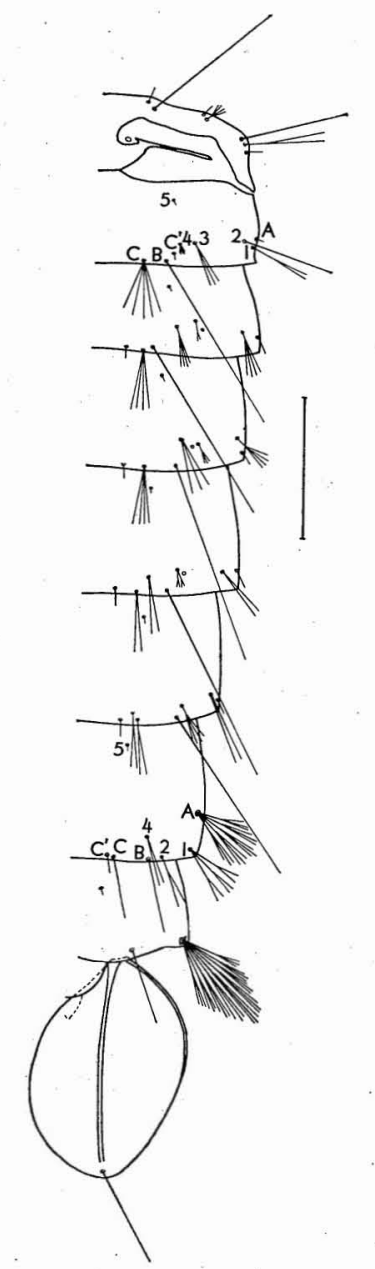

FIG. 36. Aedes bollandius: dorsal aspect of right half of abdomen of male from Hilimoi, Papua.
Segment VII: A moderate, four- to six-branched, each branch stout basally and apically three- or four-branched; B medium, simple; C medium, usually two-forked, occasionally simple or threeforked; 1 moderate, usually three-branched, range from two to five, each branch stout at base and apically two- or three-forked; 2 medium, usually two-forked near middle, rarely simple; 4 medium, usually two-forked near base, rarely simple or three-forked.

Segment VIII: A similar to A-VII but larger, six- to ten-branched, usually nine-branched, each branch stout basally but two- to threebranched or forked apically; $A^{\prime}$ medium, simple or two-forked.

Paddle: Roughly spoon-shaped, the apex somewhat pointed; margin smooth for the most part, but with very fine small teeth near apex; midrib strong, not reaching apex, dividing the paddle almost equally; terminal seta long, simple.

SPECIMENS EXAMINED.-The pupal exuviae of one male and five females from Hilimoi, Milne Bay, Papua.

Aedes (Finlaya) novalbitarsis King and Hoogstraal 1946

Fig. 37

DiAgnosis.-Very similar to $A$. bollandius but distinct from other Finlaya in having seta A-VIII dendritic.

Cephalothorax. - Postocular: 1 small, simple or two-forked, rarely three-forked; 2 medium, simple or two-forked; 3 long, simple. Anterothoracic: 4 medium, three- or fourforked, rarely five-forked; 5 long, simple or rarely two-forked; 6 small, simple or rarely twobranched; 7 medium, two- or three-forked, occasionally simple or four-forked.

Dorsal: 8 long, about one-half the length of the trumpet, two- or three-forked, rarely simple.

Supra-alar: 9 small, simple or two-forked near apex.

Metanotum: 10 medium, simple or two- to three-forked; 11 long, more than half the length of the trumpet, simple; 12 medium, two-forked or occasionally three-forked. 
Trumpet: Funnel-shaped, length about three times the greatest diameter of the meatus; pinna a little more than one-third of the total length of the trumpet; uniformly dark-pigmented.

ABDOMEN.-Segment I: $\mathrm{H}$ small, simple or rarely two-forked; $\mathrm{K}$ long, simple or rarely twoforked near apex; L small, two- or three-forked near base or occasionally five-forked; $M$ small, three-forked, occasionally four- or five-forked; s long, simple or occasionally two-forked; T long, two- or three-forked, rarely simple; $U$ small, simple.

Segment II: A small, simple spine; B very long, simple; C medium, three- or four-branched or forked near base, occasionally two- or fivebranched; $C^{\prime}$ small, simple on this and all following segments; 1 medium, two- to fourforked; 2 long, simple or two-forked; 3 small, two- or three-forked near base; 4 small, two- to four-forked near base, rarely simple or fiveforked; 5 minute, simple on this and all following segments.

Segment III: A small, simple spine; B very long, sometimes slightly plumose apically, simple; C medium, two- to four-branched; 1 small, two- to four-forked, or rarely five-forked; 2 small, twoor three-forked, rarely four-forked; 3 represented only by its socket; 4 small, two- or threeforked.

Segment IV: A small, simple spine; B very long, sometimes slightly plumose apically, simple; C medium, two- to four-branched, rarely sixbranched; 1 small, three- to five-forked, occasionally simple or two-forked; 2 small, two- or three-forked near apex or simple; 3 represented only by its socket; 4 medium, three- or fourforked.

Segment V: A small, simple spine; B very long, sometimes slightly plumose apically, simple; C small, two-forked or occasionally simple; 1 small, two- or three-forked near middle; 2 small, threeto five-forked near base or rarely two-forked; 3 represented only by its socket; 4 medium, twoforked near apex or occasionally three-forked. Segment VI: A small, simple spine; B very long, sometimes slightly plumose apically, simple; C small, two-forked or occasionally three-forked

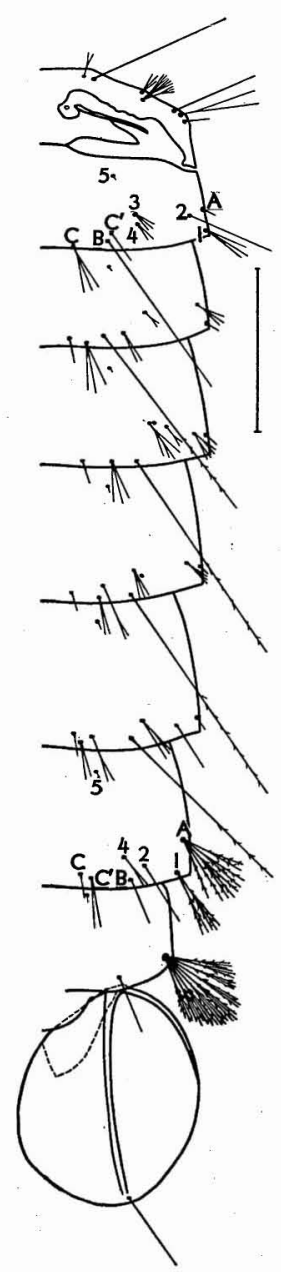

FIG. 37. Aedes novalbitarsis: dorsal aspect of right half of abdomen of male from Hilimoi, Papua.

or simple; 1 medium, simple or two-forked; 2 medium, three- or four-forked, rarely twoforked; 3 absent; 4 medium, two-forked or rarely simple.

Segment VII: A medium, stout, two- to sixbranched, usually five, each branch being twoor three-branched at about the middle; $\mathrm{B}$ medium, simple or two-forked; c medium, twobranched, rarely simple; 1 medium, stout, similar to A, two- or three-branched; 2 medium, simple or rarely two-forked; 4 small, two-forked near middle or occasionally simple.

Segment VIII: A large, stout, conspicuous, fiveto ten-branched, averages eight, each branch fur- 
ther two- to four-branched; $A^{\prime}$ medium, simple or rarely two-forked near apex.

Paddle: Roundly oval, length not greatly exceeding width; margin very finely toothed apically, not obvious without high-power magnification; midrib strong, dividing the paddle almost equally, the medial face only slightly wider than the lateral face; terminal seta strong, simple.

SPECIMENS EXAMINED.-The pupal exuviae of twelve males and four females from Hilimoi, Milne Bay, Papua.

Subgenus Macleaya Theobald

A certain diagnosis of Macleaya is not possible at present since the single species assigned to this subgenus has not been completely described in the pupal stage.

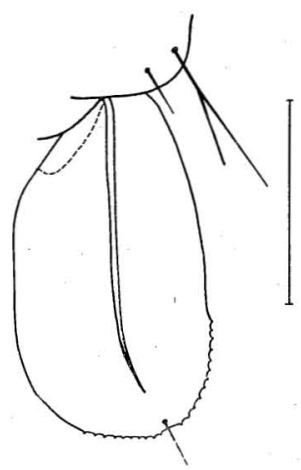

Fig. 38. Aedes tremula: right paddle (after Hill, 1925).

\section{Aedes (Macleaya) tremula (Theobald) 1903} Fig. 38

Pupa undescribed, but Hill (1925: 72) included figures of the trumpet, posterior margin of segment VIII, and the paddles of specimens from Queensland, Australia. These have been redrawn and are included here.

If Hill's figures are correct, the elongate nature of the paddles (twice as long as wide) and the coarsely serrate apex should prove to be of diagnostic value for the species as well as the subgenus among the known Aedes of New Guinea.

\section{Subgenus Pseudoskusea Theobald}

The pupa of none of the three New Guinean species belonging here has been described.

\section{Subgenus SKusEa Theobald}

Diagnosis.--Only one species of Skused has been recorded from New Guinea and only three or four from the whole Australasian Region, but these are distinct in the pupal stage from other Aedes in possessing wide paddles with a fringe of long fine hairs almost all around the margin, and in having the dorsal seta (8) of cephalothorax placed between the trumpets.

\section{Aedes (Skusea) dasyorrhus King and Hoogstraal 1946}

Fig. 39

CePhalothoraX.-Postocular: 1 small, twoor three-forked; 2 very long, stout, two- or three-forked; 3 long, two-forked or simple.

Anterothoracic: 4 long, stout, three- or fourforked; 5 small, two- to four-forked, rarely simple; 6 small, simple; 7 medium, simple or occasionally two-forked.

Dorsal: 8 medium, about one-half length of trumpet, simple or two- to three-forked.

Supra-alar: 9 long, nearly equal to trumpet, twoforked or rarely simple.

Metanotum: 10 small, simple or two-forked, rarely three-forked; 11 long, simple; 12 medium, three- or four-forked, rarely simple or twoforked.

Trumpet: Small, length a little more than three times the greatest diameter of meatus; pinna a little more than one-fourth of total length; uniformly lightly pigmented.

ABDomen.-Segment I: H medium, simple; $\mathrm{K}$ long, simple; L small, two- or three-forked or simple; $M$ medium, four- or five-forked, occasionally three-forked; s long, simple; $\mathrm{T}$ long, two- or three-forked; U small, simple.

Segment II: A small, simple spine; B long, simple; c long, four- or five-forked near basal fourth, or rarely three-forked; $C^{\prime}$ medium, simple; 1 medium, three- or four-forked near base; 2 long, two- or three-forked or occasionally simple; 3 small, two- to four-forked near middle; 4 small, two- to four-forked near middle. Segment III: A small, simple spine; B long, simple or rarely two-forked at apex; C small, simple or two-forked; $C^{\prime}$ small, simple on this 
and all following segments; 1 medium, simple; 2 small, two-forked near apex or simple, rarely three-forked; 3 represented only by its socket; 4 small, two- or three-forked, rarely simple.

Segment IV: A small, simple spine; в very long, exceeding posterior margin of segment $\mathrm{V}$, simple; C medium, two- or three-forked, rarely simple; 1 medium, two-forked or simple; 2 small, two-forked or occasionally simple; 3 represented only by its socket; 4 small, three- to five-forked.

Segment V: A small, simple spine; B very long, simple; $C$ medium, usually two-forked near base, occasionally three-forked; 1 medium, simple or two-forked; 2 medium, four- or five-forked; 3 represented only by its socket; 4 medium, two-

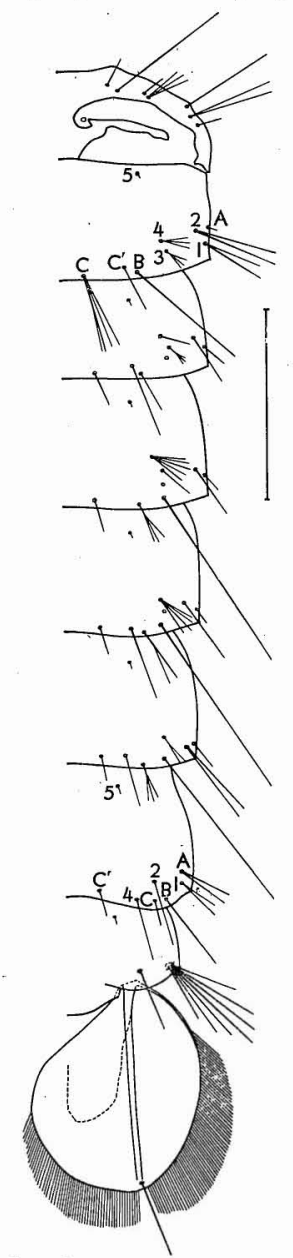

FIG. 39. Aedes dasyorrbus: dorsal aspect of right half of abdomen of male from Hilimoi, Papua. forked or simple, rarely three-forked near apex. Segnent VI: A small, simple spine; B very long, simple; C small, simple or two- to three-forked near middle; 1 long, simple or two-forked near base; 2 small, two-forked near middle or occasionally three-forked; 3 absent; 4 medium, twoforked or rarely simple.

Segment VII: A medium, two-forked or rarely simple; B long, simple or occasionally twoforked near apex; c long, two-forked or occasionally simple; 1 small, usually two-forked, range from simple to four-forked; 2 small, twoforked or simple; 4 medium, simple.

Segment VIII: A long, stout, six- to ten-branched, most often eight-branched; $A^{\prime}$ medium, simple or two-forked near middle.

Paddle: Laterally rounded more or less evenly, medially the apical half produced into a wide lobe; margin with a fringe of long hairs interrupted only at the tip of the midrib; midrib strong, dividing paddle unequally, the lateral face being about three-fourths the width of the medial face; terminal seta strong, long, simple.

SPECIMENS EXAMINED.- - The pupal exuviae of seven males and four females from Hilimoi, Milne Bay, Papua.

\section{Subgenus Geoskusea Edwards}

None of the four species assigned to Geoskusea has been described in the pupal stage. Only one species has been recorded from New Guinea.

\section{Subgenus Stegomyia Theobald}

Diagnosis.-Although many of the species of this subgenus have been described in the pupal stage, Stegomyia is rather hard to separate definitely from all other subgenera in the New Guinea area. Edwards (1941: 387) used the position of the dorsal seta (8) of the cephalothorax as diagnostic, but this is a relative character which is encroached upon by certain species of other subgenera. For the most part, however, species of Stegomyia may be distinguished by having the dorsal seta placed well behind the bases of the trumpets, i.e., at least halfway between the trumpets and the anterior margin of the metanotum, instead of between them or 
slightly behind them as in the other known subgenera.

Key to Species of Aedes (Stegomyia)

1. Paddle margins with a fringe of long hairs (Fig. 40)

A. scutellaris

A. albopictus

Paddle margins various but without a fringe of long hairs.

2. Terminal seta of paddle short, simple; apex of paddle serrate (Fig. 41)

A. aegypti

Terminal seta of paddle long, stout, threeor more branched, plumose; paddle margin smooth (Fig. 42)

A. albolineatus

\section{Aedes (Stegomyia) scutellaris (Walker)}

1859

Fig. 40

Pupa heretofore undescribed, but Hill (1925: 70 ) included figures of the trumpet and paddles.

Diagnosis.-At present inseparable from $A$ albopictus, but distinct from other Stegomyia in having the paddles fringed with long fine hairs.

Cephalothorax.-Postocular: 1 medium, simple or occasionally two-forked; 2 medium, simple; 3 medium, simple.

Anterothoracic: 4 small, two-forked or occasionally simple or three-forked; 5 small, twoforked or simple, rarely three-forked; 6 medium, simple or rarely two-forked; 7 medium, simple or two-forked.

Dorsal: 8 small, about one-fourth length of trumpet, three- or four-forked, rarely five- or six-forked.

Supra-alar: 9 long, two-thirds length of trumpet, simple.

Metanotum: 10 medium, two- or three-forked; 11 long, simple; 12 long, simple or rarely twoforked.

Trumpet: Short, length about three times greatest diameter of meatus; pinna long, about onethird of total length of the trumpet; base slightly darker than apex; tracheoid area obsolete.

ABDOMEN.-Segment I: H medium, simple; $\mathrm{K}$ long, simple; L small, two- or three-forked, rarely four- or five-forked; $M$ small, three- branched or rarely two- or four-branched; s long, simple, very rarely two- or three-forked; $\mathrm{T}$ long, two-forked near basal one-third or simple; $\mathrm{U}$ small, simple.

Segment II: A small, simple spine; в long, simple; C medium, most often seven-branched, range from five to twelve; $C^{\prime}$ small, simple spine on this and all following segments; 1 long, twoforked, rarely simple; 2 medium, simple or rarely two-forked; 3 small, two- or three-forked, rarely four-forked or simple; 4 small, twoforked near basal one-third, occasionally threeforked, rarely simple or four-forked; 5 minute, simple on this and all following segments.

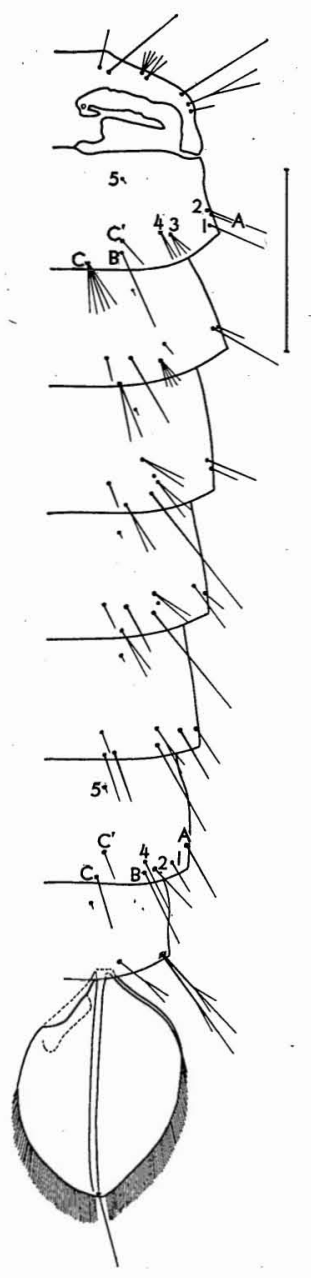

FIG. 40. Aedes scutellaris: dorsal aspect of right half of abdomen of female from Mios Woendi, Dutch New Guinea. 
Segment III: A small, simple spine; B long, simple; C long, two-branched, very rarely fivebranched; 1 long, simple, very rarely two-forked; 2 small, two-forked near middle or rarely threeforked or simple; 3 represented only by its socket; 4 small, two-forked or simple, occasionally three- or four-forked.

Segment IV: A small, simple spine; B long, simple or very rarely two-forked; C long, twoforked near base, rarely simple or three-forked; 1 medium, simple; 2 medium, two-forked or simple; 3 represented only by its socket; 4 medium, two- or three-forked, rarely simple or three-forked.

Segment $V$ : A small, simple spine; B long, simple; C medium, two-forked or occasionally simple; 1 medium, simple; 2 medium, two-forked, occasionally three-forked, rarely simple; 3 represented only by its socket; 4 medium, simple or rarely two-forked.

Segment VI: A slightly longer than $\mathrm{A}-\mathrm{V}$, simple; B long, simple; C medium, simple or occasionally two-branched; 1 medium, simple; 2 medium, two-forked near middle or simple; 3 absent; 4 medium, simple.

Segment VII: A medium, simple; B long, simple; C medium, simple; 1 small, simple or occasionally two-forked; 2 medium, simple; 4 medium, simple or rarely two-forked.

Segment VIII: A long, two-branched with small side branches at middle, occasionally simple or three- to four-branched; $A^{\prime}$ medium, simple or two-forked near apex.

Paddle: Oval with apex more or less pointed; margin with a fringe of long fine hairs; midrib strong, dividing the paddle almost equally; terminal seta long, strong, simple or occasionally two-forked.

SPECIMENS EXAMINED.-The pupal exuviae of 34 males and 33 females from Hilimoi and KanaKope, Milne Bay, Papua; Draeger Harbor, Northeast New Guinea; and Mios Woendi, Dutch New Guinea.

Aedes (Stegomyia) albopictus (Skuse) 1895

The pupa of $A$. albopictus has received considerable attention. Banks (1908: 246) gave brief notes on it, without figures, as Stegomyia samarensis; Baisas (1938: 181) gave a figure of the abdomen and paddles without description; Edwards (1941: 391) reproduced Baisas' figure and gave a diagnostic description; and Taylor (1943: 159; 1944: 87) reproduced Baisas' figure without description.

Diagnosis.-Very similar to A. scutellaris and impossible to separate on the basis of published descriptions alone. Edwards lists the following features: seta A-II-V quite small and pale, A-VI twice as long and dark, A-VII still longer and quite simple; A-VIII single or forked or with a few short branches at some distance from base. Paddle more or less pointed and with a fringe of long hairs.

\section{Aedes (Stegomyia) aegypti (Linnaeus) 1762} Fig. 41

The pupa of this species has received a great deal more attention than that of any other mosquito. The most detailed study of its chaetotaxy was that of Macfie (1920: 161) based on ten specimens from West Africa. Aedes aegypti pupae have been variously included in numerous other papers and the figures and descriptions presented have varied from the very briefest mention to rather complete diagnoses, but none has approached the completeness of Macfie's descriptions. Other than Macfie, authors who have published on this species include Mitchell (1907: 253), Banks (1908: 243), Wesche (1910: 25), Howard, Dyar, and Knab (1912-1917 [vol. 2]: pl. 150; [vol. 4]: 824), Theodor (1924: 344), Cooling (1924: 13), Buxton and Hopkins (1925: 300), Kirkpatrick (1925: 87), Buxton and Hopkins (1927: 113), Edwards (1941: 388), Taylor (1943: 152), Parr (1943: 250), Taylor (1944: 80), and Bohart and Ingram (1946: 6).

Although $A$. aegypti is recorded from New Guinea, we did not succeed in collecting specimens. Accordingly, the description which follows and the figure have been taken, with modifications, from Macfie.

DiAgnosis.-Readily separated from other 
Stegomyia in having the apical paddle margin serrate and terminal seta short and simple.

Cephalothorax.-Postocular: 1 moderate, usually simple, occasionally two-branched; 2 small, usually two-branched, occasionally simple; 3 moderate, simple.

Anterothoracic: 4 moderate, two- or threeforked; 5 moderate, simple or two- to threebranched; 6 long, stout, simple; 7 moderate, usually two-branched, occasionally simple.

Dorsal: 8 small, usually two-branched; occasionally simple or three-branched.

Supra-alar: 9 long, simple.

Metanotum: 10 moderate, usually two-branched, occasionally simple or three-branched; 11 long, stout, simple; 12 moderate, simple or twobranched.

ABDOMEN.-Segment I: H long, stóut, simple; K long, stout, simple or two-branched; L small, two- to four-branched; $M$ small, two- to five-branched; s long, simple or two-branched; T long, simple or two-branched; U small, simple.

Segment II: A short, stout; B long, simple or two-branched; C moderate, usually two- to threebranched, occasionally simple; $C^{\prime}$ moderate, simple; 1 long, simple or two-branched; 2 long, simple or two-branched; 3 moderate, simple or two- to three-branched; 4 small, two- to fivebranched; 5 minute, simple.

Segment III: A short, stout, slightly longer than A-II, simple; B long, simple or two-forked; C moderate, usually simple or two-branched, occasionally up to five-branched; $C^{\prime}$ small, relatively stout, simple; 1 long, simple or occasionally twobranched; 2 moderate, simple or two-branched, occasionally three-branched; 3 represented only by its socket; 4 small, two- to four-forked or simple.

Segment IV: A short, stout, a little longer than A-III; B long, simple; C moderate, simple or twoforked; $C^{\prime}$ small, rather stout, simple; 1 long, usually simple, occasionally two- or threebranched; 2 small, simple or two- to threeforked; 3 represented only by its socket; 4 moderate, two- or three- forked.

Segment $V$ : A stout, a little longer than A-IV;
B long, simple, occasionally two-branched; C moderate, simple or two-branched; $C^{\prime}$ short, relatively stout, simple; 1 long, simple, occasionally two-branched; 2 small, usually twoforked, occasionally simple or three-forked; 3 represented only by its socket; 4 moderate, simple or two-forked.

Segment VI: A stout, a little longer than A-V, simple or forked near apex; B long, simple; C small, simple or two-branched; $C^{\prime}$ small, stout, simple; 1 long, simple or occasionally twobranched; 2 moderate, usually two-branched, occasionally simple; 3 absent; 4 moderate, simple or occasionally two-branched.

Segment VII: A long, sometimes plumose, sim-

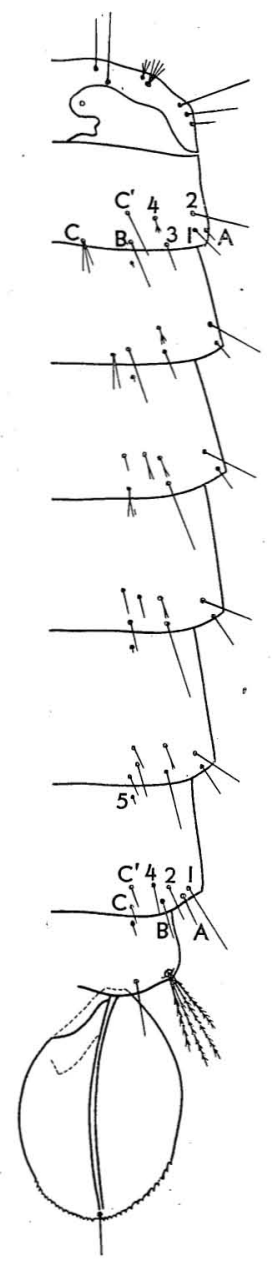

FIG. 41. Aedes aegypti: dorsal aspect of right half of abtomen of male (after Macfie, 1920). 
ple or two-branched; B long, simple; c small, simple; $C^{\prime}$ small, rather stout, simple; 1 moderate, simple or occasionally two- to threebranched; 2 long, simple; 4 small, simple or two-branched.

Segment VIII: A strong, long, plumose, usually four-branched, range from two to five; $A^{\prime}$ long, simple.

Paddle: Roughly oval, margin smooth on basal two-thirds, then serrate around apex to same point on medial side; midrib strong, dividing the paddle almost equally; terminal seta long, simple.

\section{Aedes (Stegomyia) albolineatus (Theobald) 1904}

Fig. 42

DiAgNosis.-Distinct in having the terminal seta of the paddle long and with three or more stout plumose branches.

Cephalothorax.-Postocular: 1 long, twoforked or simple, rarely three-forked; 2 medium, simple or rarely two-forked; 3 long, simple or occasionally two-forked.

Anterothoracic: 4 long, stout, simple or occasionally two-forked; 5 medium, two- or threeforked, rarely simple or four-forked; 6 small, usually simple, occasionally two- or three-forked at apex; 7 medium, simple or two-forked.

Dorsal: 8 medium, one-half length of trumpet, two-forked or occasionally simple or threeforked.

Supra-alar: 9 medium, simple.

Metanotum: 10 medium, usually two-forked, occasionally simple or three-forked; 11 long, simple; 12 long, three- or four-forked, occasionally simple.

Trumpet: Funnel-shaped, length about three times greatest diameter of meatus; pinna onethird to one-fourth of total length; very lightly pigmented.

ABDomen.-Segment I: $\mathrm{H}$ medium, stout, simple or rarely two-forked at apex; $\mathrm{K}$ very long, stout, simple; L medium, three- to six-forked above base; $M$ medium, five- to seven-forked above base; $s$ very long, simple; $T$ long, usually two-forked near middle, occasionally simple or three-forked; U small, simple.

Segment II: A small, simple spine; B long, simple; $\mathrm{C}$ medium, two-forked near base or occasionally simple; $C^{\prime}$ small, simple; 1 medium, simple or two- to three-forked; 2 long, simple; 3 medium, usually two-forked, occasionally simple or three-forked; 4 small, usually threeforked above base, occasionally two- or fourforked; 5 minute, simple on this and all following segments.

Segment III: A small, simple spine; в long, simple or rarely two-forked at apex; C medium, two-forked or rarely simple; $C^{\prime}$ small, simple or rarely two-forked at apex; 1 long, simple; 2 small, two-forked or occasionally simple or three-forked; 3 represented only by its socket; 4 medium, two-forked or occasionally simple or three-forked.

Segment IV: A small, simple spine; B very long, almost reaching to posterior margin of segment VI, simple; C long, two-forked near base; $\mathrm{C}^{\prime}$ small, simple; 1 long, simple; 2 medium, two-forked near basal third; 3 represented only by its socket; 4 medium, four- or five-forked, rarely two-forked.

Segment $V$ : A small, simple spine; B very long, simple; C long, two-forked near base or occasionally simple; $C^{\prime}$ small, simple or occasionally two-forked apically; 1 long, simple; 2 small, usually five-forked near basal third, occasionally three- or two-forked; 3 represented only by its socket; 4 long, simple or two-forked.

Segment VI: A small, simple spine; B long, simple or occasionally two-forked near apex; C medium, simple or rarely two-forked near apex; $C^{\prime}$ small, simple; 1 long, simple; 2 medium, two- or three-forked, rarely simple or four-forked; 3 absent; 4 medium, simple or twoforked at apex.

Segment VII: A long, plumose, three-branched or occasionally two- or four-branched; B long, simple; $C$ medium, simple; $C^{\prime}$ small, simple or rarely two-forked apically; 1 long, plumose, usually two-branched, occasionally three-branched or simple; 2 medium, two-forked near basal one-fourth, or occasionally simple; 4 medium, simple or occasionally two-forked. 
Segment VIII: A very long, plumose, seven- to fourteen-branched, averages eleven-branched; $A^{\prime}$ medium, simple or two-forked near middle.

Paddle: Oval, length always exceeding width by one-fourth; margin very slightly and finely serrate laterally, smooth medially; midrib strong, dividing paddle almost equally, but medial face slightly wider than lateral face; terminal seta strong, plumose, usually three-branched, occasionally as many as six-branched.

SPECIMENS EXAMINED.-The pupal exuviae of eleven males and ten females from WagaWaga, Hilimoi, and KanaKope, Milne Bay, Papua, and Mios Woendi, Dutch New Guinea.

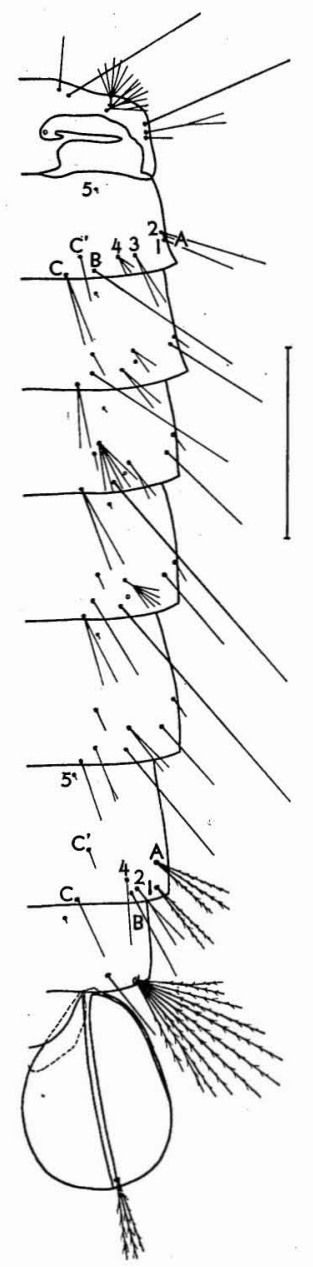

FIG. 42. Aedes albolineatus: dorsal aspect of right half of abdomen of male from Mios Woendi, Dutch New Guinea.

\section{Subgenus AEDIMORPHUs Theobald}

DiAgNosis.-Dorsal seta (8) of cephalothorax placed between or slightly behind the bases of the trumpets. Seta B comparatively short on all abdominal segments, never reaching posterior margin of the following segment; setae $B$ and $C$ either branched or forked on most of the segments.

Aedes (Aedimorphus) vexans (Meigen) 1830

\section{Fig. 43}

Pupa never fully described heretofore although brief notes and illustrations of parts of it have been included in papers by several authors including Mitchell (1907: 257), Howard, Dyar, and Knab (1912-1917 [vol. 2]: fig. 702; [vol. 4]: 694), Buxton and Hopkins (1927: 91), Matheson (1944: 27), and Bohart and Ingram (1946: 15).

Cephalothorax. - Postocular: 1 small, simple; 2 medium, simple or two-forked; 3 medium, two-forked.

Anterotboracic: 4 medium, two-forked near apex; 5 medium, two- or three-forked; 6 small, simple or two-forked; 7 medium, two- or threebranched.

Dorsal: 8 medium, two- or three-forked.

Supra-alar: 9 medium, two-forked.

Metanotum: 10 medium, four- to six-branched; 11 medium, simple; 12 medium, simple to three-forked.

Trumpet: Funnel-shaped, short, length about two and one-half times greatest diameter of meatus; pinna equal to about one-fourth of total length; uniformly dark pigmented.

ABDOMEN.-Segment I: $\mathrm{H}$ small, simple; $\mathrm{K}$ medium, simple; $\mathrm{L}$ very small, two- to fivebranched; $\mathrm{M}$ very small, simple or three-forked; $\mathrm{s}$ long, simple; $\mathrm{T}$ medium, two- or three-forked near middle; U very small, simple.

Segment II: A small, simple spine; B medium, simple; C medium, four- to seven-branched; $C^{\prime}$ small, simple spine on this and all following segments; 1 medium, two- or three-forked near basal one-third; 2 long, simple; 3 medium, 
three- or five-branched; 4 small, three-forked near base or simple; 5 minute, simple on this and all following segments.

Segment III: A small, simple spine; B medium, simple or two-forked near apex; C medium, four-forked near base; 1 long, simple or twoforked near middle; 2 small, three-branched; 3 represented only by its socket; 4 small, fivebranched.

Segment IV: A small, simple spine; в long, twoor three-branched; $C$ medium, three- or fourforked near base; 1 long, simple; 2 small, twoforked near middle; 3 represented only by its

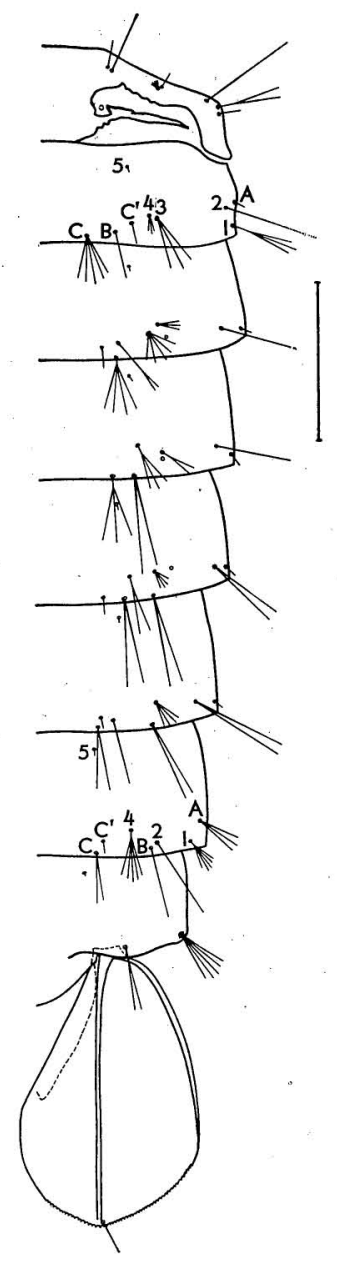

FIG. 43. Aedes vexans: dorsal aspect of right half of abdomen of male from Gamadodo, Papua. socket; 4 small, two- to five-forked near basal fourth.

Segment V: A small, simple spine; B long, twobranched; $C$ long, two-branched; 1 long, twoforked near base; 2 small, four-forked near base; 3 represented only by its socket; 4 medium, two- to three-forked near basal one-third.

Segment VI: A small, simple spine; B long, twobranched; $C$ long, two- or three-branched; 1 long, simple or two-forked near base; 2 small, two- or three-forked near base; 3 absent; 4 medium, simple or two-forked near base.

Segment VII: A medium length, stout, two- or three-branched; B long, simple or two- to threebranched; C medium, two-branched; 1 small, four- or five-forked near base; 2 small, simple to four-forked near base; 4 medium, four- or five-forked near basal one-fourth.

Segment VIII: A medium length, stout, five- or six-branched; $A^{\prime}$ medium, two-forked near basal one-third.

Paddle: Roughly pear-shaped, widest near apical one-fourth; buttress reaches widest point, from which point the margin is finely serrate around apex to medial part; midrib strong, dividing paddle unequally, lateral face about one-fourth wider than medial face; one specimen with a little dark pigment near the base of the paddle; terminal seta small, simple or two-forked near apex.

SPECIMENS EXAMINED.-The pupal exuviae of two males from Gamadodo, Milne Bay, Papua.

\section{Subgenus BANKsinella Theobald}

DiAGNOSIs.-According to Edwards (1941: 399), the species of Banksinella are distinct from all other Aedes in having setae $\mathrm{H}$ and $\mathrm{K}$ wide apart and $\mathrm{K}$ forming a small tuft, little if any larger than $\mathrm{L}$ or $\mathrm{M}$, instead of a long simple seta. On the metanotum, the simple seta 10 is in front of seta 11 instead of medial to it. None of the abdominal setae strongly developed, but C-II forming a small tuft which may be dendritic. A-VII and A-VIII very small. Paddles with weak midrib and smooth margin. 
The pupa of the single species recorded from New Guinea is unknown.

\section{Subgenus AEDEs Meigen}

Heretofore only one species of the subgenus Aedes has been partially described, and since we collected pupae of only one additional species in New Guinea the following notes must be taken with reservations as a subgeneric diagnosis.

DiAgNosis.-Setae $\mathrm{H}$ and $\mathrm{K}$ close together, well separated from $\mathrm{L}$ and $\mathrm{M}$. At least B-IV and $\mathrm{V}$ long, reaching posterior margins of following segments, usually two- or more branched; seta C-II a medium-length multibranched tuft which is often dendritic.

Aedes (Aedes) funereus (Theobald) 1903

Pupa undescribed, but Hill (1925: 73) included figures of the paddles and trumpet. Since no differences between these figures and specimens of $A$. lineatus were noted, the figures are not included here.

\section{Aedes (Aedes) lineatus (Taylor) 1914 Fig. 44}

CephalothoraX.-Postocular: 1 medium, two-forked, rarely three-forked; 2 medium, simple or rarely two-forked; 3 medium, two-forked near middle or rarely three-forked.

Anterothoracic: 4 medium, two- or three-forked; 5 medium, two- to six-forked; 6 small, simple; 7 medium, two- to four-forked.

Dorsal: 8 medium, less than one-half the length of the trumpet, three- to five-forked, rarely sixor eight-forked.

Supra-alar: 9 medium, two- or three-forked, rarely simple.

Metanotum: 10 medium, usually four-forked, range from three- to seven-forked; 11 long, longest seta on cephalothorax, simple; 12 medium, two- to six-forked.

Trumpet: Short, funnel-shaped, length ranging from about two to three times greatest diameter of meatus; pinna short; all darkly pigmented, but tracheoid area darkest.
AвDOMEN.-Segment I: $\mathrm{H}$ medium, stout, simple spine; $\mathrm{K}$ medium, two- or three-forked near base; L small, usually two-forked, occasionally three- or four-forked; $\mathrm{M}$ small, two- to five-forked; $s$ long, simple or occasionally twoforked; $T$ medium, two- to four-forked near middle, rarely five-forked; U small, simple.

Segment II: A small, simple spine; B long, simple; C medium, ten- to fifteen-branched tuft; $\mathrm{C}^{\prime}$ small, simple on this and all following segments; 1 medium, two- or three-forked near middle; 2 long, simple or rarely two-forked; 3 medium, two- to four-branched, each branch being two-forked near its middle; 4 small, twoor four-forked near base; 5 minute, simple on this and all following segments.

Segment III: A small, simple spine; в long, simple; $C$ medium, three- to eight-branched; 1 medium, two- or three-forked, occasionally fouror five-forked; 2 small, simple; 3 represented only by its socket; 4 medium, three- or fourforked.

Segment IV: A small, simple spine; B long, twobranched or rarely three-branched; C medium, three- to six-branched; 1 medium, three- or four-forked near middle, rarely simple; 2 small, two-forked near apex or simple; 3 represented only by its socket; 4 medium, two- to six-forked near middle.

Segment V: A small, simple spine; B long, twobranched or occasionally two-forked; $C$ medium, three- or four-branched; 1 medium, two- or three-forked near middle, rarely simple; 2 medium, two- to five-forked near base; 3 represented only by its socket; 4 medium, two- or three-forked near apex.

Segment VI: A small, simple spine; B long, simple or two-branched; c medium, three- or fourbranched; 1 medium, simple; 2 medium, twoto five-forked near basal one-third; 3 absent; 4 medium, two-forked near basal one-third or simple, rarely three-forked.

Segment VII: A medium, two-branched or rarely simple; B medium, two-branched or rarely simple; C medium, two- to four-branched; 1 small, two- to four-forked near base; 2 medium, two- 
or three-forked near basal third; 4 medium, two- or three-forked near basal one-third.

Segment VIII: A medium, stout, four- to eightbranched, plumose; $A^{\prime}$ medium, simple to threeforked near apex.

Paddle: Roughly oval, longer than wide; margin very finely serrate laterally and apically; midrib strong, not reaching apex, dividing the paddle almost equally; terminal seta medium, simple.

SPECIMENS EXAMINED.-The pupal exuviae of one male and three females from Gamadodo and WagaWaga, Milne Bay, Papua, and Draeger Harbor, Northeast New Guinea.

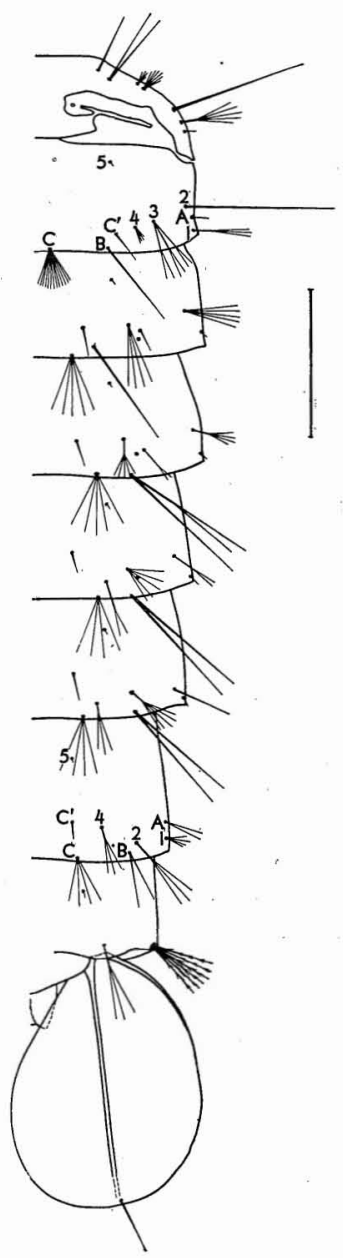

FIG. 44. Aedes lineatus: dorsal aspect of right half of abdomen of female from WagaWaga, Papua.

\section{Subgenus LePTOSOMATOMYIA Theobald}

DIAGNOSIS.-The following is based on the single species of the subgenus which is known in its immature stages. All dorsal abdominal setae on segments II-VIII small, inconspicuous, and usually simple, except A-VII and A-VIII. The latter two are large, several-branched plumose tufts. Paddles reminiscent of those of Tripteroides in general shape, though larger of course, produced apically into a truncate point.

\section{Aedes (Leptosomatomyia) aurimargo}

Edwards 1922

Cephalothorax. - Postocular: 1 small, three- or four-forked, rarely six-forked; 2 small, simple or two-forked; 3 small, two-forked.

Anterothoracic: 4 medium, two-forked near middle or occasionally simple; 5 medium, twoforked near middle or rarely simple; 6 small, simple; 7 medium, two-forked near middle or simple.

Dorsal: 8 small, about one-half the length of the trumpet, simple or occasionally two-forked near base.

Supra-alar: 9 small, simple.

Metanotum: 10 and 11 very close together, well separated from 12; 10 small, simple or two- to three-forked; 11 medium, simple; 12 small, twoforked near middle or occasionally three-forked. Trumpet: Small, funnel-shaped, length usually not more than twice the greatest width; pinna short, ranging from one-fourth to one-sixth of the total length of the trumpet; uniformly dark-pigmented.

ABDOMEN.-Segment I: H medium, simple; $\mathrm{K}$ long, simple; 1 small, two-forked near middle; M small, four- or five-forked near middle; s long, simple; $\mathrm{T}$ long, two-forked near base; $\mathrm{U}$ minute, simple.

Segment II: A small, simple spine; в medium, stout, simple; $C$ long, stout, simple; $C^{\prime}$ medium, usually simple or two- to three-forked; 1 small, simple or two- to three-forked, rarely fourforked; 2 medium, simple or rarely two-forked; 3 small, two- to five-forked; 4 medium, stout, 
simple; 5 minute, simple on this and all following segments.

Segment III: A small, simple spine; B medium, stout, simple; C long, stout, simple; C' small, simple spine on this and all following segments; 1 small, simple; 2 small, simple or rarely twoforked; 3 represented only by its socket; 4 small, simple spine.

Segment IV: A small, simple spine; B long, stout, simple; C small, two-forked or occasionally simple; 1 small, simple or rarely two-forked; 2 small, simple or occasionally two-forked; 3 represented only by its socket; 4 small, four- or fiveforked, rarely six-forked.

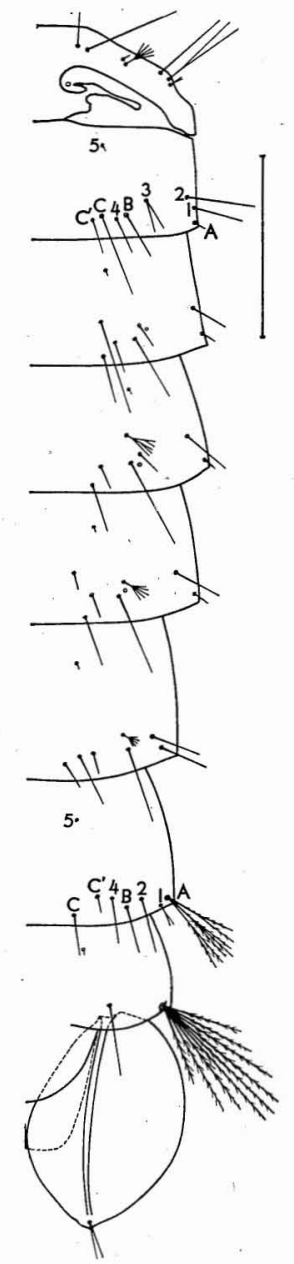

FIG. 45. Aedes aurimargo: dorsal aspect of right half of abdomen of male from Draeger Harbor, Northeast New Guinea.
Segment V: A small, simple spine; B long, stout, simple; C medium, simple; 1 small, simple; 2 small, five- or six-forked, occasionally two- to four-forked; 3 represented only by its socket; 4 small, two-forked or simple.

Segment VI: A small, simple; B medium, stout, simple; C small, simple, stout; $\dot{C}^{\prime}$ small, stout spine, simple or rarely two-forked at apex; 1 small, simple; 2 small, two- to four-forked near middle; 3 absent; 4 small, simple, stout, rarely two-forked at apex.

Segment VII: A long, stout, black, plumose, twoto four-branched; B small, simple or occasionally two-forked near middle; C small, simple; 1 small, three-forked, rarely two-forked; 2 small, simple or two-forked; 4 small, simple.

Segment VIII: A very large, black, stout, plumose, five- to nine-branched, usually nine; $A^{\prime}$ long, simple.

Paddle: Long, narrow oval, apically with a blunt point; margin slightly serrate laterally becoming coarser near apex; midrib strong basally, declining apically, dividing paddle unequally, the lateral face being nearly twice the width of the medial face; terminal seta stout, black, usually two-branched or forked, rarely simple or three-forked.

SPECIMENS EXAMINED.-The pupal exuviae of four males and two females from Draeger Harbor, Northeast New Guinea.

\section{Genus ARMIGERES Theobald}

DiAgNosis.-Trumpets of moderate length, tracheoid portion obsolete, pinna very oblique. Dorsal seta (8) of cephalothorax placed far posterior to trumpets. Setae $\mathrm{H}$ and $\mathrm{K}$ close together, well separated from $\mathrm{L}$ and $\mathrm{M}$. Seta $\mathrm{A}$ a small simple spine on segments II-VI, but a strong plumose tuft on VII and VIII; seta $\mathbf{B}$ a long simple seta on segments II-V, same length throughout but closer to lateral margin on the posterior segments; seta $\mathrm{C}$ a small tuft on segments II-VII. Paddles fringed with long hairs around apical one-half of margin, with an irregular line of black pigment at base; midrib strongest on basal one-third; terminal seta strong, accessory seta absent. 
Key to Species of Armigeres

Setae B and C on segment II placed close together; C-II a small three- or four-branched tuft; paddle not notched at apex (Fig. 46)

A. breinli

Setae B and C on segment II placed relatively far apart; C-II a conspicuous five- or sixforked tuft; paddle notched at apex (Fig. 47).

A. milnensis

Armigeres breinli (Taylor) 1914

Fig. 46

CephalothoraX.-Postocular: 1 small, fiveor six-branched; 2 long, two- or three-branched; 3 long, two-branched.

Anterothoracic: 4 small, three- to five-forked; 5 small, five- or six-forked; 7 small, two-forked or rarely simple; 6 long, stout, pale, simple.

Dorsal: 8 medium, five-forked.

Supra-alar: 9 small, three-forked.

Metanotum: 10 medium, four-branched; 11 long, stout, simple; 12 small, six-branched.

Trumpet: Short, length about twice the greatest diameter of meatus; pinna long, about one-half the total length of trumpet; tracheoid area obsolete; uniformly light-pigmented.

AвDOMEN.-Segment I: H medium, stout, simple; K long, stout, plumose, simple; L very small, simple; $M$ small, six-branched; s medium, three-branched; $\mathrm{T}$ medium, five- or sixbranched; U very small, simple.

Segment II: A small, simple spine; B long, simple, plumose; c small, three- or four-branched; 1 small; four- or five-branched; 2 very small, three-branched; 3 very small, four- to sixbranched; 4 medium, simple; 5 minute, simple on this and all following segments.

Segment III: A small, simple spine; B long, simple, plumose; $C$ very small, three- or fourbranched; $C^{\prime}$ small, simple on this and all following segments; 1 very small, two- or threebranched; 2 very small, three-branched; 3 represented only by its socket; 4 small, threebranched.

Segment IV: A small, simple spine; в long, simple, plumose; C small, five-branched; 1 very small, simple or two-forked; 2 small, three- to five-forked; 3 represented only by its socket; 4 small, three-forked.

Segment V: A small, simple spine; в long, simple, plumose; c small, five-branched; 1 small, simple to four-branched; 2 small, two- to four-forked; 3 represented only by its socket; 4 small, three- or four-forked.

Segment VI: A small, simple spine; B long, twobranched, plumose; C small, three-branched; 1 small, two- or three-forked, mesad of $\mathbf{B}$ in position; 2 small, two- to five-forked; 3 absent; 4 small, four- to seven-forked, mesad of $\mathrm{C}$ in position.

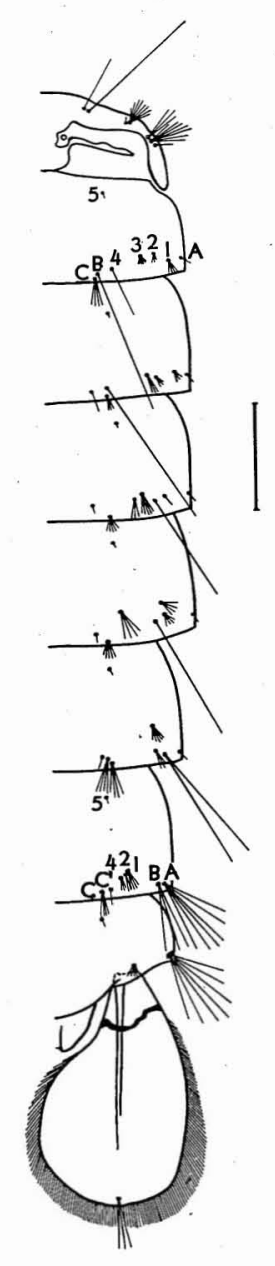

FIG. 46. Armigeres breinli: dorsal aspect of right half of abdomen of female from Mios Woendi, Dutch New Guinea. 
Segment VII: A large, strong, plumose, five- to eight-branched; B size various, from small to long on different specimens, usually threebranched, placed very close to A; C small, fourbranched; 1 small, four-branched; 2 very small, two-branched; 4 very small, three-branched.

Segment VIII: A large, strong, plumose, subequal to A-VII, seven- or eight-branched; $A^{\prime}$ very small, four- or five-forked.

Paddle: Elongate, more or less blunt-tipped, medially produced into a wide flap, medial face one-third wider than lateral face; midrib strong basally, disappears at about middle; margin with a fringe of long hairs almost all around; with an irregular line of black pigment at base of paddle; terminal seta strong, two- or threeforked.

SPECIMENS EXAMINED.-The pupal exuviae. of fourteen males and seven females from Hilimoi, Milne Bay, Papua; Draeger Harbor, Northeast New Guinea; Mios Woendi and Amsterdam Island, Dutch New Guinea.

\section{Armigeres milnensis Lee 1944}

Fig. 47

Cepralothorax.-Postocular: 1 long, stout, black, plumose, nearly equal to length of trumpet, two-branched; 2 absent; 3 long, stout, black, plumose apically, simple.

Anterothoracic: 4 small, four- or five-branched; 5 small, four-branched; 6 long, stout, pale, simple; 7 medium, black, two-forked.

Dorsal: 8 medium, four-forked.

Supra-alar: 9 medium, two-forked.

Metanotum: 10 medium, seven- or eightforked; 11 long, stout, black, simple; 12 small, four-branched.

Trumpet: Short, length about twice greatest diameter of meatus; tracheoid portion obsolete; pinna long, nearly one-half the total length of trumpet; pale-brown colored, darker than cephalothorax.

ABDOMEN.-Segment I: H small, simple; $\mathrm{K}$ long, simple, plumose, rarely two-forked near apex; L very small, simple or two-forked; M very small, usually six- to eight-forked near middle, range from four to thirteen; $s$ small, usually three-branched, range from two- to six-branched; $\mathrm{T}$ 'small, usually three-branched, range from two- to six-branched; $\mathrm{U}$ very small, two-forked near base or simple.

Segment II: A small, simple spine; в long, plumose, simple; C medium, usually five- or sixforked from near base, range from four to nine; 1 small, usually six-branched, range from four to seven; 2 small, usually three-forked, range from two to six; 3 very small, usually four- to six-branched, range from four to ten; 4 small, simple; 5 minute, simple on this and all following segments.

Segment III: A small, simple spine; B very long, plumose, simple; $\mathrm{C}$ small, usually three- or fourbranched, rarely five- to seven-branched; $C^{\prime}$ small, simple on this and all following segments; 1 small, either two-, three-, or four-branched; 2 very small, two- to five-forked from near base; 3 represented only by its socket; 4 small, threeor four-branched or forked.

Segment IV: A small, simple spine; B very long, plumose, simple; C small, variable, usually four-branched, but ranges from two to eight; 1 small, usually three- to four-branched, rarely two- or five-branched; 2 small, usually threeor four-branched, rarely two- or five-branched; 3 represented only by its socket; 4 small, usually four-branched, range from two to five.

Segment $V$ : A small, simple spine; B very long, plumose, simple; C small, usually three- or fourbranched, rarely five- to seven-branched; 1 small, usually three-branched, range from two to five; 2 very small, usually four- or five-branched, rarely two- or three-branched; 3 represented only by its socket; 4 small, three- or four-branched. Segment VI: A small, simple spine; B long, stout, black, plumose, simple or two-branched, only rarely three-branched; C very small, two- or three-forked near base, occasionally four-forked; 1 very small, two- or three-forked; 2 small, usually three-forked near base, occasionally twoor four-forked; 3 absent; 4 small, two- or threeforked, rarely simple or four-forked. 
Segment VII: A long, stout, black, plumose, very similar to B-VI, three- or four-branched, rarely two-branched or forked; B small, various, twoto six-forked near base; $\mathrm{C}$ very small, simple or two-forked near base; 1 small, two- or threeforked near base, rarely simple; 2 very small, two-forked near base or simple; 4 small, usually three-forked near base, occasionally simple or two- to four-forked.

Segment VIII: A very long, large, conspicuous, black, plumose tuft, range from six- to elevenbranched, usually nine-branched; $A^{\prime}$ small, twoor three-branched, occasionally simple or fourbranched.

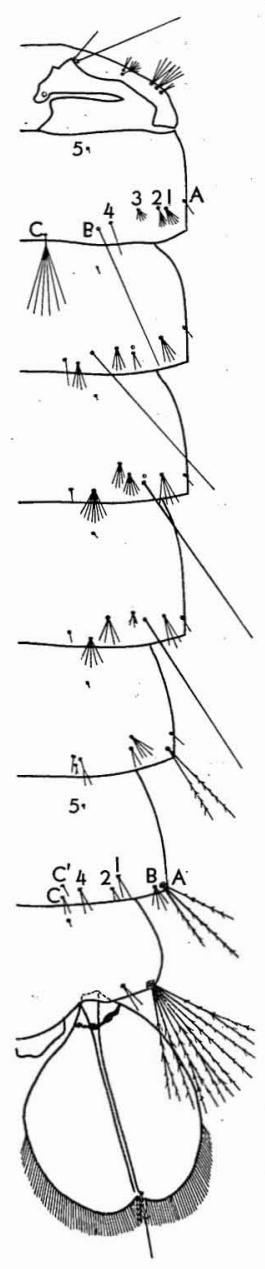

Fig. 47. Armigeres milnensis: dorsal aspect of right half of abdomen of female from Hilimoi, Papua.
Paddle: Roundly oval, slightly longer than wide; with a fringe of long fine hairs on the margin starting at the apical one-third laterally and extending to the apical one-half medially; midrib stronger than in breinli, dividing the paddle almost equally into halves; with an irregular broken line of black pigment across basal part of paddle; terminal seta medium, strong, simple.

SPECIMENS EXAMINED.-The pupal exuviae of two males and eight females from Hilimoi, Milne Bay, Papua, and Draeger Harbor, Northeast New Guinea.

\section{Armigeres lacuum Edwards 1922}

Pupa undescribed, but Hill (1925: 70) included figures of the trumpets, terminal abdominal segments, and paddles. These figures are not included here since they lack the detail necessary to bring out features which would distinguish $A$. lacuum from the other species in New Guinea.

\section{Genus CULEX Linnaeus}

DiAgnosis.-The pupae of Culex can usually be distinguished from those of other genera by the presence of an accessory seta situated beside the terminal seta at the tip of the midrib of the paddle, and by the presence of a small spine-like seta on the postero-lateral corner of segment IX. These features are both somewhat difficult to appreciate on all specimens and are not absolutely diagnostic because the New Guinean species of the subgenus Acallyntrum have neither terminal nor accessory paddle setae, and the accessory seta is absent from C. squamosus; seta v-IX is extremely difficult to see on most species and apparently is not always present on $C$. sitiens. Two other features characterize the large majority of Culex pupae, though again there are exceptions; the trumpets have a dark tracheoid area close to the base; and setae A-VII and A-VIII, which usually form wellmarked plumose tufts, are placed well before the corners of the segments. The dorsal seta (8) of cephalothorax is usually placed well behind the bases of the trumpets. 


\section{Subgenus LUtzia Theobald}

DiAgNosis.-Practically inseparable as a subgenus from Culex (Culex) except in the position of seta A on III-VI far anterior to the corners of the segments; the paddles slightly notched at the apex of the midrib; and always of large size.

\section{Culex (Lutzia) halifaxii Theobald 1903} Fig. 48

Pupa undescribed, but. Hill (1925: 73) included figures of its paddles and trumpet.

Cephalothorax. -- Postocular: 1 small, simple; 2 small, simple or occasionally twoforked at apex; 3 small, simple.

Anterothoracic: 4 small, simple; 5 small, simple; 6 small, simple; 7 small, simple.

Dorsal: 8 small, one-third length of trumpet, simple or rarely two-forked.

Supra-alar: 9 small, simple.

Metanotum: 10 small, three- or four-forked, or rarely five-forked; 11 small, simple or rarely two-forked; 12 small, simple.

Trumpet: Medium length, length about three times the greatest diameter of meatus; pinna long, nearly one-half the total length of trumpet; . tracheoid area indistinct; basal part of trumpet darkest, although the whole trumpet is darkly pigmented.

ABDOMEN-Segment I: $\mathrm{H}$ small, simple; $\mathrm{K}$ long, two-forked near basal one-third; I small, two-forked near apex, or occasionally fiveforked or simple; $\mathrm{M}$ small, two- to four-forked near apex; s long, simple; $\mathrm{T}$ long, simple or rarely two-forked; U minute, simple.

Segment II: A small, simple spine; B long, simple or rarely two-forked near middle; $\mathrm{C}$ small, three- to five-forked near middle; $C^{\prime}$ small, simple on this and all following segments; 1 long, simple or rarely two-forked; 2 long, simple; 3 small, two- to four-forked or rarely simple; 4 long, simple; 5 minute, simple on this and all following segments.

Segment III: A small, simple spine; B long, simple or occasionally two-forked; c long, plumose, five- to eight-forked near base; 1 me- dium, simple; 2 small, two- or three-forked at apex; 3 represented only by its socket; 4 long, two- to four-forked, rarely simple or five-forked. Segment IV: A small, simple spine; B long, plumose, three- to six-branched; $C$ long, plumose, three- to six-branched; 1 long, simple or rarely two-forked at apex; 2 small, two-forked near apex, or rarely three-forked; 3 represented only by its socket; 4 small, five-forked near middle, or occasionally four- or six-forked.

Segment V: A small, simple spine; B very long, plumose, two- or three-branched, rarely fourbranched; C very long, plumose, two- or threebranched; 1 long, simple; 2 medium, three- or

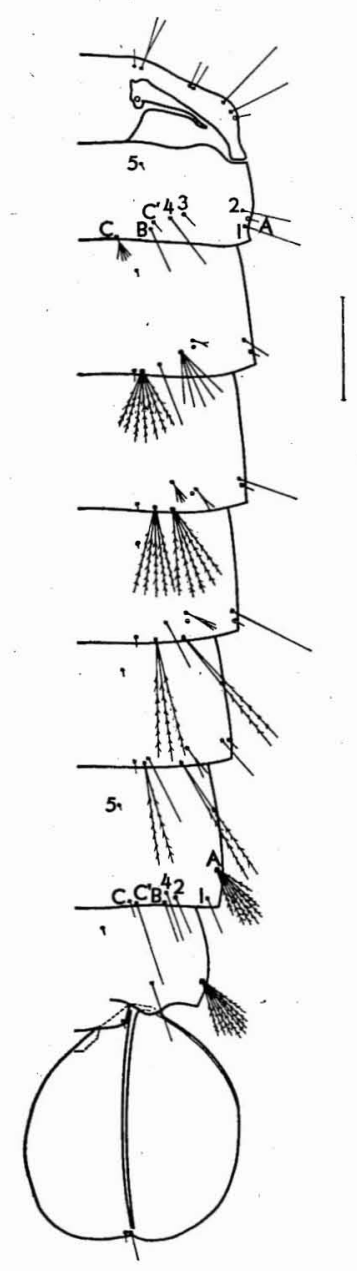

FIG. 48. Culex halifaxii: dorsal aspect of right half of abdomen of female from WagaWaga, Papua. 
four-forked near middle; 3 represented only by its socket; 4 medium, simple or rarely twoforked.

Segment VI: A small, simple spine; B very long, plumose, two- or three-branched; $\mathrm{C}$ long, plumose, two- or three-branched; 1 medium, simple or occasionally two-forked; 2 medium, twoforked near middle or occasionally four-forked; 3 absent; 4 long, simple or rarely two-forked. Segment VII: A long, plumose, four- to eightbranched, most frequently seven-branched; $\mathrm{B}$ medium, simple; c long, simple; 1 small, twoforked or rarely simple; 2 medium, simple; 4 medium, simple.

Segment VIII: A long, plumose, nine- to thirteen-branched, most frequently eleven-branched; $A^{\prime}$ long, simple.

Segment IX: v minute, stout, simple.

Paddle: Rounded, slightly longer than greatest width, apex with a notch at end of midrib; margin smooth; midrib dividing paddle unequally, lateral face a little wider than medial face; terminal seta very small, simple; accessory seta a little longer, simple.

SPECIMENS EXAMINED.-The pupal exuviae of three males and seven females from Gamadodo, WagaWaga, and Hilimoi, Milne Bay, Papua.

\section{Subgenus Neoculex Dyar}

None of the four species recorded from New Guinea has been seen in the pupal stage, and so few pupae of Neoculex have been described that it is impossible to present a subgeneric diagnosis at the present time.

\section{Subgenus MOCHTHOGENES Edwards}

DiagNOSIS.-Only two of the species of this subgenus have been described in the pupal stage. For these Edwards (1941: 412) notes the following features: All cephalothoracic setae inconspicuous; seta 11 of metanotum double; setae $\mathrm{K}$ and $\mathrm{S}$ about equally long and simple; $\mathrm{T}$ also simple but shorter; paddle seta somewhat stronger than usual, and accessory seta present.

The pupa of the single species recorded from New Guinea is unknown.

\section{Subgenus LOPHOCERAOMYIA Theobald}

DiAgnosis.-The pupae of the two species recorded from New Guinea agree in the following features: Trumpets fairly long, with welldeveloped tracheoid portion. Seta $\mathrm{C}$ with more than six branches on segments II and III; seta 2 on segment II long and simple, the most conspicuous seta on the segment; setae A-VII and A-VIII, the only plumose tufts on the abdomen.

\section{Key to Species of Culex (Lophoceraomyia)}

Seta B on segments IV through VII less than the length of the following segment; seta 1 on segments III through VI a branched tuft (Fig. 49) .................................. fraudatrix

Seta B on segments IV through VI much longer than the following segment; seta 1 on segments III through VI usually simple, never more than two-branched (Fig. 50)

C. uniformis

\section{Culex (Lophoceraomyia) fraudatrix}

(Theobald) 1905

Fig. 49

Cephalothorax. - Postocular: 1 small, three- to six-forked; 2 medium, two- to fourforked; 3 medium, three- or four-forked, rarely five-forked.

Anterothoracic: 4 medium, three- or fourforked, rarely five-forked; 5 medium, simple or two-forked, rarely three-forked; 6 small, simple or two-forked, rarely three-forked; 7 medium, two-forked or occasionally three-forked.

Dorsal: 8 medium, one-half length of trumpet, two-forked.

Supra-alar: 9 small, simple or two-forked, rarely three-forked.

Metanotum: 10 medium, two-forked or rarely simple; 11 medium, two-forked or rarely simple; 12 medium, two- to four-forked.

Trumpet: Long, narrow, length about twelve times the greatest diameter of the meatus; tracheoid area fairly well developed, dark; pinna short, less than one-eighth of the total length of the trumpet.

ABDOMEN.-Segment I: $\mathrm{H}$ small, simple; $\mathrm{K}$ long, two-branched; L very small, two-forked; 
M small, four- to seven-forked near base, rarely three-forked; s long, simple; $\mathrm{T}$ long, two-forked near base or occasionally three-forked; U small, simple.

Segment II: A small, simple spine; B long, twoforked near base; C medium, six- or sevenforked near base, rarely with each branch double so that it appears to be twelve-forked; $C^{\prime}$ small, simple, laterad of B in position; 1 medium, twoforked or occasionally three-forked; 2 very long, simple; 3 small, three-forked, or occasionally four- or five-forked; 4 medium, four-forked or occasionally three-forked; 5 minute, simple on this and all following segments.

Segment III: A small, simple spine; B long, two-

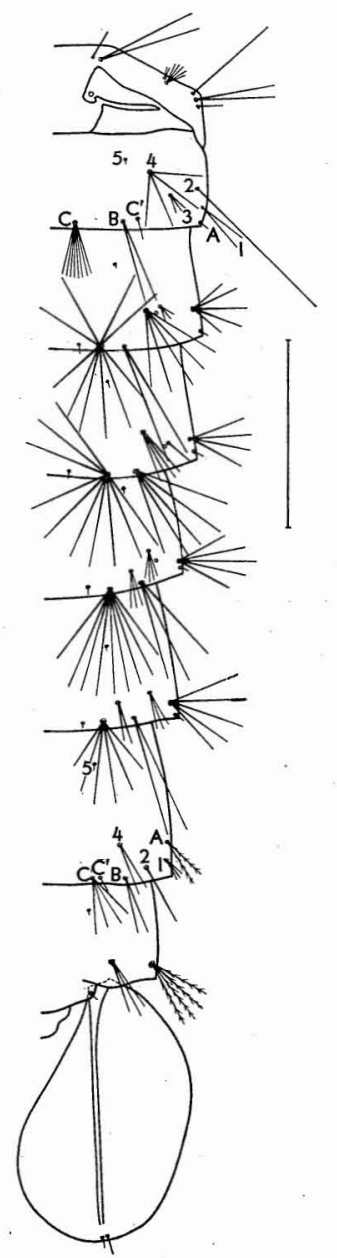

FIG. 49. Culex fraudatrix: dorsal aspect of right half of abdomen of female from Hilimoi, Papua. branched, rarely simple or three-branched; C long, nine-branched, or rarely seven- or tenbranched; 1 medium, three- to five-forked near base, rarely two-forked; 2 small, three-forked or occasionally simple or two-forked; 3 represented only by its socket; 4 long, five-forked or occasionally four-forked.

Segment IV: A small, simple spine; в long, fiveor six-branched, rarely four-branched; C long, seven- to ten-branched; 1 medium, four- or fiveforked near base, occasionally two- or threeforked; 2 small, two-forked or simple; 3 represented only by its socket; 4 medium, four- or five-forked near base, rarely six-forked.

Segment V: A small, simple spine; B long, twoor three-branched, rarely four-branched; C long, seven-branched or occasionally from five- to nine-branched; 1 medium, five- or four-forked near base, occasionally three-forked; 2 small, three- to six-forked near base; 3 represented only by its socket; 4 medium, three- or twoforked near base.

Segment VI: A small, simple spine; B long, twobranched or occasionally three-branched; c medium, four- to six-forked near base, occasionally two- or three-forked; 1 medium, four- or fiveforked near base, rarely three-forked; 2 small, three-forked, occasionally simple or two- to four-forked; 3 absent; 4 small, two-forked or occasionally simple.

Segment VII: A medium, three-branched, plumose, occasionally two- or four-branched; B medium, two-forked or occasionally simple; C medium, four- to six-forked or rarely threeforked; 1 small, two- or three-forked; 2 medium, simple or rarely two-forked; 4 medium, threeor four-forked or rarely two-forked.

Segment VIII: A medium, four- or five-branched, plumose, occasionally six- or seven-branched; $A^{\prime}$ medium, two- or three-forked near base.

Segment IX: v small, simple spine.

Paddle: Elongate oval; margin smooth; midrib dividing the paddle unequally, the lateral face a little wider than the medial face; terminal seta small, simple; accessory seta a little longer, simple. 
SPECIMENS EXAMINED.-The pupal exuviae of five females from Gamadodo, WagaWaga, and Hilimoi, Milne Bay, Papua.

\section{Culex (Lophoceraomyia) uniformis}

Theobald 1905

Fig. 50

Cephalothorax. - Postocular: 1 small, three- to five-forked; 2 small, two- to fourforked; 3 medium, simple.

Anterothoracic: 4 long, stout, two-forked; 5 medium, two-forked or simple; 6 small, simple; 7 medium, two-forked.

Dorsal: 8 medium, one-half length of trumpet, two- to four-forked.

Supra-alar: 9 medium, simple or two-forked.

Metanotum: 10 small, three-forked or rarely two- or four-forked; 11 medium, simple; 12 small, three-forked or rarely simple.

Trumpet: Long, length nine to ten times greatest diameter of meatus; pinna short, one-fifth to one-sixth of total length of trumpet; tracheoid area fairly well developed, dark pigmented.

AвDOMEN.-Segment I: $\mathrm{H}$ small, simple; $\mathrm{K}$ long, simple; L small, two-forked near apex or rarely three-forked; $M$ small, five-forked near base or occasionally three- or four-forked; s very long, simple; $\mathrm{T}$ long, simple; U small, two-forked near base or simple.

Segment II: A small, simple spine; B medium, simple; $C$ medium, nine- to eleven-forked near basal one-fifth; $C^{\prime}$ small, simple, lateral and anterior to $\mathrm{B}$ in position; 1 long, simple; 2 very long, simple, rarely three-forked at apex; 3 small, three- to four-forked; 4 small, three- or four-forked or rarely two-forked; 5 minute, simple on this and all following segments.

Segment III: A small, simple spine; B long, simple, very close to $\mathrm{C}$ in position; $\mathrm{C}$ medium, seven- or eight-branched, rarely ten-branched; $\mathrm{C}^{\prime}$ small, simple, mesad of $\mathrm{C}$ on this and all following segments; 1 long, simple or occasionally two-forked; 2 small, simple or occasionally twoor three-forked; 3 represented only by its socket on this and segments IV and V; 4 small, fourbranched, or rarely six-branched.
Segment IV: A small, simple spine; B very long, nearly reaching posterior margin of segment VI, two-branched, plumose; c long, usually fourbranched, range from two to six; 1 long, simple or occasionally two-forked; 2 small, simple or rarely two-forked; 4 medium, three- to sevenforked.

Segment V: A small, simple spine; в very long, plumose, two-branched; $C$ medium, two- or three-forked; 1 long, two-forked or simple; 2 small, three- or four-forked, rarely five-forked; 4 medium, two-forked or rarely three-forked.

Segment VI: A small, simple spine; B very long,

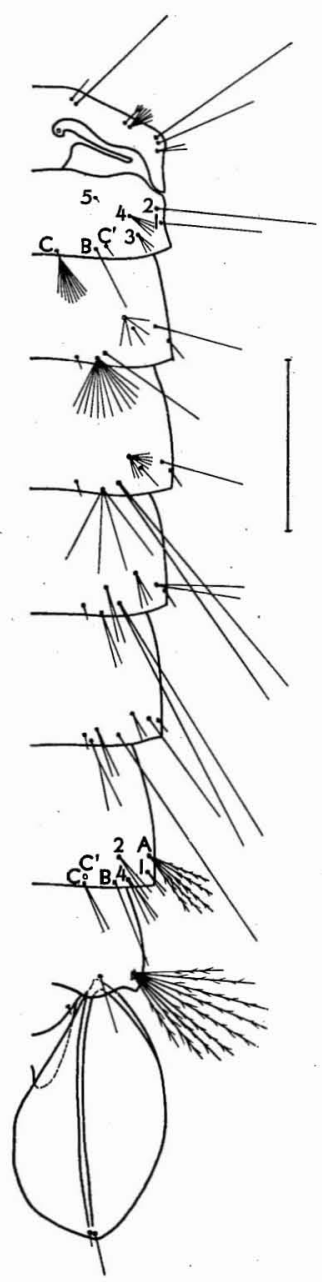

FIG. 50. Culex uniformis: dorsal aspect of right half of abdomen of male from Mios Woendi, Dutch New Guinea. 
plumose, simple or rarely three-forked near apex; c long, two-forked near basal one-third; 1 long, simple or rarely two-forked; 2 small, three- or two-forked; 3 absent; 4 medium, twoforked or occasionally simple or three-forked.

Segment VII: A fairly long, plumose, four- or five-branched; rarely three-branched; $\mathbf{B}$ fairly long, simple or rarely two-branched; c medium, two-forked or occasionally simple; 1 small, twoforked or occasionally simple; 2 medium, simple or two- to three-forked; 4 medium, two-forked or rarely simple.

Segment VIII: A large, conspicuous, plumose, six- to nine-branched, most frequently ninebranched; $A^{\prime}$ medium, simple or two-forked.

Segment IX: v small, simple spine.

Paddle: Elongate oval; margin smooth; a little black pigment near base of paddle on one specimen; midrib dividing paddle almost equally; terminal seta small, simple; accessory seta medium, simple or occasionally two-forked at apex."

SPECIMENS EXAMINED.-The pupae of seven males and two females from Mios. Woendi, Dutch New Guinea. It should be recorded that although a representative number of larvae of this species was collected on several occasions we were not successful in rearing any imagines. It is possible that although the larvae agree fairly well with the brief description published by Barraud (1934) this may be an undescribed species.

\section{Subgenus Culiciomyia Theobald}

Diagnosis.--The three New Guinean species of which the pupae are known agree in the following respects: Seta C-II a multibranched short tuft of fifteen or more branches; at least setae B-IV-VI plumose.

\section{Key to Species of Culex (Culiciomyia)}

1. Setae B-IV-VI exceeding posterior margins of following segments; setae C-III-VI never plumose (Fig. 51) ..........C. fragilis

Setae B-IV-VI never exceeding posterior margins of following segments; setae CIII-VI always plumose.
2. Setae $\mathrm{K}$ and $\mathrm{B}$-II plumose; seta 1 on segment VI not plumose (Fig. 52)

C. papuensis

Setae $\mathrm{K}$ and $\mathrm{B}$-II not plumose; seta 1 on segment VI plumose (Fig. 53 )

C. pullus

Culex (Culiciomyia) fragilis Ludlow 1903

Fig. 51

Cephalothorax. - Postocular: 1 medium, three- or four-forked; 2 medium, two- to fourforked; 3 medium, two-forked or rarely threeforked.

Anterotboracic: 4 long, three- or four-forked, rarely two-forked; 5 medium, two-forked, rarely simple; 6 small, simple or two-forked; 7 long, two-forked or occasionally simple.

Dorsal: 8 long, one-half length of trumpet, twoor three-forked.

Supra-alar: 9 long, simple or two-forked.

Metanotum: 10 medium, six- to ten-forked; 11 medium, two-forked or simple; 12 medium, two- to four-forked.

Trumpet: Funnel-shaped, length equal to a little more than four times the greatest diameter of meatus; pinna long, a little less than one-third of the total length; tracheoid portion darkpigmented, remainder of trumpet lightly pigmented.

ABDOMEN.-Segment I: $\mathrm{H}$ small, simple; $\mathbf{K}$ medium, two-forked or occasionally simple; L small, two- or three-forked near middle, rarely five-forked; $M$ small, three- or four-forked near base, occasionally simple; $\mathrm{s}$ long, simple; $\mathrm{T}$ long, simple or two-forked; U small, simple.

Segment II: A small, simple; в medium, twoforked near middle or rarely simple; $\mathrm{C}$ medium, twenty- to twenty-five-branched; $C^{\prime}$ small, simple spine on this and all following segments; 1 medium, simple or occasionally two-forked; 2 long, simple or two-forked; 3 small, simple, rarely two- or three-forked near middle; 4 medium, usually four-branched, occasionally two- or three-branched; 5 minute, simple on this and all following segments. 
Segment III: A small, simple; B medium, twoforked near middle; $\mathrm{C}$ medium, three- or fourbranched, occasionally two- or five-branched; 1 medium, two-forked or rarely simple; 2 small, two- or three-forked at base; 3 represented only by its socket on this and segments IV and V; 4 medium, usually four-branched, occasionally five- or three-branched.

Segment IV: A small, simple; B long, two- or three-branched, slightly plumose apically; $\mathrm{C}$ medium, three-branched, occasionally four- or fivebranched; 1 medium, two- or three-forked, rarely simple; 2 small, two-forked, rarely simple; 4

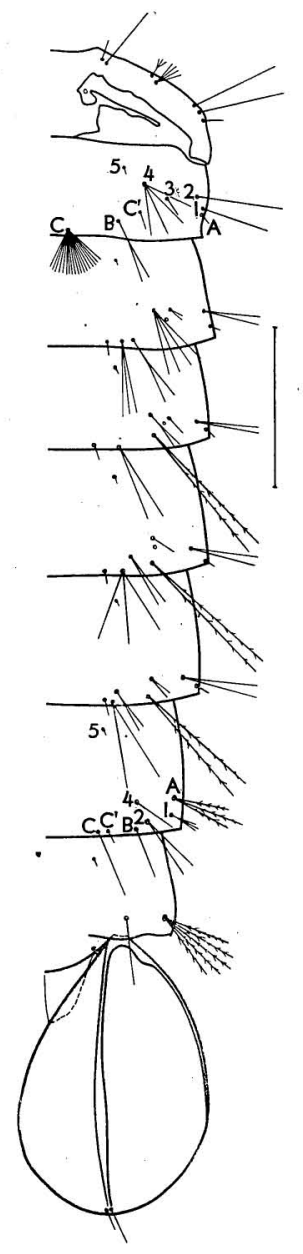

FIG. 51. Culex fragilis: dorsal aspect of right half of abdomen of male from Hilimoi, Papua. small, three- or four-forked near basal one-third, rarely simple.

Segment $V$ : A small, simple; B long, twobranched, slightly plumose apically; $\mathrm{C}$ medium, three- or four-branched, occasionally two- or five-branched; 1 medium, two- or three-forked; 2 small, usually three- or four-forked, rarely twoor five-forked; 4 medium, two-forked near base or occasionally simple.

Segment VI: A small, simple; B long, twobranched, slightly plumose apically; c long, twoor three-branched; 1 medium, two-forked near base, rarely simple; 2 small, two- to four-forked, rarely simple; 3 absent; 4 medium, simple or two-forked.

Segment VII: A medium, stout, plumose, threeor four-branched, rarely five-branched; B medium, simple or rarely two-forked; c medium, simple to three-branched, rarely four-branched; 1 small, usually three-forked, occasionally fourforked; 2 medium, two-forked; 4 small, twoforked or occasionally simple.

Segment VIII: A medium, stout, plumose, fiveor six-branched, rarely four-branched; $A^{\prime}$ medium, simple or two-forked.

Segment IX: v small, simple spine.

Paddle: Large, long, broadest at about apical one-third; margin smooth; midrib strong, dividing paddle unequally, the lateral face slightly wider than medial face; terminal seta small, stout, two-branched or simple; accessory seta small, simple.

SPECIMENS EXAMINED.-The pupal exuviae of eight males and eight females from Gamadodo and Hilimoi, Milne Bay, Papua, and Draeger Harbor, Northeast New Guinea.

Culex (Culiciomyia) papuensis (Taylor) 1914

Fig. 52

Cephalothorax. - Postocular: 1 small, two-branched, occasionally more; 2 medium, two- or three-branched; 3 medium, threebranched or simple. 
Anterothoracic: 4 medium, five- or six-branched, rarely simple or two-branched, plumose; 5 small, two- to four-forked; 6 small, two- or threeforked, rarely simple; 7 medium, two-forked.

Dorsal: 8 medium, one-half length of trumpet, two- or three-branched.

\section{Supra-alar: 9 small, two-forked.}

Metanotum: 10 medium, five-forked, plumose; 11 medium, two-forked or occasionally simple, plumose; 12 medium, two-forked and plumose. Trumpet: Length five or six times the greatest diameter of the meatus; pinna about one-fourth of the total length of trumpet; tracheoid portion darkly pigmented.

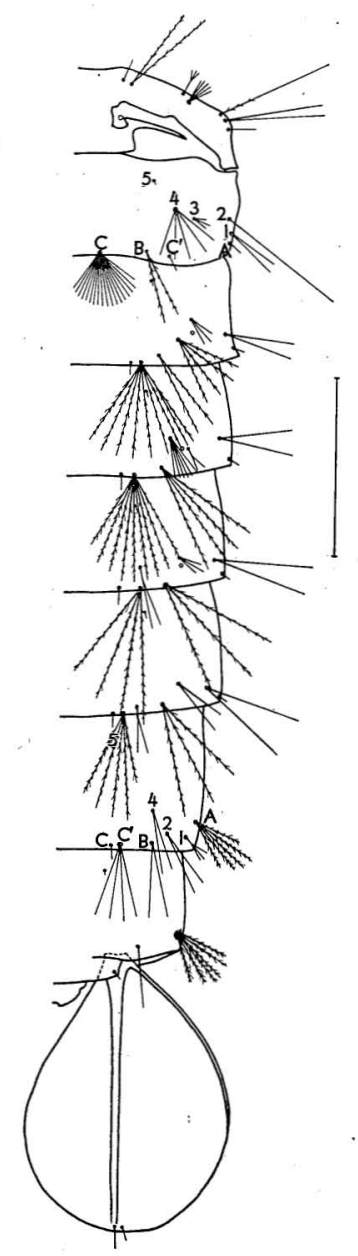

FIG. 52. Culex papuensis: dorsal aspect of right half of abdomen of female from Hilimoi, Papua.
ABDOMEN.-Segment I: $\mathrm{H}$ small, simple; $\mathrm{K}$ long, two-branched or simple, plumose; L small, simple or two- to three-forked near apex; $M$ small, three- or four-forked near base, rarely five-forked; $\mathrm{s}$ long, simple; $\mathrm{T}$ ' medium, twoforked; U small, simple.

Segment II: A small, simple spine; B long, twobranched or occasionally simple, plumose; $\mathrm{C}$ medium, twenty-five- to thirty-branched tuft; $C^{\prime}$ small, simple on this and all following segments; 1 medium, two-forked or simple; 2 long, simple; 3 small, two- to four-forked; 4 medium, four- to five-branched, occasionally simple or two-forked; 5 minute, simple on this and all following segments.

Segment III: A small, simple spine; B long, twobranched or occasionally simple or threebranched, plumose; c long, five- to twelvebranched, plumose; 1 medium, simple or twobranched; 2 small, two- to four-forked; 3 represented only by its socket on this and segments IV and V; 4 long, two-branched or occasionally four-branched, plumose.

Segment IV: A small, simple spine; B long, twobranched, occasionally four- or five-branched, plumose; c long, two- or four-branched, rarely eight- or nine-branched, plumose; 1 medium, two-branched or simple; 2 small, two-forked near basal one-third or occasionally simple; 4 medium, four- to six-branched.

Segment V: A small, simple spine; B long, twoto three-branched, plumose; C long, two- to four-branched, plumose; 1 long, simple or occasionally two-branched; 2 small, two- to fourbranched; 4 medium, two-forked near basal onethird or rarely simple.

Segment VI: A small, simple spine; B long, simple or two- to three-branched, plumose; C long, three- to six-branched, plumose; 1 long, two-branched or occasionally simple; 2 medium, two-forked or occasionally simple; 3 absent; 4 medium, two-forked near middle or rarely simple.

Segment VII: A medium, four- to six-branched, plumose; в medium, simple or occasionally twobranched; C medium, four-branched or occasion- 
ally two-branched; 1 small, four-forked near middle or rarely three-forked; 2 medium, simple or two-branched; 4 medium, two-forked.

Segment VIII: A medium, stout, six- to tenbranched, plumose; $\mathrm{A}^{\prime}$ medium, simple or twoforked near middle.

Segment IX: v small, simple spine.

Paddle: Elongate oval shaped, length roughly about one-fourth greater than width; margin smooth; midrib strong, teaching apex; terminal seta short, simple; accessory seta short, simple.

SPECIMENS EXAMINED.-The pupal exuviae of four males and three females from Gamadodo and Hilimoi, Milne Bay, Papua.

Culex (Culiciomyia) pullus Theobald 1905 Fig. 53

Pupa heretofore undescribed, although Hill (1925: 74) included figures of the paddles and trumpet of specimens from Rabaul, New Britain.

Cephalothorax. - Postocular: 1 medium, four- or three-branched; 2 medium, twobranched; 3 medium, three-branched or occasionally two-branched.

Anterothoracic: 4 medium, three- or fourbranched, rarely five- or six-branched; 5 small, two- or three-forked; 6 small, simple or twoforked; 7 medium, two- or three-forked.

Dorsal: 8 medium, one-half length of the trumpet, two-branched or occasionally four-branched. Supra-alar: 9 medium, two-branched.

Metanotum: 10 medium, five- to eight-branched, plumose; 11 medium, two-forked near base, rarely four-forked, plumose; 12 medium, twoto four-forked.

Trumpet: Length equal to five or six times the greatest diameter of the meatus; pinna short, roughly equal to the greatest diameter of the meatus; tracheoid portion darkly pigmented.

AвDOMEN.-Segment I: $\mathrm{H}$ small, stout, simple or rarely two-forked near apex; $\mathbf{K}$ long, twobranched; L small, two- to six-forked; M small, four- to six-forked; s long, simple; $\mathrm{T}$ long, twoforked near base; U small, simple or rarely twoforked.
Segment II: A small, simple spine; в long, twoforked near base or occasionally simple; $\mathrm{C}$ medium, fifteen- to twenty-branched tuft; $C^{\prime}$ small, simple on this and all following segments; 1 medium, two-forked near base or occasionally three-forked or simple; 2 long, simple; 3 small, three-forked or rarely simple or two-forked; 4 medium, four- or five-forked, rarely two- o: three-forked; 5 minute, simple on this and all following segments.

Segment III: A small, simple spine; в long, twoforked near base, plumose; c long, six- or sevenbranched, only occasionally five- or ninebranched, plumose; 1 medium, two-forked or

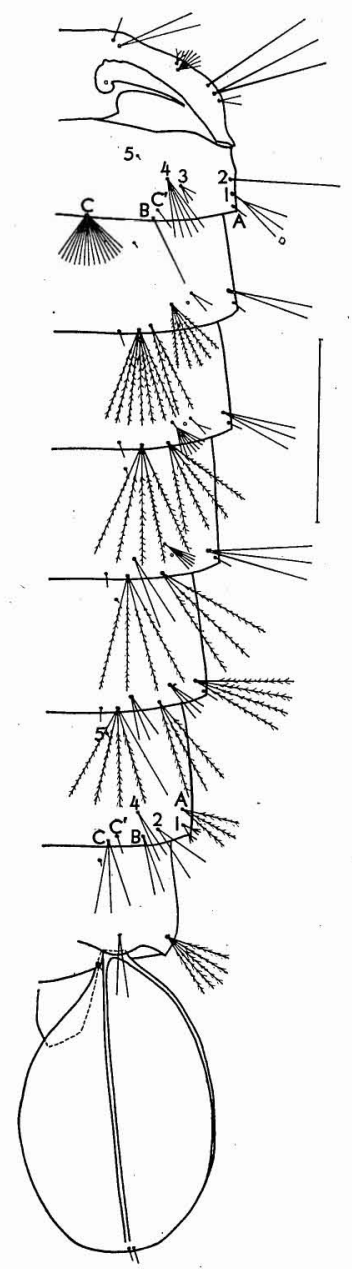

FIG. 53. Culex pullus: dorsal aspect of right half of abdomen of male from Hilimoi, Papua. 
occasionally simple; 2 small, three- or fourforked; 3 represented only by its socket on this and segments IV and V; 4 medium, three- to five-branched, plumose.

Segment IV: A small, simple spine; в long, fourbranched or occasionally three-branched, plumose; $\mathrm{C}$ long, five- or four-branched, rarely threeor six-branched, plumose; 1 medium, twoforked; rarely three-forked; 2 small, two-forked near middle, rarely four-forked; 4 small, five- to seven-forked near basal one-third.

Segment V: A small, simple spine; в long, threebranched or occasionally two-branched, plumose; C long, four-branched or rarely threebranched, plumose; 1 long, two-branched, or occasionally three-branched; 2 small, two- to six-forked near basal one-third; 4 medium, twoforked or rarely simple.

Segment VI: A small, simple spine; в long, twoor three-branched, rarely four-branched, plumose; C long, four-branched, rarely three- to six-branched, plumose; 1 long, two- or threebranched, rarely four-branched, plumose; 2 small, two- or three-forked, rarely simple; 3 absent; 4 small, two-forked or occasionally threeforked.

Segment VII: A medium, three- or fourbranched, plumose; B medium, two-branched or occasionally three-branched; $\mathrm{C}$ medium, threeor four-branched; 1 small, four- or five-branched; 2 medium, two-forked or occasionally simple; 4 medium, two-forked.

Segment VIII: A medium, stout, usually fivebranched, occasionally six- or eleven-branched, "plumose; $A^{\prime}$ medium, two-forked near base or rarely simple.

Segment IX: v small, simple spine.

Paddle: Elongate oval shaped, length nearly one-third greater than width; margin rounded, smooth; midrib strong, reaching apex, dividing the paddle almost equally although the lateral face is slightly wider than the medial face; terminal seta small, simple or two-branched; accessory seta small, simple.

SPECIMENS EXAMINED.-The pupal exuviae of nine males and eleven females from Gama- dodo, WagaWaga, and Hilimoi, Milne Bay, Papua, and Draeger Harbor, Northeast New Guinea.

\section{Subgenus Acallyntrum Stone and Penn}

DiAgNosis.-The pupae of the two New Guinean species of Acallyntrum are distinct from those of all other Culex of the island in the absence of both the terminal and accessory paddle setae.

Key to Species of Culex (Acallyntrum). Lateral margins of paddles finely serrate; only the larger setae of segments III to VII plumose, all other setae non-plumose (Fig. 54)

C. bicki

Lateral margins of paddles smoothly rounded, not serrate; nearly all of the dorsal abdominal setae finely plumose (Fig. 55)

C. binigrolineatus

Culex (Acallyntrum) bicki Stone and Penn 1947

Fig. 54

This pupa was described and figured by Stone and Penn (1947: 89). The following description is taken from this paper with additional unpublished notes on the species.

Cephalothorax. - Postocular: 2 prominent, plumose, three- or four-branched.

Metanotum: 10 usually three-branched; 11 long, simple; 12 usually three-branched.

ABDOMEN.-Segment I: $\mathrm{H}$ small, simple; $\mathrm{K}$ long, simple; L small, four-forked near middle; M small, six-forked near base; $\mathrm{s}$ long, simple; $\mathrm{T}$ long, two-branched; U small, simple.

Segment II: A small, simple spine; B medium, simple; $C$ small, six- or seven-branched; $C^{\prime}$ small, simple on this and all following segments; 1 medium, two-branched; 2 long, simple; 3 small, simple; 4 small, three-forked near base; 5 minute, simple on this and all following segments. Segment III: A small, simple spine; B long, simple; C medium, three-branched; 1 medium, simple; 2 small, two-branched; 3 represented only by its socket on this and segments IV and V; 4 small, three-branched. 
Segment IV: A small, simple spine; B very long, two-branched, plumose; c long, six-branched; 1 medium, two-forked; 2 small, four-forked; 4 medium, four-forked near middle.

Segment V: A small, simple spine; B very long, two-branched, plumose; c long, three-branched; 1 medium, two-forked; 2 small, six-branched; 4 medium, two-forked near apex.

Segment VI: A small, simple; B very long; twobranched, plumose; C long, four-branched; 1 medium, two-branched; 2 small, three-forked; 3 absent; 4 small, two-forked.

Segment VII: A small, five-branched; B small, six-branched; C medium, two-branched; 1 me-

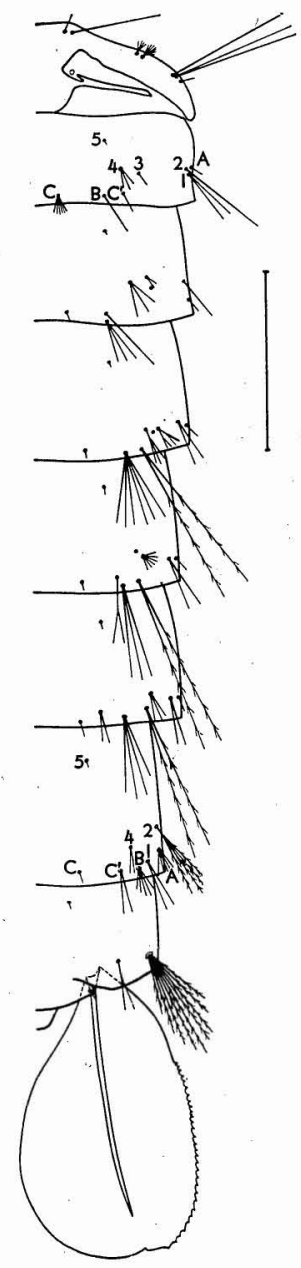

FIG. 54. Culex bicki: dorsal aspect of right half of abdomen of female from Hilimoi, Papua. dium, two-forked; 2 long, four-branched, plumose; 4 small, two-forked.

Segment VIII: A long, strong, plumose, ninebranched; $A^{\prime}$ medium, two-forked near middle.

Segment IX: v small, simple spine.

Paddle: Long, roughly oval; margin finely serrate laterally, apex slightly notched beyond midrib; midrib weak, not reaching apex of paddles; sometimes with an irregular line of black pigment basally on paddle; without terminal setae.

\section{Culex (Acallyntrum) binigrolineatus}

Knight and Rozeboom 1945

\section{Fig. 55}

The pupa was described and figured by Knight and Rozeboom (1945: 289) from which paper the following description and figure have been taken; additional data were obtained by examination of one of the paratypes.

Cephalothorax. - Postocular: 1 small, four-forked near apex; 2 prominent, nearly twice the length of other setae of cephalothorax, three-branched, plumose; 3 medium, threeforked.

Anterothoracic: 4 medium, six-forked; 5 small, four-forked; 6 small, two-forked near apex; 7 . medium, fouf-forked near middle.

Dorsal: 8 small, two-forked.

Supra-alar: 9 medium, two-branched.

Metanotum: 10 medium, four-forked near middle; 11 long, simple, plumose; 12 long, fourforked near basal one-fourth.

Trumpet: Basal one-third darkly pigmented; tracheoid portion fairly well developed; pinna about one-third length of the trumpet.

ABDOMEN.-Segment I: $\mathrm{H}$ small, simple; $\mathrm{K}$ long, simple, stout, plumose; L medium, fourforked near middle; $M$ medium, five-forked near base; $\mathrm{s}$ long, two-branched; $\mathrm{T}$ long, twobranched; U small, two-forked near apex.

Segment II: A small, simple spine; B long, plumose, simple; C small, four-branched; $\mathrm{C}^{\prime}$ small, simple on this and all following segments; 1 medium, three-branched, plumose; 2 medium, two-forked near middle; 3 small, four-forked 
near middle; 4 medium, three-forked near middle; 5 minute, simple on this and all following segments.

Segment III: A small, simple spine; B long, simple, plumose; $\mathrm{C}$ medium, simple or rarely twoforked near apex; 1 medium, two-branched; 2 small, three-branched; 3 represented only by its socket on this and segments IV and V; 4 small, two-branched.

Segment IV: A small, simple; B long, three- or four-branched, plumose; $\mathrm{C}$ medium, two- to four-branched, plumose; 1 medium, threeforked; 2 small, three-forked; 4 small, fourforked.

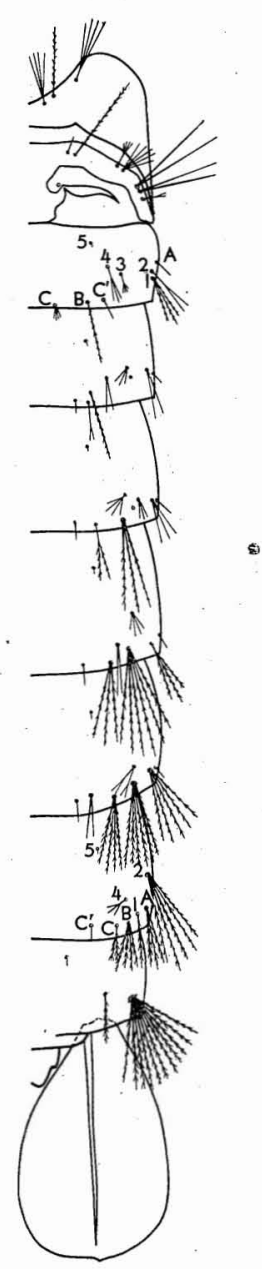

FIG. 55. Culex binigrolineatus: dorsal aspect of right half of abdomen of male (after Knight and Rozeboom, 1945).
Segment $V$ : A small, simple; B long, three- to five-branched, plumose; C long, two- to fourbranched, plumose; 1 medium, three-forked, plumose; 2 small, four-forked; 4 medium, twobranched.

Segment VI: A small, simple; в exceedingly well developed, four- to seven-branched, plumose; c long, plumose, simple to four-branched; 1 long, five-branched, plumose; 2 small, fourforked; 3 absent; 4 small, two-branched.

Segment VII: A medium, three-branched, plumose; B medium, three- to seven-branched, plumose; C small, two-forked, plumose; 1 medium, simple, plumose; 2 long, five-branched, plumose; 4 small, three-forked.

Segment VIII: A strongly developed, fan-like, nine- to fourteen-branched, plumose; $A^{\prime}$ medium, simple, plumose.

Paddle: Long, roughly oval, with apex somewhat drawn out into a point; only basal third of lateral margin buttressed, entire margin smooth; without terminal setae.

\section{Subgenus Culex Linnaeus}

Diagnosis.-The four New Guinean species of this subgenus known in the pupal stage all have seta $\mathrm{K}$ on segment I two-forked; seta $\mathrm{A}$ on segments II-VI is a small, simple spine set close to the postero-lateral corners of the segments; setae A-VII and A-VIII are fairly well-developed plumose tufts placed some distance anterior to the postero-lateral corners of the segments; setae 4-II and 4-III well-developed tufts placed anterior to and usually between B-II and $\mathrm{C}^{\prime}$-II, and between B-III and 2-III respectively.

Key to Species of Culex (Culex)

1.Paddles with medial one-half conspicuously brown-pigmented; without accessory seta on paddle (Fig: 56)

C. squamosus

Paddles without brown pigment; accessory seta of paddle present.

2. Seta 1 on segments III-VI simple or twoforked, never a well-developed tuft (Fig. 57)

C. sitiens

Seta 1 on segments III-VI a well-developed tuft of three or four branches. 
3. Seta B-IV a large tuft of five to eight branches; setae C-III-VI six- to fourteenbranched (Fig. 58) …........ annulirostris . Seta B-IV only two- or three-branched; setae C-III-VI three- or four-branched....

C. fatigans

Culex (Culex) squamosus (Taylor) 1914 Fig. 56

Diagnosis. - Readily separated from all other New Guinean species of Culex in having the medial one-half of the paddle pigmented a dark brown.

Cephalothorax. - Postociular: 1 small, three- or four-forked; 2 small, three-forked; 3 medium, two- to five-forked.

Anterotboracic: 4 medium, three- to five-forked; 5 medium, two- to four-forked; 6 small, twoforked or occasionally three-forked; 7 medium, two-forked or simple.

Dorsal: 8 medium, one-third length of trumpet, four-branched or occasionally three-branched. Supra-alar: 9 small, three-forked.

Metanotum: 10 long, eight-branched; $11 \mathrm{me}-$ dium, two-forked; 12 small, three- or fourforked.

Trumpet: Fairly long, length about three times the greatest diameter of the meatus; tip greatly expanded, pinna about one-third the length of the trumpet; tracheoid portion fairly well developed, dark pigmented.

ABDOMEN.-Segment I: $\mathrm{H}$ small, simple; $\mathrm{K}$ medium, two-forked near base or rarely threeforked; $\mathrm{L}$ very small, three-forked near apex or occasionally two-forked; $\mathrm{M}$ very small, five- to eight-forked near base; $s$ long, simple; $T$ medium, two- or three-forked; U small, simple.

Segment II: A small, simple spine; B medium, two-branched; $C$ small, four- to seven-branched; $\mathrm{C}^{\prime}$ small, simple, laterad of $\mathrm{B}$ in position; 1 medium, two-branched or simple; 2 medium, two-branched or simple; 3 small, two- to fiveforked; 4 medium, three-branched, rarely these branches may all be doubled so that seta appears to be six-branched; 5 minute, simple on this and all following segments.

Segment III: A small, simple spine; B medium, two-branched; $\mathrm{C}$ long, plumose, five- to eight- branched; $\mathrm{C}^{\prime}$ small, simple spine on this and all following segments; 1 medium, simple; 2 small, two- to five-forked near base; 3 represented only by its socket on this and segments IV and V; 4 medium, four- or five-forked near base.

Segment IV: A small, simple spine; B long, plumose, three-branched; $c$ long, plumose, threebranched or occasionally four- or five-branched; 1 medium, simple; 2 very small, two-forked; 4 small, five-forked or occasionally four-forked. Segment V: A small, simple spine; в long, plumose, two-branched or rarely simple; c long, plumose, two- or three-branched; 1 medium, simple; 2 small, five- to seven-forked near base; 4 medium, two-forked or simple.

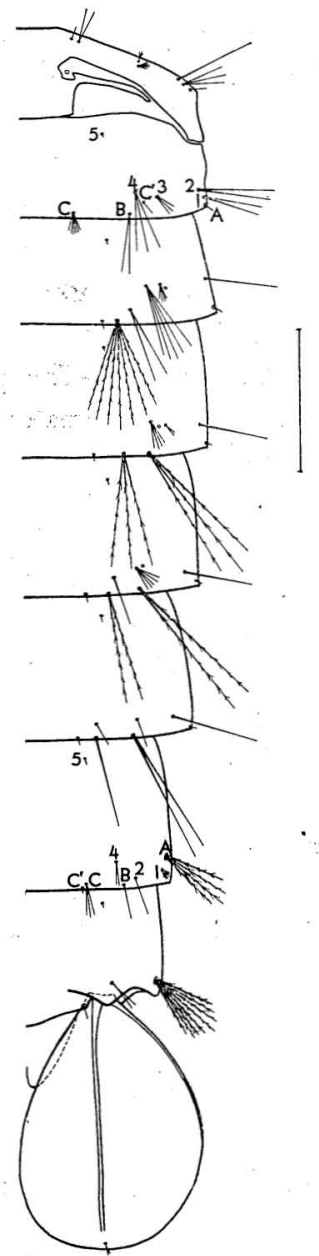

FIG. 56. Culex squamosus: dorsal aspect of right half of abdomen of male from Gamadodo, Papua. 
Segment VI: A small, simple spine; B long, twobranched; c long, simple or occasionally twobranched; 1 long, simple; 2 small, simple to four-forked; 3 absent; 4 small, simple or twoforked.

Segment VII: A medium length, stout, plumose, three- to five-branched; B small, simple or occasionally two-branched; C small, two-branched or occasionally three-branched; 1 very small, threeto five-branched; 2 small, simple to four-forked; 4 small, two-forked.

Segment VIII: A medium length, stout, plumose, five- to eight-branched, usually six-branched; $\mathrm{A}^{\prime}$ small, two-forked near middle:

Segment IX: v small, stout, simple spine.

Paddle: Elongate oval; margin smooth; midrib dividing the paddle unequally, the lateral face a little wider than the medial face; medial face entirely dark-brown pigmented, the brown pigment extending somewhat less intensely into the apical third of the lateral face; terminal seta small, simple or rarely two-forked at apex; accessory seta absent.

SPECIMENS EXAMINED.-The pupal exuviae of eight males and four females from Gamadodo, WagaWaga, and KanaKope, Milne Bay, Papua.

\section{Culex (Culex) sitiens Wiedemann 1828}

Fig. 57

Pupa partially described without figures by Edwards (1941: 417) and Taylor (1943: 99); Hill ('1925: 73) and Buxton and Hopkins (1927: 79) included figures of the paddles and trumpets without accompanying descriptions.

Cephalothorax. - Postocular: 1 medium, three- to five-forked; 2 medium, two-forked; 3 long, two-forked.

Anterothoracic: 4 long, three-forked or occasionally two-forked; 5 medium, two- or threeforked; 6 small, three-forked or occasionally simple or two-forked; 7 medium, two-forked or occasionally three-forked.

Dorsal: 8 long, half length of trumpet, twobranched.
Supra-alar: 9 long, two-branched.

Metanotum: 10 long, plumose, five-branched or occasionally two- to four-branched; 11 long, plumose, two-forked; 12 long, three-forked or occasionally two-forked.

Trumpet: Fairly long, length about five times greatest diameter of meatus; tracheoid portion fairly well developed, dark-pigmented; pinna long, about one-third of total length of trumpet.

ABDOMEN.-Segment ${ }^{\circ} \mathrm{I}: \mathrm{H}$ small, simple; $\mathrm{K}$ long, two-forked near base; L small, two-forked near base or occasionally simple or three-forked; M small, five- or six-forked near base; $s$ long,

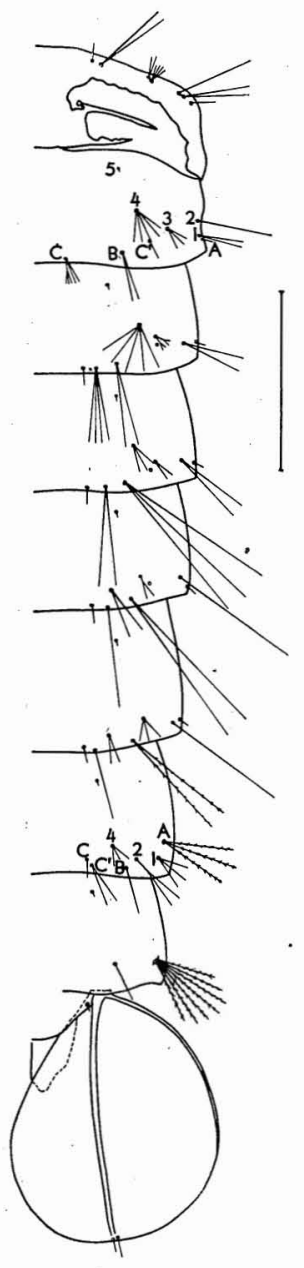

FIG. 57. Culex sitiens: dorsal aspect of right half of abdomen of male from Amsterdam Island, Dutch New Guinea. 
simple or occasionally two-forked; $T$ long, simple or rarely three-forked near apex; U small, simple.

Segment II: A small, simple spine; B medium, two-branched; C small, four- to seven-forked; $\mathrm{C}^{\prime}$ small, simple, laterad of B in position; 1 medium, simple or two-forked; 2 long, two-forked near base or occasionally simple; 3 medium, four- or three-forked; 4 medium, five-forked or occasionally three-forked; 5 minute, simple on this and all following segments.

Segment III: A small, simple spine; B long, twobranched; c long, three- or four-branched; $\mathbf{C}^{\prime}$ small, simple, placed mesad of $\mathrm{C}$ on this and all following segments; 1 medium, two-forked or occasionally simple; 2 small, three- to fiveforked; 3 represented only by its socket on this and segments IV and V; 4 medium, five-forked or occasionally four-forked.

Segment IV: A small, simple spine; B very long, exceeding posterior margin of segment $\mathrm{V}$, threebranched; c long, two-branched or occasionally three- to four-branched; 1 medium, two-forked or occasionally simple; 2 small, simple or occasionally two- or three-forked; 4 small, three- to five-forked.

Segment $V$ : A small, simple spine; B very long, exceeding posterior margin of segment VI, twobranched; c long, simple or two-branched; 1 very long, simple; 2 small, two- to four-forked near middle; 4 medium, two- or three-forked near base.

Segment VI: A small, simple spine; B long, slightly plumose, two-branched; C long, simple or two-branched; 1 long, simple; 2 small, twoto four-forked; 3 absent; 4 small, two-forked.

Segment VII: A fairly long, stout, plumose, three-branched or occasionally four-branched; B medium, simple; c medium, two-branched; 1 small, three-forked or rarely simple or fourforked; 2 medium, two-forked or occasionally three-forked; 4 small, three-forked or occasionally simple or two-forked.

Segment VIII: A fairly long, stout, plumose, eight-branched or occasionally three-branched; $\mathrm{A}^{\prime}$ medium, simple or two-forked.
Segment IX: $\nabla$ very small, simple spine on only 30 per cent of the specimens examined.

Paddle: Rounded, length not greatly exceeding width as in other species of the subgenus Culex; margin smooth; midrib dividing the paddle unequally, the lateral face a little wider than medial face; terminal seta small, simple; accessory seta small, simple.

SPECIMENS EXAMINED.-The pupal exuviae of 25 males and 16 females from Hilimoi and KanaKope, Milne Bay, Papua, and Amsterdam Island, Dutch New Guinea.

\section{Culex (Culex) annulirostris Skuse 1889}

Fig. 58

Pupa heretofore undescribed, although Buxton and Hopkins (1925: 79) included it in a key to the Culex pupae of Samoa and the New Hebrides and gave a figure of the trumpet.

Cephalothorax.-Postocular: 1 medium, four- or five-branched; 2 medium, four-branched, range from two- to five-branched; 3 medium, four-branched, range from two to five.

Anterothoracic: 4 medium, five-branched, range from two to six; 5 small, four- or three-forked; 6 small, three-branched, occasionally two- or four-branched; 7 medium, two-branched.

Dorsal: 8 long, over one-half the length of trumpet, two- to five-branched.

Supra-alar: 9 small, two- to five-branched.

Metanotum: 10 medium, ten-to twelve-branched, occasionally seven- to nine- branched; 11 medium, plumose, two-forked or occasionally threeforked; 12 medium, usually three-forked, range from two to six.

Trumpet: Fairly long, length about five times greatest diameter of the meatus; tracheoid portion fairly well developed, dark pigmented; pinna a little more than one-fourth of the total length.

ABDOMEN.-Segment $\mathrm{I}: \mathrm{H}$ small, simple; $\mathrm{K}$. long, two-forked near base, plumose; L small, six- to eight-forked near middle, occasionally three- to five-forked; $M$ small, seven- to elevenbranched; $\mathrm{s}$ very long, simple; $\mathrm{T}$ long, two- 
forked near base or rarely three-forked; U small, simple.

Segment II: A small, simple spine; B medium, two-branched or rarely three-branched; $\mathrm{C}$ medium, six- to fourteen-branched; $c^{\prime}$ small, simple, laterad of $\mathbf{B}$ in position; 1 medium, twoforked or rarely simple; 2 long, simple; 3 small, five- or six-forked, rarely seven-forked; 4 medium, eight- to ten-forked near base, occasionally five- or six-forked; 5 minute, simple on this and all following segments.

Segment III: A small, simple spine; B long, plumose, two-branched or forked near middle; C

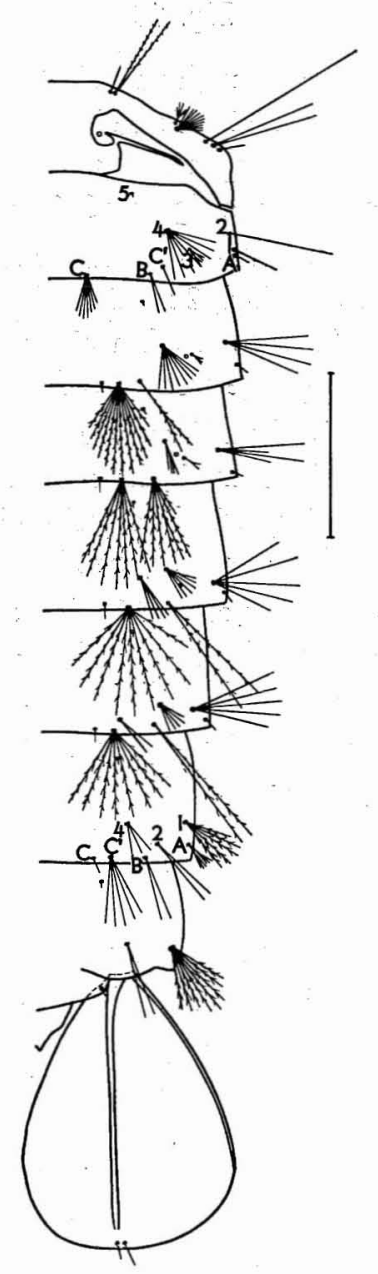

FIG. 58. Culex annulirostris: dorsal aspect of right half of abdomen of male from Mios Woendi, Dutch New Gùinea. long, plumose, ten- to fifteen-branched, rarely less; $C^{\prime}$ small, simple on this and all following segments mesad of $\mathrm{C}$ in position; 1 long, threeor four-branched; 2 small, two- or three-forked at apex, rarely five- to seven-forked; 3 represented only by its socket on this and segments IV and V; 4 medium, six- to eleven-forked near base.

Segment IV: A small, simple spine; B long, plumose, five- to eight-branched, rarely less; c long, plumose, five- to ten-branched, usually eight or nine; 1 long, four-forked near base, rarely threeor five-forked; 2 small, simple or occasionally two- to five-forked near middle; 4 medium, sixforked near base, rarely five- to eight-forked.

Segment V: A small, simple spine; B long, plumose, two- or three-branched; c long, plumose, seven- to nine-branched, rarely less; 1 long, fiveor six-branched; 2 medium, seven-branched, range from three to nine; 4 medium, three- or four-forked near base, rarely two-forked or simple.

Segment VI: A small, simple spine; B very long, plumose, two-branched or rarely three-branched; c long, plumose, four- to eight-branched, rarely less; 1 long, six-branched, rarely five-branched or less; 2 medium, three- to five-forked; 3 absent; 4 medium, two- or three-forked.

Segment VII: A long, plumose, four- or fivebranched; B fairly long, two-branched; C fairly long, four- or five-branched usually, range from two to six; 1 small, five- to eight-forked; 2 fairly long, two-forked; 4 medium, four-forked, range from two to five.

Segment VIII: A long, stout, plumose, six- to eleven-branched, usually eight-branched; $A^{\prime}$ long, two- or three-forked near base, rarely fourforked.

Segment IX: v small, stout spine.

Paddle: Elongate paddle-shaped, widest point at about apical one-fourth; margin smooth, buttress extending to the widest point; midrib dividing the paddle unequally, the lateral face somewhat wider than medial face; terminal seta small, simple; accessory seta small, simple. 
SPECIMENS EXAMINED.-The pupal exuviae of four males and three females from Gamadodo and WagaWaga, Milne Bay, Papua, and Mios Woendi and Amsterdam Island, Dutch New Guinea.

Culex (Culex) fatigans Wiedemann 1828 (=quinquefasciatus Say 1823, of American authors)

The pupa of C. fatigans has received considerable attention but a complete description has not previously been published. Among those who have considered fatigans pupae to some degree are Banks (1908: 250), Cooling (1924: 9), Buxton and Hopkins (1925: 301; 1927: 83), Edwards (1941: 421), and Taylor (1943: 101).

Cephalothorax.-Postocular: 1 long, twoor three-branched; 2 medium, four-branched; 3 long, two-branched.

Anterothoracic: 4 long, five-branched; 5 medium, five-branched; 6 medium, two-forked; 7 long, two-forked.

Dorsal: 8 long, one-half length of trumpet, three-branched.

Supra-alar: 9 medium, two- or three-forked.

Metanotum: 10 long, six- or seven-branched; 11 long, two- or three-forked; 12 long, threeforked.

Trumpet: Fairly long, length about four times the greatest diameter of the meatus; tracheoid portion fairly well developed, dark-pigmented; pinna long, a little more than one-third of total length of trumpet.

ABDOMEN.-Segment I: $\mathrm{H}$ small, simple; $\mathrm{K}$ long, two-forked; L small, two- or three-forked; M small, five-forked; s long, simple; $\mathrm{T}$ long, two-forked; U small, simple.

Segment II: A small, simple spine; B long, twobranched; C medium, twelve- to fourteenbranched tuft; $C^{\prime}$ small, simple; 1 very long, two-forked; 2 very long, simple; 3 small, fouror five-forked; 4 medium, three- or four- branched; 5 minute, simple on this and all following segments.

Segment III: A small, simple spine; B long, twoforked; C long, four-branched; $C^{\prime}$ small, simple on this and all following segments; 1 medium, three-branched; 2 small, five-forked near middle; 3 represented only by its socket on this and segments IV and V; 4 medium, seven-branched.

Segment IV: A small, simple spine; в very long, slightly plumose, exceeding the posterior margin of segment V, two- or three-branched; C long, three- or four-branched; 1 medium, fourbranched; 2 small, three- or four-forked near middle; 4 small, five- or six-forked.

Segment $V$ : A small, simple spine; B very long, exceeding the posterior margin of segment VI, slightly plumose, two-branched; C long, fourbranched; 1 long, three-branched; 2 small, twoto four-forked; 4 medium, two-forked.

Segment VI: A small, simple spine; B very long, exceeding the posterior margin of segment VII, two-branched or simple; c long, two- or threebranched; 1 long, three- or four-branched; 2 small, three-forked; 3 absent; 4 small, simple or two-forked.

Segment VII: A long, stout, plumose, three- to four-branched; B medium, two-branched or simple; C medium, three- or four-branched; 1 small, four- or five-forked; 2 medium, two-forked; 4 medium, two-forked.

Segment VIII: A long, stout, plumose, ninebranched; $A^{\prime}$ medium, two-forked near middle.

Segment IX: v small, simple spine.

Paddle: Elongate oval; margin smooth; midrib dividing paddle unequally, the lateral face slightly wider than the medial face; one specimen with a slight amount of black pigment at base of paddle; terminal seta small, simple; accessory seta small, simple.

SPECIMENS EXAMINED.-The pupal exuviae of five females from Mios Woendi, Dutch New Guinea. 


\section{REFERENCES}

BAISAS, F. E. 1936a. Notes on Philippine mosquitoes. IV. The pupal and certain adult characters of some rare species of Anopbeles. Philippine Jour. Sci. 59(1) : 65-84.

1936b. Notes on Philippine mosquitoes. VI. The pupal and adult characters of anophelines of the subgenus Myzomyia. Philippine Jour. Sci. 61 (2): 205-220.

-1938. Notes on Philippine mosquitoes. VII. A-Culex (Culex) with banded proboscis and tarsi. B-Anopheles: the pupae of three rare species; the leucospbyrus-subgroup. Pbilippine Bur. Health, Montbly Bul. 18(5): 175-232.

BANKs, Charles S. 1908. Biology of Philippine Culicidae. Philippine Jour. Sci. 3A (4) : 235258.

BARRAUD, P. J. 193i. The early stages of some Indian mosquitoes: Megarbinus. Indian Jour. Med. Res. 18(4) 1127-1132. 1934. The fauna of British Indid: Diptera, Vol. V. family Culicidae: tribes Megarbinini and Culicini. 463 p. Taylor and Francis, London.

Belkin, JoHn Nicholas. The genus Tripteroides in the Solomon Islands. [Manuscript thesis in Cornell University Library, Ithaca, New York.]

KENNETH L. KNIGHT, and LloYD E. RozEBOOM. 1945. Anopheline mosquitoes of the Solomon Islands and the New Hebrides. Jour. Parasitol. 31(4): 241-265.

Bick, George Hermann. Distribution and larval ecology of the mosquitoes of $\mathrm{New}$ Guinea. [Manuscript thesis in Cornell University Library, Ithaca, New York.]

BOHART, RICHARD M., and ROBERT L. INGRAM. 1946. Mosquitoes of Okinawa and islands in the central Pacific. U. S. Navy, Bur. Med. and Surg., Navmed 1055: 1-110.

BRUG, S. L. 1931. Culiciden der Deutschen Limnologischen Sunda-Expedition. Arch. $f$. Hydrobiol., 9(suppl.): 1-42.

Buxton, Patrick A., and G. H. E. Hopkins. 1925. The early stages of Samoan mosquitoes. Bul. Ent. Res. 15 (3) : 295-301.

1927. Researches in Polynesia and Melanesia. An account of investigations in Samoa, Tonga, the Ellis Group, and the New Hebrides, in 1924, 1925. London School Hyg. and Trop. Med., Mem. No. 1. 1-260.

ConNAL, S. L. M. Summers. 1928. A note on the larva and pupa of Taeniorbynchus (Man- sonioides) africanus. Bul. Ent. Res. 19(3): 293.

CooliNG, L. E. 1924. Seven common species of mosquitoes described for purposes of identification. Austral., Dept. Health, Serv. Pub. (Trop. Div.) 1: 1-24.

CRAWFORD, R. 1938. Some anopheline pupae of Malaya with a note on pupal structure. $110 \mathrm{p}$. Govt. Straits Settlements, Singapore.

De Mei Jere, J. C. H. 1911. Zur Metamorphose der myrmecophilen Culicide, Harpagomyia splendens de Meij. Tijdschr. v. Ent. 54(2): 162-167.

EDWARDS, F. W. 1926. Mosquito notes-VI. Bul. Ent. Res. 17 (2): 101-131.

1932. Diptera: Family Culicidae. Wytsman's Genera Insectorum, Fasc. 194: $1-258$.

1941. Mosquitoes of the Etbiopian Region. III.-Culicine adults and pupae. viii +499 p., 4 pl. British Mus. (Nat. Hist.), London.

and D. H. C. GIveN. 1928. The early stages of some Singapore mosquitoes. Bul. Ent. Res. 18(4): 337-357.

Graham, David H. 1929. Mosquitoes of the Auckland district. New Zeal. Inst., Trans, and Proc. 60(2): 205-244.

HILl, Gerald F. 1925. The distribution of anopheline mosquitoes in the Australian Region, with notes on some culicine species. Roy. Soc. Victoria, Proc. 37 (1): 62-77.

Howard, Leland O., Harrison G. Dyar, and FrederICK KNAB, 1912-1917. The mosquitoes of North and Central America and the West Indies. Carnegie Inst. Pub. No. 159, 4 vols. Carnegie Institution of Washington, Washington, D. C.

INGRAM, A., and J. W. SCOTT MACFIE. 1917. Notes on some distinctive points in the pupae of West African mosquitoes. Bul. Ent. Res. 8(1): 73-91.

West African 1919. The early stages of $10(1)$ : 59-69.

JACOBSON, EDw. 1911. Nähere Mitteilungen über die myrmecophile Culicide, Harpagomyia splendens deMeij. Tijdschr. v. Ent. 54(2): 158-161.

KING, Willard V., and Harry HoOgstraAl. 1947. New species of New Guinea Uranotaenia of the tibialis group. Ent. Soc. Amer., Ann. 39(4): 585-596. 
KIRKPATRICK, T. W. 1925. The mosquitoes of Egypt. 224 p. Govt. Press, Cairo.

KNIGHT, KenNeTH L., and Lloyd E. RozeвоOм. 1945. A new species of Culex from New Guinea. Ent. Soc. Wash., Proc. 47(9): 289-295.

LeE, DAVID J., and A. R. WoOdHILl. 1944. The anopheline mosquitoes of the Australasian Region. Sydney Univ. Pubs., Dept. Zool. Monogr. No. 2: 1-209.

MACFIE, J. W. S. 1920. The chaetotaxy of the pupa of Stegomyia fasciata. Bul. Ent. Res. $10(2)$ : 161-169.

Marks, Elizabeth N. 1947a. Studies of Queensland mosquitoes. Part I. The Aedes (Finlaya) kocbi group with descriptions of new species from Queensland, Bougainville and Fiji. Queensland Univ. Papers, Dept. Biol. 2(5): 1-66.

1947b. Studies of Queensland mosquitoes. Part II. New species of Aedes (Subgenus Finlaya). Queensland Univ. Papers, Dept. Biol. 2(6): 1-10.

Matheson, Robert. 1944. Handbook of the mosquitoes of Nortb America. 314 p. Comstock Publ. Co., Ithaca.

Mitchell, Evelyn Groesbeeck. 1907. Mosquito life. 281 p. G. P. Putnam's Sons, New York.

Paine, R. W., and F. W. Edwards. 1929. Mosquitoes from the Solomon Islands. Bul. Ent. Res. 20(3): 303-320.

PARR, H. C. M. 1943. The culicine mosquitoes of Syria and Lebanon. Bul. Ent. Res. 34(4): 245-251.

Rozeboom, Lloyd E., and KenNeth L. KNIGHT. 1946. The punctulatus complex of Anopbeles. Jour. Parasitol. 32(2) : 95-131.
Senevet, G. 1930. Contribution à l'étude des nymphes de culicidés. Description de celles de certains anophélinés et plus spécialement des espèces européenes et méditerrannéenes. Inst. Pasteur d'Algérie, Arch. 8(3-4) : 297382. (Also in: Compte-Rendu Deuxieme Congrès Internatl. Paludisme, 1: 60-154, 1931.)

- 1931. Contribution à l'étude des nymphes d'anophélinés ( $2^{\ominus}$ mémoire). Inst. Pasteur d'Algérie, Arch. 9(1): 17-112.

1932. Contribution à l'étude des nymphes d'anophélinés ( $3^{e}$ mémoire). Inst. Pasteur d'Algérie, Arch. 10(2): 204-254.

1934. Contribution à l'étude des nymphes d'anophélinés ( $4^{ }$mémoire). Inst. Pasteur d'Algérie, Arch. 12(1): 29-76.

Stone, Alan, and George Henry PenN. 1947. A new species of Culex from New Guinea. Wash. Acad. Sci., Jour. 37(3): 89-91.

TAylor, Frank H. 1929. Notes on Australian Culicidae. Bul. Ent. Res. 20(3): 271-278. 1943. Dengue, Part II. Entomological. Austral., Dept. Health, Serv. Pub. (School Pub. Health and Trop. Med.) 4: 1-154. 1944. Contributions to a knowledge of Australian Culicidae, No. VII. Linn. Soc. New South W ales, Proc. 69(3/4): 120-128.

Theodor, OsCar. 1924. Pupae of some Palestinian culicines. Bul. Ent. Res. 14(3): 341345.

Wesche, W. 1910. On the larval and pupal stages of West African Culicidae. Bul. Ent. Res. 1(1): 7-50.

WIGGLESWORTH, V. B. 1920. The early stages of some West African mosquitoes. Bul. Ent. Res. 10(1): 59-68. 